\title{
Experimental and Kinetic Modeling Study of 1-Hexanol Combustion in an Opposed-Flow Diffusion Flame
}

by

Coleman Yue Yeung

A thesis submitted in conformity with the requirements

for the degree of Master of Applied Science

Department of Chemical Engineering and Applied Chemistry

University of Toronto

(C) Copyright by Coleman Yue Yeung 2011 


\title{
Experimental and Kinetic Modeling Study of 1-Hexanol Combustion in an Opposed-Flow Diffusion Flame
}

\author{
Coleman Yue Yeung \\ Master of Applied Science \\ Department of Chemical Engineering and Applied Chemistry \\ University of Toronto \\ 2011
}

\section{Abstract}

Biofuels are of particular interest as they have the potential to reduce our dependence on petroleum-derived fuels for transportation. 1-Hexanol is a promising renewable long chain alcohol that can be used in conventional fuel blends or as a cosolvent for biodiesel mixtures. However, the fundamental combustion properties of 1-hexanol have not been fully characterized in the literature.

Thus, new experimental results, consisting of temperature and concentration profiles of stable species were obtained for the oxidation of 1-hexanol generated in an opposed-flow diffusion flame at $0.101 \mathrm{MPa}$. The kinetic model consists of 361 chemical species and 2687 chemical reactions (most of them reversible). This experimental data were compared to the predicted values of a detailed chemical kinetic model proposed in literature to study the combustion of 1-hexanol. Reaction pathway and sensitivity analyses were performed to interpret the results. In addition, several improvements were investigated to optimize the proposed chemical kinetic mechanism. 


\section{Acknowledgments}

First and foremost, I would like to thank Professor Murray Thomson for his endless guidance and support throughout the entire process. Murray, you are a true inspiration and thank you for always having confidence in me. Thank you for giving me the opportunities to partake in various projects that allowed me to travel not only the country, but the world.

This all would not have been possible without the love and support of my family. Mom \& Dad, thank you for never saying "No," and giving me the opportunities and freedom I have appreciated and enjoyed.

I extend my deepest gratitude to Dr. S. Mani Sarathy, who provided me with invaluable knowledge and training for this project. Thank you for your patience and time. Completing this project would have been much more difficult had you not shown me the way to succeed. I am truly honoured to have worked alongside you for the past two years.

To my colleagues in the Combustion Research Group, thank you all for the many laughs in between work sessions and the supportive words of encouragement. Best wishes in your future endeavours and may our paths cross again in the near future. Thank you to my friends, who were also working on their graduate research in different areas and schools - although our projects were our own, I am grateful that we were able to relate to and support one another through the tough times of the process.

My appreciation goes out to Professor Ya-Hui (Cathy) Chin and Professor Don W. Kirk for serving on my M.A.Sc. defense committee. Your time and efforts are much valued.

Finally, I would like to acknowledge the AUTO21, a Network of Centres of Excellence, and the Agricultural Biorefinery Innovation Network (ABIN) for funding my research and studies. 


\section{Table of Contents}

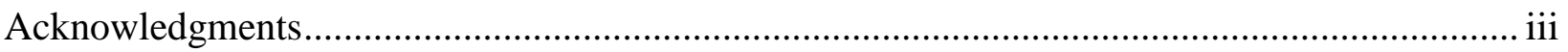

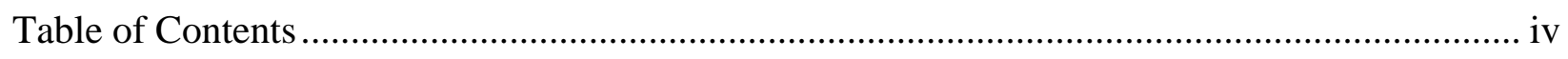

List of Tables ................................................................................................................ vii

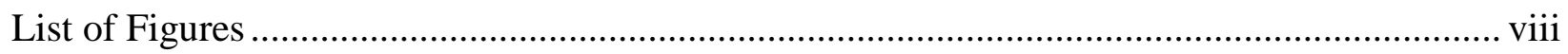

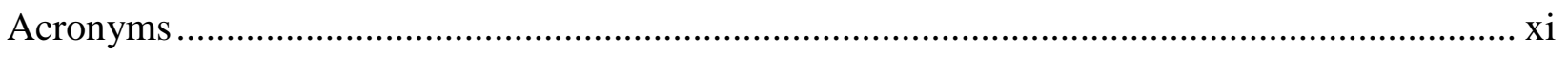

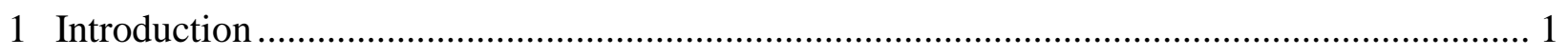

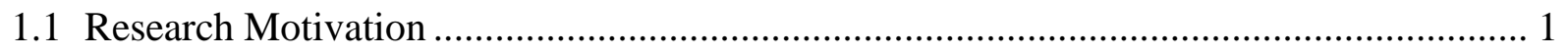

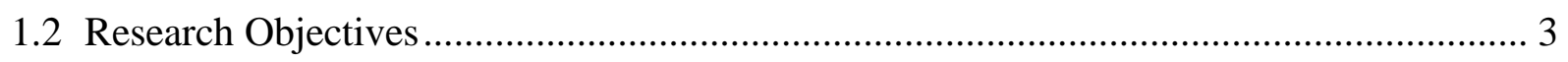

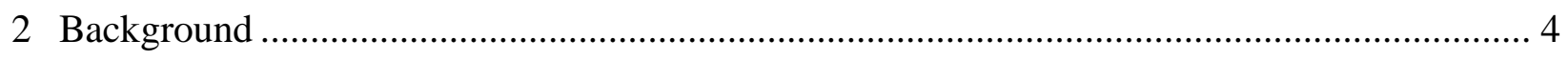

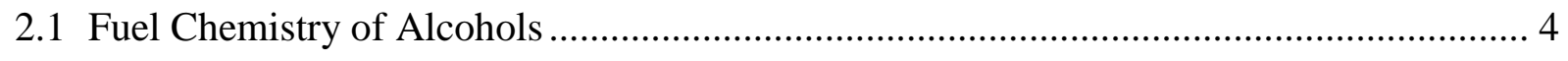

2.2 Combustion studies of Bioalcohols .......................................................................... 5

2.2.1 Opposed-Flow Diffusion Flame Studies on Butanol …………………................ 5

2.2.2 Combustion Studies of 1-Hexanol ................................................................... 7

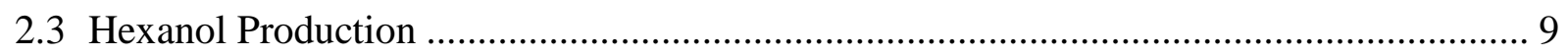

2.4 1-Hexanol Fuel Properties ......................................................................................... 10

3 Experimental Apparatus and Analytical Methodology …….................................................. 12

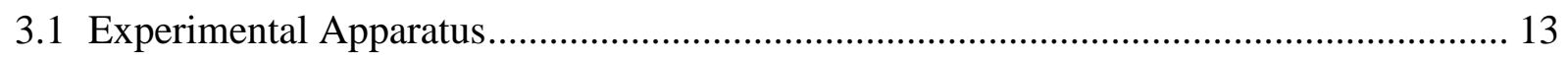

3.1.1 Opposed-Flow Configuration ………………………..................................... 13

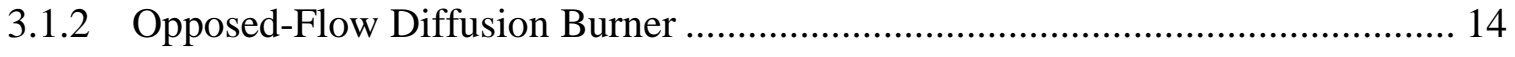

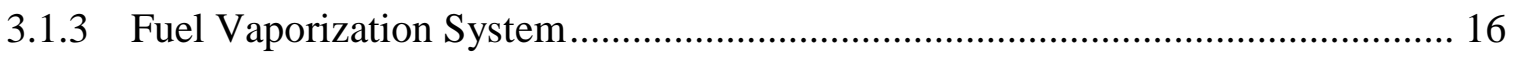

3.1.4 Reynolds Number and Strain Rate Calculations................................................ 19

3.1.5 Gas Sampling System …………………………....................................... 20 


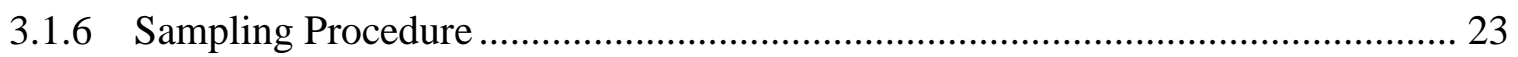

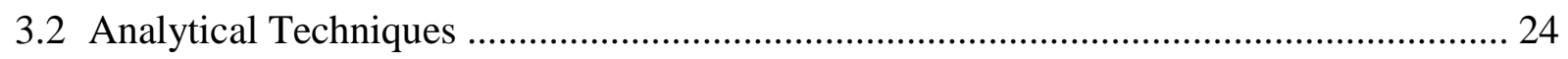

3.2.1 Gas Chromatography …………………………………………………….... 24

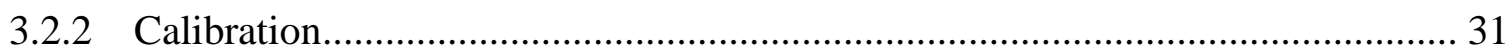

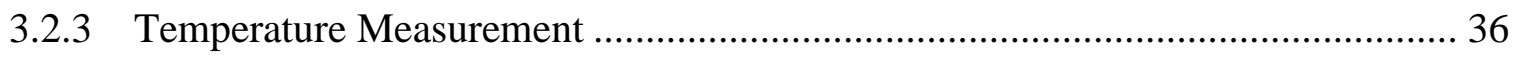

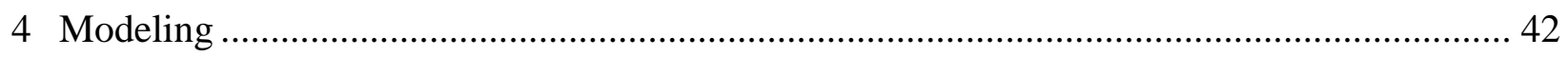

4.1 Modeling Combustion Chemistry ……………………................................................... 43

4.1.1 Chemical Kinetic Database ................................................................................ 45

4.1.2 Thermochemical Properties ........................................................................... 46

4.1.3 Transport Properties .................................................................................... 47

4.1.4 Validating Chemical Kinetic Mechanisms ………………………….................. 49

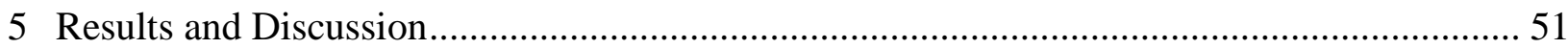

5.1 Temperature, Fuel, and Species Concentrations …………………………………....... 52

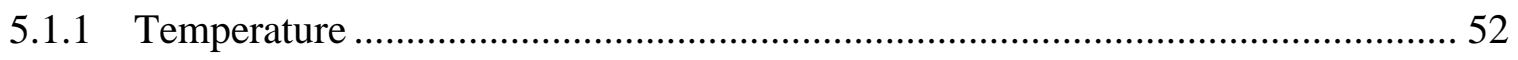

5.1.2 Fuel and Species Concentrations .................................................................... 54

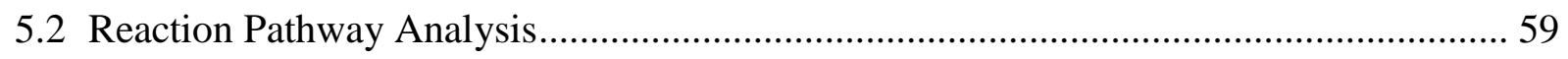

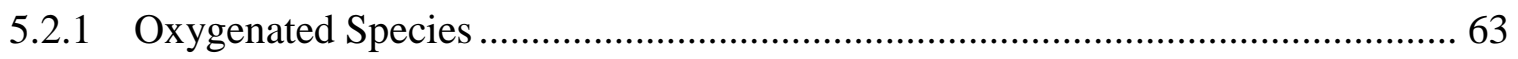

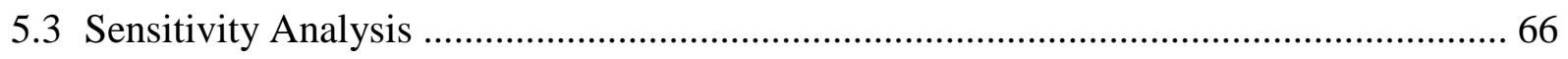

5.4 Reaction Rate Sensitivity of the Proposed Chemical Kinetic Mechanism ........................ 69

5.4.1 Reaction Rate Sensitivity for Ethylene …………................................................. 70

5.4.2 Reaction Rate Sensitivity for 1-Hexene............................................................ 71

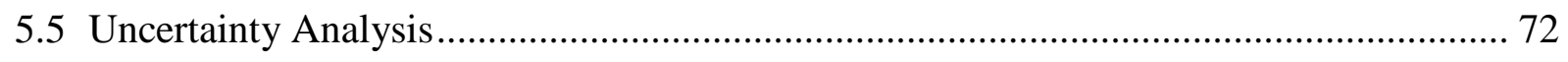

5.5.1 Experimental Uncertainties........................................................................ 72

5.5.2 Modeling Uncertainties................................................................................... 73

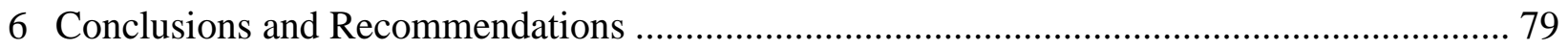

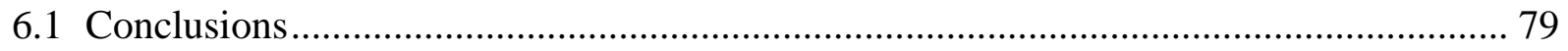




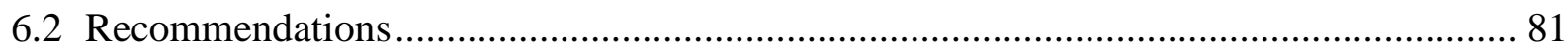

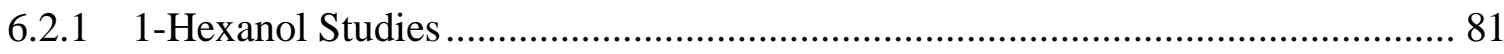

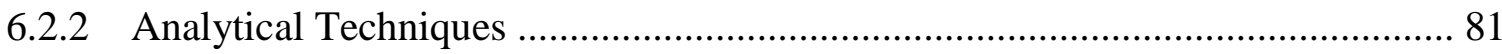

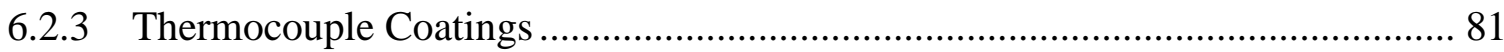

6.2.4 Chemical Kinetic Mechanism........................................................................... 82

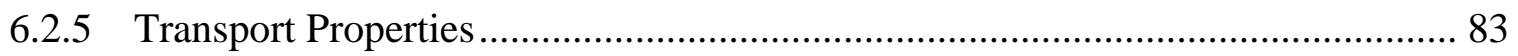

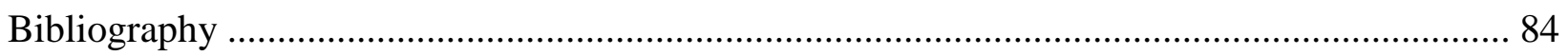

Appendix A - Sample Gas Chromatogram from GC/FID............................................................. 95

Appendix B - Sample Gas Chromatogram from GC/TCD ........................................................ 96

Appendix C - Retention Times of Measured Species ..................................................................... 97

Appendix D - Governing Equations for the Opposed-Flow Diffusion Flame ............................. 99

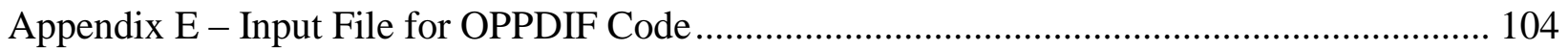

Appendix F - Experimental Data of 1-Hexanol in an Opposed-Flow Diffusion Flame ............ 106

Appendix G - Procedures for Lighting an Opposed-Flow Diffusion Flame............................... 109 


\section{List of Tables}

Table 2.1: Select fuel properties of diesel, ethanol, $n$-butanol, and 1-hexanol

Table 3.1: GC/FID Dual Column Method Parameters. ..................................................... 28

Table 3.2: GC/TCD Method Parameters. .......................................................................... 30

Table 4.1: Select boundary conditions and input parameters for 1-hexanol flame in OPPDIF code.

Table 5.1: Measured and predicted peak temperatures and species concentrations in the opposedflow diffusion flame. Italicized numbers are measured values, bold numbers are predicted values, and underlined values are the ratio of measured to predicted. 58

Table 5.2: Seven radicals produced from $\mathrm{H}$-atom abstraction of 1-hexanol. 60

Table 5.3: Change in peak temperature and species concentrations after a $25 \%$ increase in LJ collision diameter and an $87 \%$ increase in LJ potential well depth of 1-hexanol.

Table 5.4: Comparison of measured and predicted peak temperatures and species concentrations in the opposed-flow diffusion flame with the original transport data and the modified transport data. Italicized numbers are measured values, bold numbers are predicted values, and underlined values are the ratio of measured to predicted. 


\section{List of Figures}

Figure 2.1: Vapour pressure plots for ethanol, $n$-butanol, and 1-hexanol.

10

Figure 3.1: Schematic of opposed-flow diffusion flame burner setup.................................. 12

Figure 3.2: Opposing streams of fuel and oxidizer create a stagnation plane (dashed line) near the centre of the region in between the two ports [48]. 14

Figure 3.3: Components of McKenna flat flame burner [49].

15

Figure 3.4: Bronkhorst liquid delivery system with vapour control, where liquid fuel is vapourized in a heated gas stream [51] 17

Figure 3.5: Vapour pressure of 1-hexanol as a function of temperature with Antoine's equation.

Figure 3.6: Schematic of microprobe setup (not to scale). 21

Figure 3.7: Microprobe positioning between the two flat flame burner ports [16]. 24

Figure 3.8: Schematic of dual column GC/FID with methanizer setup [51]. 26

Figure 3.9: Schematic of dual column GC/TCD setup [51]. 30

Figure 3.10: Calibration gas generator apparatus for oxygenated compounds [51]. 34

Figure 3.11: Schematic of thermocouple apparatus for temperature measurements (not to scale).

Figure 4.1: Geometry and axis of the axisymmetric opposed-flow diffusion flame configuration [66].

Figure 4.2: Iterative procedure for developing and validating chemical kinetic mechanisms. .... 50

Figure 5.1: Carbon sites for 1-hexanol oxidation 51 
Figure 5.2: Comparison of experimental temperature profiles of 1-hexanol flame using a uncoated (bare) thermocouple and a coated thermocouple. Measured temperatures and corrected temperatures for both thermocouples are shown.

Figure 5.3: Experimental (symbols) and predicted (lines) profiles obtained from the oxidation of 1-hexanol in an atmospheric opposed-flow diffusion flame $\left(2.45 \%\right.$ fuel, $\left.60 \% \mathrm{O}_{2}\right) \ldots \ldots \ldots \ldots \ldots . . . . . . . . .77$

Figure 5.4: Reaction pathway diagram for 1-hexanol oxidation in an opposed-flow diffusion flame at $\mathrm{T}=1000 \mathrm{~K}$.

Figure 5.5: Bond dissociation energies of $n$-butanol, with an accuracy of $\pm 1 \mathrm{~kJ} / \mathrm{mol}[17] \ldots \ldots \ldots 6$

Figure 5.6: Bond dissociation energies of 1-hexanol reported by Luo [82].

Figure 5.7: Reaction pathway diagram for consumption of 2-propen-1-ol in the opposed-flow diffusion flame at $1000 \mathrm{~K}$.

Figure 5.8: Reaction pathway diagram for consumption of butanol radical, B1OL4J, in the opposed-flow diffusion flame at $1000 \mathrm{~K}$.

Figure 5.9: Reaction pathway diagram for consumption of 3-buten-1-ol in the opposed-flow diffusion flame at $1000 \mathrm{~K}$.

Figure 5.10: Reaction pathway diagram for consumption of 4-penten-1-ol in the opposed-flow diffusion flame at $1000 \mathrm{~K}$.

Figure 5.11: Sensitivity of 1-hexanol concentration to select reactions in the atmospheric opposed-flow diffusion flame $\left(2.45 \%\right.$ fuel, $\left.60 \% \mathrm{O}_{2}\right)$.

Figure 5.12: Sensitivity of $\mathrm{C}_{2} \mathrm{H}_{4}$ concentration to select reactions in the atmospheric opposedflow diffusion flame $\left(2.45 \%\right.$ fuel, $\left.60 \% \mathrm{O}_{2}\right)$. 68

Figure 5.13: Sensitivity of 1- $\mathrm{C}_{6} \mathrm{H}_{12}$ concentration to select reactions in the atmospheric opposedflow diffusion flame $\left(2.45 \%\right.$ fuel, $\left.60 \% \mathrm{O}_{2}\right)$. 69 
Figure 5.14: Experimental and predicted profiles obtained from the oxidation of 1-hexanol in an atmospheric opposed-flow diffusion flame $\left(2.45 \%\right.$ fuel, $\left.60 \% \mathrm{O}_{2}\right)$ with an $87 \%$ increase in $\mathrm{LJ}$ potential well depth and a $25 \%$ increase in $\mathrm{LJ}$ collision diameter.

Figure 5.15: Laminar flame speed of 1-hexanol-air mixtures at $423 \mathrm{~K}$ and at 1 and 3 bar. The effect of the modified transport parameters on laminar flame speed is compared to the original results from Togbé et al. [12] ........................................................................................ 78 


\section{Acronyms}

\begin{tabular}{|c|c|}
\hline ALFA-BIRD & Alternative Fuels and Biofuels for Aircraft Development \\
\hline $\mathrm{BP}$ & British Petroleum \\
\hline CEM & Controlled Evaporative Mixer \\
\hline $\mathrm{Pc}$ & Critical Pressure \\
\hline Tc & Critical Temperature \\
\hline EFC & Electronic Flow Control \\
\hline FID & Flame Ionization Detector \\
\hline GC & Gas Chromatography \\
\hline GSV & Gas Sampling Valve \\
\hline GHG & Greenhouse Gas \\
\hline $\mathrm{Ci}$ & Hydrocarbon with $i$ number of carbon(s) \\
\hline ID & Inner Diameter \\
\hline JSR & Jet-Stirred Reactor \\
\hline LHV & Lower Heating Value \\
\hline MFC & Mass Flow Controller \\
\hline NDIR & Non-Dispersive Infrared \\
\hline OD & Outer Diameter \\
\hline TCD & Thermal Conductivity Detector \\
\hline
\end{tabular}




\section{Introduction}

As populations grow and economies expand around the world, the demand for energy will continue to rise. Exxon Mobil projects energy demand to rise about 35\% from 2005 to 2030 [1]. This growth in energy demand will ultimately lead to greater use of oil, natural gas, and other forms of modern energy carbon-related emissions. With this greater use, the global carbon dioxide $\left(\mathrm{CO}_{2}\right)$ emissions are likely to rise about $25 \%$ from 2005 to 2030 [1]. The carbon emissions from industrial activities and changes in land use have caused the concentration of carbon dioxide to increase by $40 \%$ during the past 200 years [2]. Thus, renewable energy sources must be expanded in order to meet the future energy needs in a sustainable manner.

As the world's energy needs expand and evolve over time, so do the types of energy used to meet those needs. According to British Petroleum's (BP) Energy Outlook 2030, renewables (solar, wind, geothermal, and biofuels) are expected to outpace the growth of oil in primary energy [3]. These primary energy sources, which include oil, natural gas, and coal, are expected to meet $80 \%$ of the world's energy demand by 2030, while renewable sources will expand significantly [1]. In the next 20 years, BP expects renewables to contribute a higher percentage an $18 \%$ contribution to energy growth from 2010 to 2030, compared to a 5\% of energy growth from 1990 to 2010 [3]. Therefore, technology will continue to evolve and expand in an important role for increasing energy efficiency and mitigating carbon-related emissions.

\subsection{Research Motivation}

The greenhouse gases (GHG) in the atmosphere cause the greenhouse effect, where thermal infrared radiation is reemitted to cause a warming in the Earth's temperature. The risks of global warming include the extinction of coral reef ecosystems, the possible collapse of the Greenland ice sheet, the extinction of 15 to $30 \%$ of species of life on earth, the reduction of agricultural productivity, the acidification of oceans and the shortage of water in semi-arid regions [4].

As part of the Kyoto Protocol Implementation Act, the Government of Canada is committed to reducing national GHG emissions by $20 \%$ below the 2006 level by 2020 (or approximately $280 \mathrm{Mt}$ of $\mathrm{CO}_{2}$-equivalent below forecasted levels for 2020) [5]. In addition, the G8 leaders 
reaffirmed their commitment to the goal of reducing global emissions by at least $50 \%$ by 2050 [6].

With great concerns about the long term availability of petroleum based fuels and the escalating GHG emissions in the atmosphere, there is a need to develop alternative fuels that are sustainable. In 2007, the transportation sector was the top contributor (around 27\%) to Canada's total GHG emissions [7]. In the transportation sector, biofuels are of great interest and recent legislations in many countries, including Canada, require their use to reduce greenhouse gas (GHG) emissions. In December 2010, the Government of Canada finalized a Federal Renewable Fuels Regulations, whereby an average of 5\% renewable content must exist in gasoline. This addition of renewables to gasoline fuel is equivalent to removing 1 million cars from the road [8]. More recently, the Government of Canada issued a mandate on July 1, 2011, whereby an average of $2 \%$ renewable content in diesel fuel and heating distillate oil, with temporary exemptions for Quebec and all Atlantic provinces until December 31, 2012. This period of grace will allow for the provinces to install biodiesel blending infrastructure [9].

To understand the fundamental combustion properties of biofuels, combustion research studies are conducted in order to help improve vehicle performance and minimize pollutant emissions. From these combustion studies, chemical kinetic mechanisms are developed and serve as important tools that describe the molecular level transformation of reactants into products from a series of elementary reaction steps during combustion. These chemical kinetic mechanisms may be used to predict ignition properties, heat release and emission rates, and the types and concentrations of intermediate species in any combustion system [10].

Ethanol accounts for over $90 \%$ of all biofuels' produced worldwide [11]. However, ethanol's simple alcohol structure and its ability to be miscible with water may cause mixing stability and storage issues. Larger alcohols, such as 1-hexanol, have low miscibility with water, as miscibility decreases with an increase in carbon atoms, and would have better mixing with petroleum-based fuels given their longer alkyl carbon chains [12].

Chemical kinetic mechanisms for bioalcohols have been established for short chain alcohols, like ethanol and $n$-butanol. However, validated chemical kinetic mechanisms for long chain alcohols have not been well characterized in the literature, so this research will help fill in that void. New experimental results are presented for the oxidation of 1-hexanol, a high molecular weight 
alcohol, in an opposed-flow diffusion flame at $0.101 \mathrm{MPa}$. The results will also be used to validate the chemical kinetic mechanism proposed by Togbé et al. [12].

\subsection{Research Objectives}

The focus of this thesis is to research the combustion kinetics of 1-hexanol. The goals may be divided into three main objectives:

- To perform fundamental combustion experiments on 1-hexanol in an opposed flow diffusion flame

- To validate a previously proposed chemical kinetic model for 1-hexanol oxidation

- To suggest improvements for the proposed chemical kinetic model 


\section{Background}

The combustion characteristics of several other alcohol fuels have been studied and reported in literature. Since the announcement of the joint venture between BP and DuPont to produce biobutanol in 2006, numerous studies $n$-butanol have been conducted to address its fundamental combustion characteristics $[13,14,15,16,17,18,19,20]$. Like ethanol, butanol can be produced from the fermentation of lignocellulosic biomass using microorganisms [21].

More recently, the combustion and kinetics of oxidation of a larger alcohol, 1-pentanol, were also studied $[22,23]$ as bio-pentanol production was shown to be possible through the use of some microbial strains [24]. 1-Hexanol, which is the next subsequent alcohol in size, can be blended with conventional fuels or used as a co-solvent for ethanol-diesel fuel mixtures [25]. In addition, the thermochemical and physical properties of 1-hexanol make it suitable as an alternative aviation fuel.

\subsection{Fuel Chemistry of Alcohols}

The presence of the $\mathrm{OH}$ group in alcohols makes the oxidation of alcohol fuels an interesting variation of the analogous alkane hydrocarbons. To date, the combustion chemistry for large straight-chain alcohols is not fully understood. A summary of basic alcohol combustion is described by Glassman in the following paragraph [26]:

When it comes to the initiation, there are two fundamental pathways. In one pathway, the $\mathrm{OH}$ group can be displaced while an alkyl radical remains as a product. In the other pathway, the alcohol is attacked at a different site and forms an intermediate oxygenated species, like an aldehyde. The dominant pathway depends on the alcohol's bond strengths and on the overall stoichiometry that determines the number of reactive radicals. Since C-C bonds are weaker than the $\mathrm{C}-\mathrm{OH}$ bond, alcohols larger than methanol do not lose the $\mathrm{OH}$ group in the initiation step. Similar to hydrocarbon combustion, the main oxidation route for alcohols is by radical abstraction. Also, as the chain length of a primary alcohol increases, thermal decomposition of $\mathrm{C}-\mathrm{C}$ bonds becomes more prevalent. 


\subsection{Combustion studies of Bioalcohols}

\subsubsection{Opposed-Flow Diffusion Flame Studies on Butanol}

Combustion studies of $n$-butanol in an opposed-flow diffusion flame have been presented in literature. Sarathy et al. [16] provided experimental data from an opposed-flow diffusion flame to validate an improved version of a novel chemical kinetic mechanism for $n$-butanol oxidation in a JSR at 10 atm, which was first proposed by Dagaut et al. [15]. The study by Dagaut et al. was restricted to premixed systems with no flow. The chemical kinetic mechanism was built upon a previously proposed mechanism for gasoline, which included C1 to C4 hydrocarbons $[27,28,29]$. A sub-mechanism of reactions was added to represent the oxidation of $n$-butanol and the various species (i.e., oxygenated species) formed during its decomposition. The proposed chemical kinetic mechanism consists of 878 reactions involving 118 species.

In the counterflow, non-premixed configuration, the proposed chemical kinetic mechanism showed good qualitative agreement with experimental results. The major species produced were $\mathrm{CO}, \mathrm{CO}_{2}, \mathrm{C}_{2} \mathrm{H}_{4}, \mathrm{C}_{2} \mathrm{H}_{2}, \mathrm{CH}_{4}$, and $\mathrm{C}_{3} \mathrm{H}_{6}$. Moreover, major oxygenated species that were measured in the flame and predicted by the model included formaldehyde, acetaldehyde, and butyraldehyde. However, the results indicate weaknesses in predicting the formation of unsaturated alcohols during the oxidation of $n$-butanol in an opposed-flow diffusion flame.

Moreover, the proposed model determined that H-atom abstraction is the major pathway for the decomposition of $n$-butanol and the resulting fuel radicals would undergo $\beta$-scission to form various species. H-atom abstraction is dominant in the opposed-flow diffusion flame because radicals produced near the flame front can diffuse into the fuel stream to further consume the fuel. Unimolecular decomposition of the fuel was observed to be insignificant in this flame configuration.

In these experiments, the $n$-butanol flames were made with an oxidizer stream of air enriched with oxygen. In addition, the experiments were characterized by high values of stoichiometric mixture fractions and low values of strain rate.

To complement the study conducted by Sarathy et al., Grana et al. [18] conducted an experimental and kinetic study on the combustion of the four isomers of butanol (e.g., $n$-butanol, iso-butanol, sec-butanol, and tert-butanol) in a counterflow, non-premixed configuration. The 
development of the detailed chemical kinetic mechanism for the butanol isomers found in this study was based on a hierarchal approach. The kinetic parameters of similar reactions already studied for ethanol, $n$-propanol, and iso-propanol were used as an extension in the development of the decomposition reaction set for the butanol isomers [30]. The proposed chemical kinetic mechanism can be used to describe the primary reactions related to the combustion and pyrolysis of the four isomers of butanol. The chemical kinetic mechanism consists of over 7000 reactions with 300 species. However, it does not describe low temperature chemistry. According to Peters [31], combustion in practical systems are characterized by low values of stoichiometric mixture fraction and both low and high values of strain rates. Thus, the experiments used an oxidizer stream of only air and the conditions were characterized by low values of stoichiometric mixture fraction and moderately high values of strain rate.

The study resulted in new experimental data for the validation of $n$-butanol and iso-butanol combustion in an opposed-flow diffusion flame. The agreement between the experimental results and model predictions were stated to be generally satisfactory for the $n$-butanol flame, in regards to the reactivity and selectivity of major products and intermediate species. These intermediate species included $\mathrm{CH}_{4}, \mathrm{C}_{2} \mathrm{H}_{2}, \mathrm{C}_{2} \mathrm{H}_{4}, \mathrm{C}_{2} \mathrm{H}_{6}, \mathrm{C}_{3} \mathrm{H}_{6}, \mathrm{C}_{4} \mathrm{H}_{6}$ and $\mathrm{C}_{4} \mathrm{H}_{8}$. Moreover, the measured oxygenated species profiles include formaldehyde and acetaldehyde. Butanal (butyraldehyde) was detected in the $n$-butanol flame, but was not shown in the results as the concentration was very low.

A comparison of the predicted flame structure of $n$-butanol with the experimental data of Sarathy et al. [16] was done as well to consider the influence of strain rate and stoichiometric mixture fraction on the flame structure. The overall agreement between the predicted and experimental profiles for intermediate species is satisfactory, with some discrepancies for the aldehydes.

The flame structures and overall combustion characteristics of these butanol isomers were found to be similar to one another and similar to the combustion of the two propanol isomers. Authors suggest that the proposed kinetic model, with reference kinetic parameters of the reactions involving the hydroxyl group, is a good starting point for the extension to higher alcohols. 


\subsubsection{Combustion Studies of 1-Hexanol}

\subsubsection{Engine Studies of 1-Hexanol Blends}

The combustion of 1-hexanol has received some attention in literature. Sathiyagnanam et al. [25] added hexanol to blends of ethanol and diesel and studied combustion and emission characteristics in a direct injection diesel engine. In this study, the hexanol was used to prevent separation of the ethanol from the diesel and the results were compared to those of the engine on diesel fuel. Experiments showed that the increase in oxygen content of the hexanol-ethanoldiesel blend significantly reduced smoke/particle emission. However, nitrogen oxide (NOx) emission was the same or slightly higher in the hexanol-ethanol-diesel than that of diesel. The engine performance was shown to be slightly improved with the hexanol-ethanol-diesel blend.

The characteristics of hexanol-diesel blends have been evaluated by Aloko et al. [32] over a range of composition, from $5 \%$ to $45 \%$ by volume. It was shown that there was a strong reduction in particle emission with the increase in hexanol content. Similarly, a study by Raj et al. [33] showed significant reductions in smoke, $\mathrm{CO}$, and unburned hydrocarbons with hexanoldiesel blends ( $10 \%$ to $50 \%$ by volume) burning in a single-cylinder air-cooled, direct injection diesel engine.

\subsubsection{Fundamental Studies of 1-Hexanol}

To date, no studies have been conducted on the oxidation of 1-hexanol in an opposed-flow diffusion flame. However, Togbé et al. studied the combustion of 1-hexanol in a jet stirred reactor (JSR) and a combustion bomb, and proposed a chemical kinetic mechanism [12]. The chemical kinetic mechanism was based on previously proposed mechanisms for the oxidation of methanol, ethanol, 1-butanol, and 1-pentanol at $1-10$ atm in JSR and flames [15,16,23,34,35]. The proposed chemical kinetic mechanism consists of 2977 reactions involving 600 species and includes the reactions of $\mathrm{H}_{2} / \mathrm{O}_{2}, \mathrm{C} 1$ to $\mathrm{C} 6$ linear hydrocarbons, and aromatics (C6 to $\mathrm{C} 8$ ). The reaction chemistry of $\mathrm{C} 1$ to $\mathrm{C} 5$ alcohols was extended to include the chemistry of 1-hexanol oxidation. The oxidation scheme for 1-hexanol is similar to that of C4 and C5 alcohols [15,23]. 
Species concentration profiles were measured in a premixed JSR at 10 atm over a range of equivalence ratios and temperatures. Measured concentration profiles were produced for 1-hexanol, $\mathrm{O}_{2}, \mathrm{H}_{2}, \mathrm{CO}, \mathrm{CO}_{2}, \mathrm{CH}_{2} \mathrm{O}, \mathrm{CH}_{4}, \mathrm{C}_{2} \mathrm{H}_{4}, \mathrm{C}_{2} \mathrm{H}_{6}, \mathrm{C}_{2} \mathrm{H}_{2}, \mathrm{C}_{3} \mathrm{H}_{6}, 1-\mathrm{C}_{4} \mathrm{H}_{8}, 1-\mathrm{C}_{5} \mathrm{H}_{10}, 1-\mathrm{C}_{6} \mathrm{H}_{12}$, $\mathrm{CH}_{3} \mathrm{CHO}$, 2-propenal, propanal, pentanal, and hexanal using FTIR and gas chromatography. The main $n$-alkanes formed as intermediate hydrocarbon species were ethylene and methane. The main aldehydes produced were formaldehyde, hexanal, acetaldehyde, and acrolein and these products of incomplete combustion are potential pollutants. At low temperatures (between $650 \mathrm{~K}$ and $750 \mathrm{~K}$ ), a negative temperature coefficient regime was observed. At higher temperatures (i.e., > $750 \mathrm{~K}$ ), the main oxidation regime was seen with the full conversion of the reactants to its final products. In the cool flame regime, the proposed chemical kinetic mechanism appeared to over predict the production of intermediate species (e.g., ethylene, formaldehyde). However, the proposed mechanism showed reasonably good agreement with the experimental data in the oxidation regime. The greatest discrepancy between the predicted model and experimental results was observed for $\mathrm{C}_{2} \mathrm{H}_{4}$. The proposed chemical kinetic mechanism was shown to under predict the peak concentration of $\mathrm{C}_{2} \mathrm{H}_{4}$ by as much as $33 \%$ for fuel rich conditions.

Reaction pathway analyses were conducted to determine the main reaction paths for the oxidation of 1-hexanol in a JSR at 10 atm, stoichiometric conditions, and at temperatures of $630 \mathrm{~K}, 860 \mathrm{~K}$, and $1200 \mathrm{~K}$. At these three temperatures, majority of the 1-hexanol reacts by $\mathrm{H}$-atom abstraction with $\mathrm{OH}$ radicals.

Sensitivity analyses were also performed for the oxidation of 1-hexanol in a JSR at $630 \mathrm{~K}$ and $1200 \mathrm{~K}$. The analyses showed that at high temperatures, the fuel concentration is most sensitive to the main branching reaction of $\mathrm{H}+\mathrm{O}_{2} \leftrightarrow \mathrm{OH}+\mathrm{O}$ and the recombination reaction $\mathrm{H}+\mathrm{O} 2+\mathrm{M} \leftrightarrow \mathrm{HO}_{2}+\mathrm{M}$

Using a combustion bomb, laminar flame speed measurements were measured for mixtures of 1-hexanol and air under premixed conditions at 1 to 10 bar and over a range of equivalence ratios (i.e., 0.7 to 1.5). The proposed chemical kinetic model was shown to well predict the variation of laminar burning velocity as a function of equivalence ratio. As seen with for other $\mathrm{C} 1-\mathrm{C} 4$ alcohols in literature, the flame speed decreases with increasing pressure. The maximum burning velocity predicted by the model is $62.8 \mathrm{~cm} / \mathrm{s}$ at $\varphi=1.1$ at $1 \mathrm{bar}$ and $49.4 \mathrm{~cm} / \mathrm{s}$ at $\varphi=1.1$ at 3 bar. However, the proposed model over predicts the maximum flame speed by $<4 \%$ at 1 bar and by 
$<2 \%$ at 3 bar. Thus, the propose model was shown to be in good agreement with the experimental data for the measured 1-hexanol-air flame speeds and the pressure dependency.

\subsection{Hexanol Production}

The production of 1-hexanol from biological and biochemical processes and from catalytic systems using synthetic gas has been reported. However, research is ongoing in regards to the 1-hexanol production and there is currently no literature covering its production on a large scale.

Zhang et al. have been able to combine protein engineering and metabolic engineering approaches to use the metabolism of $E$. coli to produce various $\mathrm{C} 5$ to $\mathrm{C} 8$ alcohols that are not easily produced by microorganisms [36].

The catalytic conversion of synthetic gas to high molecular weight alcohols is another potential process for the production of fuels [37]. Catalytic studies have been performed on the synthesis of high molecular weight alcohols from synthetic gas using Co-Rh-Mo catalysts [38,39].

1-Hexanol can be produced through the fermentation process [40]. A process for the conversion of carbohydrates into butanol and hexanol for fuel or chemicals has been patented [41]. The process combines homoacetogenic fermentation and acidogenic fermentation. The homoacetogenic fermentation produces an acetic acid intermediate that is chemically converted to ethanol. This ethanol and a remaining portion of the acetic acid intermediate are used as a substrate in an acidogenic fermentation to produce butyric and caproic acid intermediates, which are then chemically converted to butanol and hexanol [41].

There is currently no microorganism that can synthesize 1-hexanolas a primary metabolic product. Some microbial strains of methane-utilizing bacteria oxidized $n$-alkanes (e.g., propane, butane, pentane, hexane) to their corresponding secondary alcohols (e.g., 2-propanol, 2-butanol, 2-pentanol, 2-hexanol), but the concentrations of these secondary alcohols are very low [42]. Most bacteria cannot tolerate high concentrations of hexanol because the alcohol is toxic to the bacteria and alters the cell membranes, which results in loss of cell integrity [43]. 


\subsection{1-Hexanol Fuel Properties}

Select fuel properties of 1-hexanol are tabulated in Table 2.1 and are compared to those of conventional diesel, ethanol and $n$-butanol. The overall properties of 1-hexanol fit with specified jet fuel properties used in aviation. Thus, the ALFA-BIRD (Alternative Fuels and Biofuels for Aircraft Development) project has considered 1-hexanol as a potential component in aviation blends [44].

1-Hexanol has a higher energy density (i.e., LHV) than ethanol, which would lead to better vehicle fuel economy. The long alkyl chain of 1-hexanol will cause it to be more non-polar than ethanol, so it would have greater mixing stability and the potential to be blended at higher proportions with conventional fuels. Unlike ethanol, which is miscible with water, $n$-butanol and 1-hexanol are immiscible with water. Thus, 1-hexanol could be distributed in existing pipelines without risk of water contamination, and may lead to fewer storage and transportation problems. 1-Hexanol is less volatile and has less evaporative emissions compared to the other biofuels. As shown in Figure 2.1, 1-hexanol has a lower vapour pressure than ethanol and $n$-butanol at any given temperature.

The solubility values were found in the CRC Handbook of Chemistry and Physics [45]. Moreover, the fuel properties of diesel were obtained from Environment Canada [46] and a report from the Edwards et al. [47].

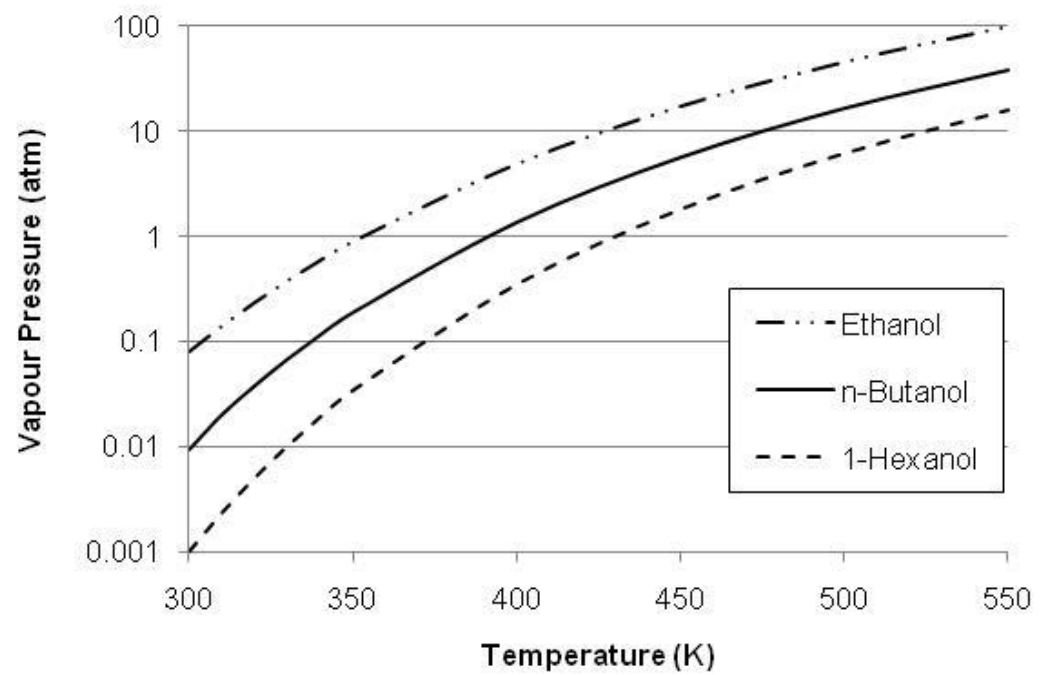

Figure 2.1: Vapour pressure plots for ethanol, $n$-butanol, and 1-hexanol. 
Table 2.1: Select fuel properties of diesel, ethanol, $\boldsymbol{n}$-butanol, and 1-hexanol.

\begin{tabular}{|c|c|c|c|c|}
\hline & Diesel & Ethanol & n-Butanol & 1-Hexanol \\
\hline Formula & $\begin{array}{c}\text { C8 to C21 } \\
\text { Hydrocarbons }\end{array}$ & $\mathrm{C}_{2} \mathrm{H}_{5} \mathrm{OH}$ & $\mathrm{C}_{4} \mathrm{H}_{9} \mathrm{OH}$ & $\mathrm{C}_{6} \mathrm{H}_{13} \mathrm{OH}$ \\
\hline Structure & N/A & $\mathrm{OH}$ & & \\
\hline Boiling Point $\left({ }^{\circ} \mathrm{C}\right)$ & $150-360$ & 78 & 117 & 156 \\
\hline $\begin{array}{c}\text { Energy Density } \\
\qquad(\mathrm{MJ} / \mathrm{L})\end{array}$ & 35.86 & 21.1 & 29.2 & 31.7 \\
\hline $\begin{array}{c}\text { Fuel Density at } \\
20{ }^{\circ} \mathrm{C}(\mathrm{kg} / \mathrm{L})\end{array}$ & 0.832 & 0.789 & 0.810 & 0.814 \\
\hline $\begin{array}{c}\text { Oxygen Content } \\
(\% w t)\end{array}$ & 0 & 34.7 & 21.6 & 15.7 \\
\hline Water Miscibility & No & Yes & No & No \\
\hline $\begin{array}{c}\text { Solubility at } 25^{\circ} \mathrm{C} \\
\text { (g/kg of Water) }\end{array}$ & $<0.01$ & Infinitely Soluble & 79 & 5.9 \\
\hline Volatility & Low & High & Medium & Low \\
\hline
\end{tabular}




\section{Experimental Apparatus and Analytical Methodology}

The setup is designed to generate an opposed flow diffusion flame from a liquid fuel. The concentrations of stable species and the temperature profile in the flame are measured. The setup consists of a fuel vaporization system, an opposed flow diffusion flame burner, a sample collection apparatus, and a series of analytical instruments.

The liquid fuel is vaporized in a stream of nitrogen gas and this fuel mixture is delivered to the bottom burner port, while the oxidizing mixture of oxygen enriched air is delivered to the top burner port. A flame is produced once these two gas streams meet and diffuse into each other. Samples from the flame region are extracted using a fused silica micro-probe that is connected to a heated vacuum pump. Hydrocarbon compounds are analyzed by a gas chromatography equipped with flame ionization detectors (GC/FID). Levels of carbon dioxide and carbon monoxide are analyzed by a gas chromatography with a thermal conductivity detector (GC/TCD). The flame temperature is measured with an R-Type thermocouple. An overall schematic of the experimental setup is illustrated in Figure 3.1.

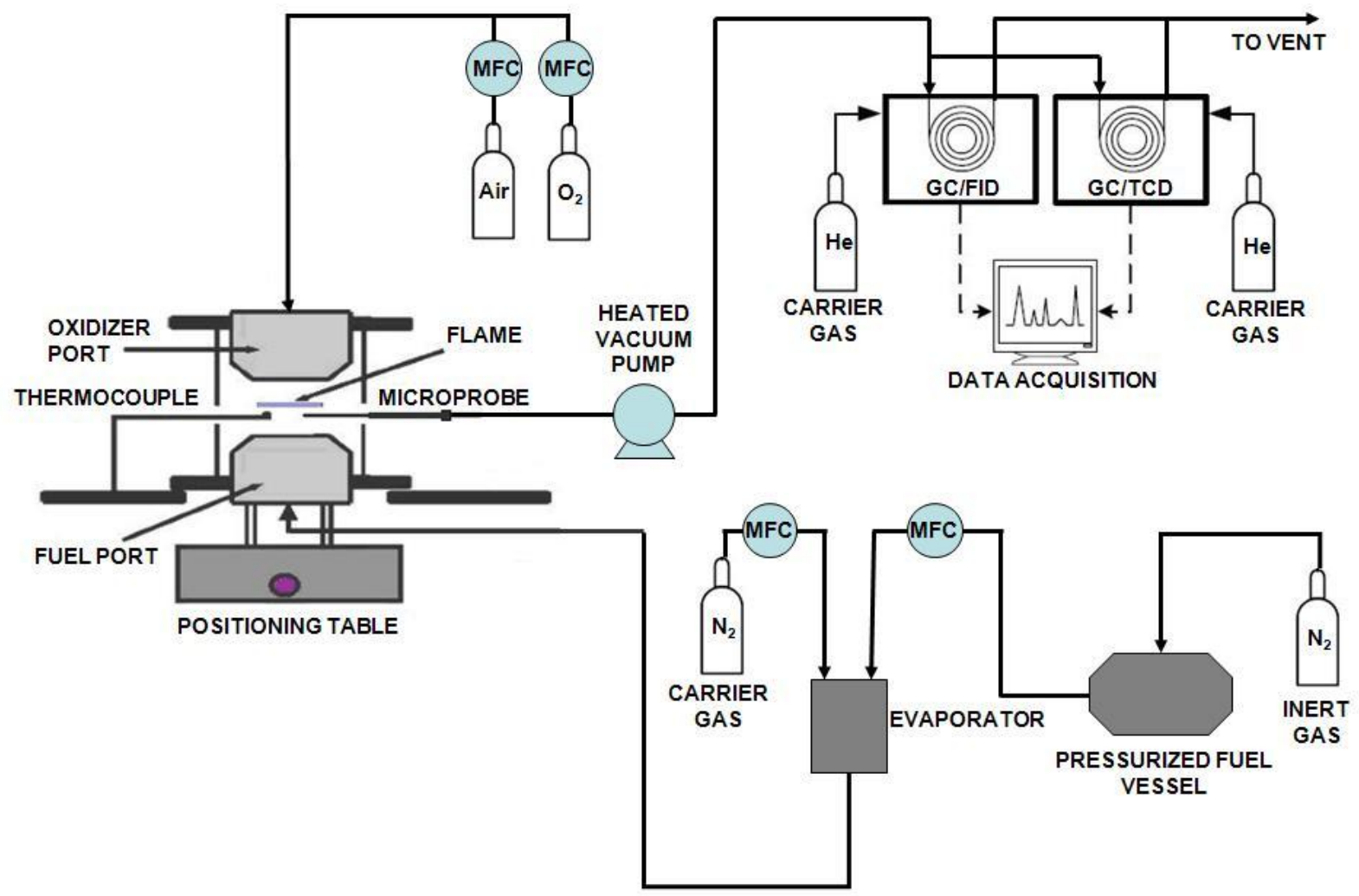

Figure 3.1: Schematic of opposed-flow diffusion flame burner setup. 


\subsection{Experimental Apparatus}

\subsubsection{Opposed-Flow Configuration}

The opposed-flow (or counterflow) diffusion flame provides a fundamental understanding of the detailed structure of diffusion flames. It offers experimental and modeling advantages over jet flames, even though their stability is more sensitive to flow conditions [26]. The opposed-flow diffusion flame has been proposed as a fundamental element in the complex structure of turbulent non-premixed flames [48].

In this non-premixed configuration, the two streams are introduced through burner ports and when they come into contact and diffuse into one another, a stagnation plane is formed. At this stagnation plane, the axial velocity goes to zero and it prevents any non-diffusional mixing between the fuel and oxidizer streams. The location of the stagnation plane depends on the relative initial momentum fluxes of each stream. For equal momentum fluxes, the stagnation plane would lie near the midpoint between the two burner porters. However, if the momentum flux of one stream is greater than the other, the stagnation plane moves closer to the burner port with the lower momentum flux. For most hydrocarbons burning in air, stoichiometric conditions require more air than fuel, so the fuel must diffuse across the stagnation plane to the flame location, as illustrated in Figure 3.2 [48]. In contrast, if more fuel than air is required for stoichiometric conditions, then the flame would lie on the fuel side of the stagnation plane.

Once the two streams meet, a flat flame is formed. This flame is located where the mixture fraction is stoichiometric. The experimental configuration of an opposed flow diffusion flame is rather distinctive as it allows for very fuel rich and very fuel lean conditions to coexist in the same combustion system. 


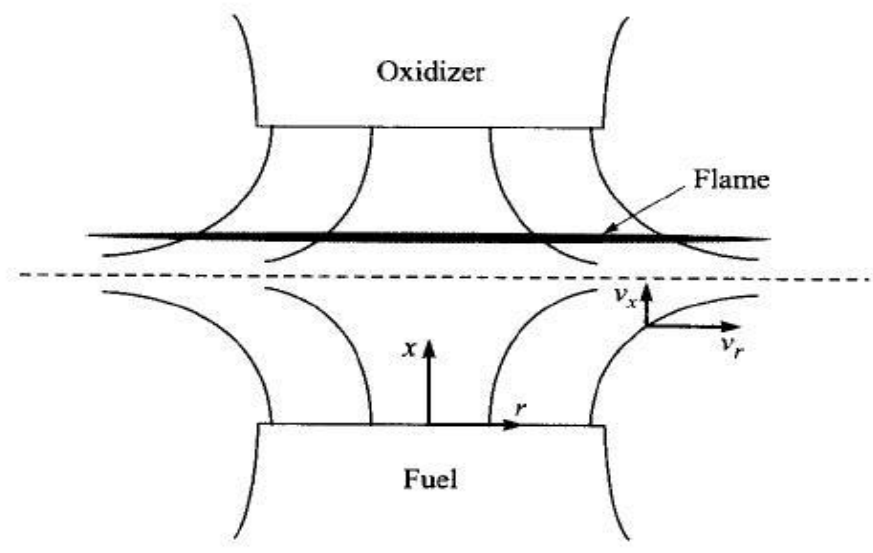

Figure 3.2: Opposing streams of fuel and oxidizer create a stagnation plane (dashed line) near the centre of the region in between the two ports [48].

\subsubsection{Opposed-Flow Diffusion Burner}

The experimental setup requires two identical McKenna flat flame burners that are coaxially mounted $20 \mathrm{~mm}$ apart and are facing each other. The fuel stream is fed through the bottom port, while the oxidizer stream is fed through the top port.

Each burner port consists of a stainless steel housing that encloses a porous sintered bronze matrix. The porous matrix is divided into inner and outer coaxial cylinders with diameters of $25.4 \mathrm{~mm}$ and $38.1 \mathrm{~mm}$, respectively. The inner cylinder directs the fuel or oxidizer stream and the outer cylinder can be used to create a nitrogen shroud around the flame to minimize external flow disturbances. The annulus' shrouding feature was not used in this study. The porous plugs ensure that the gases have a uniform laminar flow and flat velocity profile at the port's surface. The temperature of the gases flowing through the ports was controlled by circulating hot air through the porous plugs packed between two coaxial cylinders. 


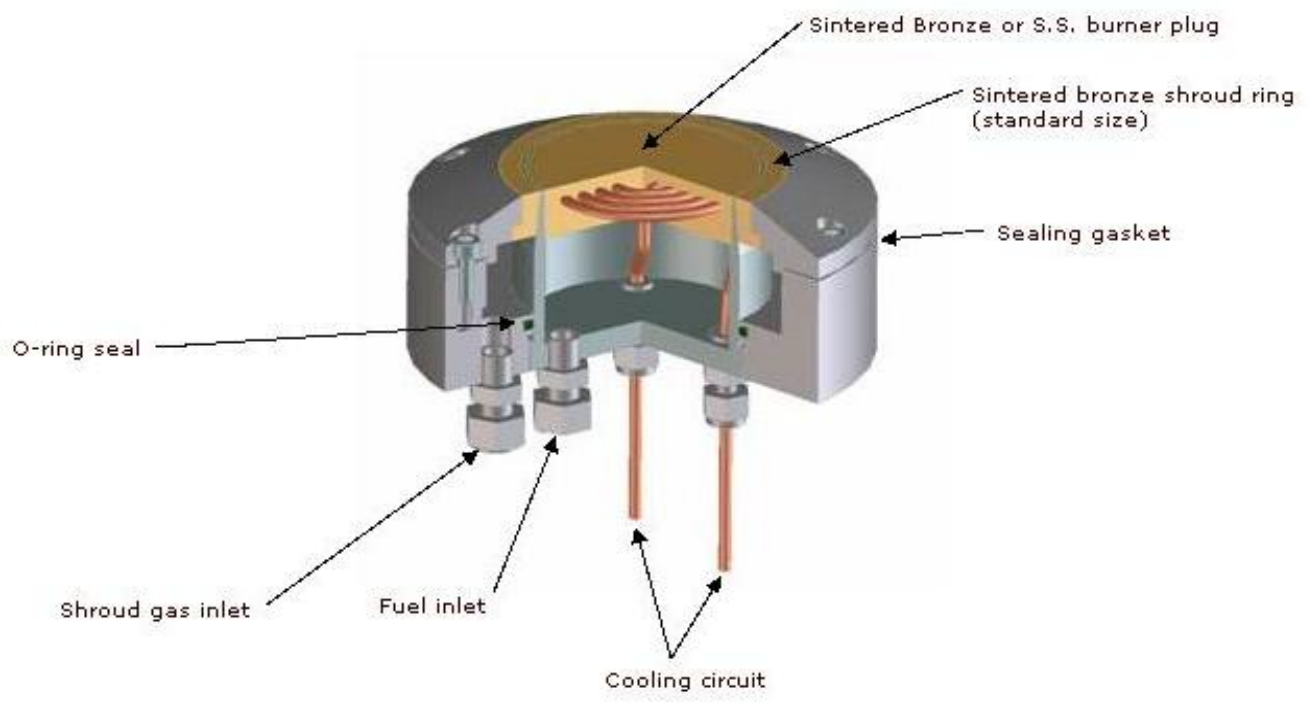

Figure 3.3: Components of McKenna flat flame burner [49].

A custom built aluminum holder provides support for the two burners and a clear quartz shroud with a diameter of $22 \mathrm{~cm}$ protects the flame from airflow disturbances from the surrounding environment. The unit is mounted on a translation stage, which moves along the vertical axis with the rotation of a micrometer knob. This stage allows for the vertical profile of the flame to be analyzed for temperature and species concentrations between the two burner ports. Combustion gases from the burner are vented through a canopy hood, which is vented to the laboratory fume hood.

A fuel mixture of $97.55 \%$ nitrogen gas and $2.45 \%$ fuel $\left(99 \%\right.$ pure 1 -hexanol ${ }^{1}$ ) was fed through the bottom port at a mass flux of $0.01597 \mathrm{~g} / \mathrm{cm}^{2}-\mathrm{s}$, while an oxidizer mixture of $40.09 \%$ of nitrogen gas and $59.91 \%$ of oxygen gas was fed through the top port at a mass flux of $0.0154 \mathrm{~g} / \mathrm{cm}^{2}$-s. Nitrogen is added to the fuel to prevent condensation in the lines and soot formation in the flame. Oxygen is added to air to produce a nitrogen to oxygen ratio (N/O) similar to air in the flame (i.e., For $\varphi \approx 1, \mathrm{~N} / \mathrm{O} \approx 3.76$ ). The momentum fluxes of the fuel mixture and the oxidizer mixture exiting their respective port were $0.2619 \mathrm{~g} / \mathrm{cm}-\mathrm{s}^{2}$ and $0.2692 \mathrm{~g} / \mathrm{cm}-\mathrm{s}^{2}$, respectively. The momenta of the two gas streams are similar in order to achieve a stagnation plane near the centre of the burner. Also, the mass fluxes used are tuned to produce a stable

${ }^{1}$ Sigma-Aldrich, 1-hexanol, anhydrous, $\geq 99 \%$ 
flame that is not prone to external disturbances. The temperatures of the gases exiting the top (oxidizer mixture) and bottom (fuel mixture) burner ports were measured to be $500 \mathrm{~K}$ and $400 \mathrm{~K}$, respectively. With these flow rates and temperatures, the opposed-flow diffusion flame is situated on the fuel side of the stagnation plane. Thus, the oxidizer mixture must diffuse through the exhaust to reach the flame.

\subsubsection{Fuel Vaporization System}

The vaporization of heavy molecular weight liquid fuels is a significant challenge. To overcome this challenge, the liquid fuel is highly diluted and vaporized in a stream of nitrogen carrier gas.

To prepare the fuel mixture, liquid fuel was pressurized with inert nitrogen $\left(\mathrm{N}_{2}\right)$ gas in a 1 US gallon Millipore pressure vessel. The pressure vessel is pressurized to $36 \mathrm{psig}$ in order to supply the liquid mass flow controller. Solubility of nitrogen gas in the fuel, while in the pressure vessel, was an initial concern, as nitrogen solubility increases with the number of carbons in straight-chain alcohols [50]. At $25^{\circ} \mathrm{C}$, the mole fraction of nitrogen gas in 1-hexanol was found to be $5.84 \times 10^{-4}$ [50]. At such a low pressure of $36 \mathrm{psig}$, the solubility of 1-hexanol in nitrogen is

less than $1.00 \times 10^{-3}$ at all temperatures. Thus, the solubility of nitrogen in the 1-hexanol was assumed to be negligible in the pressure vessel.

A Bronkhorst Controlled Evaporator Mixer (CEM) unit was used to vaporize the pressurized liquid fuel into a stream of $\mathrm{N}_{2}$ gas. This unit includes a temperature-controlled evaporator chamber, a liquid mass flow controller, and a gas mass flow controller. The liquid fuel and $\mathrm{N}_{2}$ gas streams were mixed in a mixing device, which includes an atomizer and a control valve, before entering the heated chamber. In order to prevent fuel condensation, the vapourized fuel/ $\mathrm{N}_{2}$ mixture was transferred from the CEM evaporator to the burner via a heated transfer line from Unique Heated Products. The mass flow controller used to deliver nitrogen to the CEM unit had a reported error of $\pm(0.5 \%$ reading value $+0.1 \%$ full scale $)$. And, the error of the mass flow controller for the liquid fuel is $\pm 0.1 \%$ of full scale. 


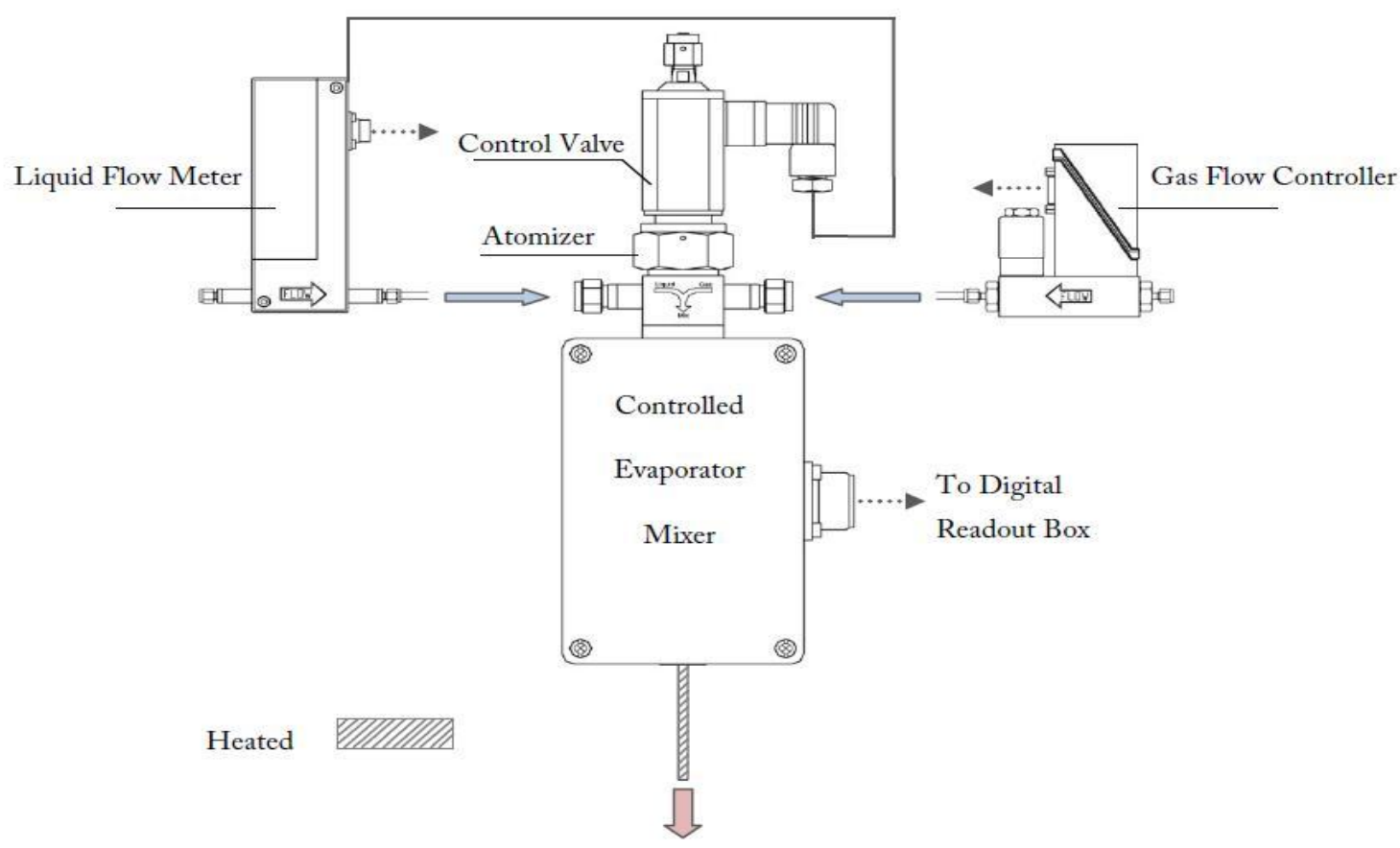

Figure 3.4: Bronkhorst liquid delivery system with vapour control, where liquid fuel is vapourized in a heated gas stream [51].

To verify the flow rate of the fuel being sent to the Bronkhorst CEM unit, an Ohaus digital bench scale $^{2}$ was used to measure the weight of the pressure vessel and the decrease in weight was tracked over time during the extent of the experiments. The scale was calibrated using a set of physical weights from 1 gram to 1 kilogram. The measured accuracy of the flow rate out of the pressure vessel using the scale is \pm 0.1 gram. The reproducibility of measurements using the scale for the fixed fuel flow rate was verified to be within the reported accuracy. The temperature of the CEM unit was set to $170^{\circ} \mathrm{C}$ to ensure that the fuel is completely vapourized.

The boiling point of 1 -hexanol is $156^{\circ} \mathrm{C}$. However, the fuel sent through the fuel port is heavily diluted in a stream of nitrogen, so the actual boiling point of the fuel will be much lower. Given that the mole fraction of 1-hexanol in the fuel mixture is 0.0245 and the fuel mixture exits the port at atmospheric pressure, the partial pressure of 1-hexanol in the fuel mixture would be

2 Ohaus Adventurer Pro - Model AV8101N 
0.0245 atm, according to Raoult's law and assuming ideal gas conditions. With Antoine's equation and the parameters for 1-hexanol from NIST Chemistry WebBook [52], the vapour pressure of 1-hexanol is plotted as a function of temperature in Figure 3.4. According to the relationship, a temperature above $310 \mathrm{~K}$ is sufficient to keep the 1-hexanol fraction in the gas phase at a vapour pressure of 0.0245 atm as the fuel mixture exits the burner port.

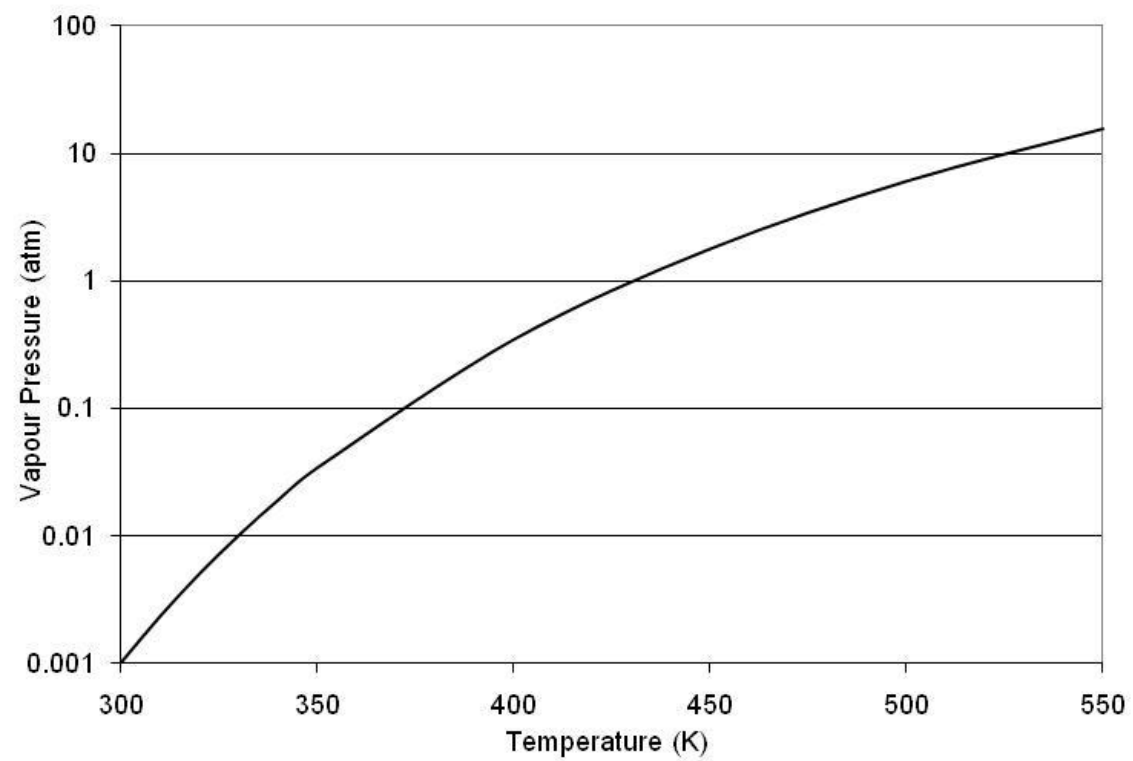

Figure 3.5: Vapour pressure of 1-hexanol as a function of temperature with Antoine's equation. 


\subsubsection{Reynolds Number and Strain Rate Calculations}

The Reynolds number ( $\mathrm{Re}$ ) is calculated to verify if the flow exiting the burner port is laminar ( $\operatorname{Re}<2300)$, transient $(2300<\operatorname{Re}<4000)$, or turbulent $(\operatorname{Re}>4000)$. An opposed-flow diffusion flame is laminar, so the fluid velocity must be set accordingly. Equation 3.1 is used to calculate the Reynolds number for flow in the burner port. At the flow conditions described in Section 3.1.2, the Reynolds number is in the laminar flow regime (i.e., $\operatorname{Re}=190$ ).

$$
R e=\frac{\rho D u}{\mu}
$$

Where Re $=$ Reynolds Number

$$
\begin{aligned}
& \rho=\text { gas density }\left(\mathrm{kg} / \mathrm{m}^{3}\right) \\
& \mathrm{u}=\operatorname{gas} \text { velocity }(\mathrm{m} / \mathrm{s}) \\
& \mathrm{D}=\text { burner port diameter }(\mathrm{m}) \\
& \mu=\text { dynamic viscosity }\left(\mathrm{N} \cdot \mathrm{s} / \mathrm{m}^{2}\right)
\end{aligned}
$$

The strain rate is defined as the normal gradient of the normal component of the flow velocity. It describes the inverse of the characteristic flow time in the counterflow configuration. For plug flow conditions, whereby the axial velocity profile is radially uniform across the port exit, Seshadri and Williams [53] have derived an expression for the velocity gradient near the stagnation plane. Equation 3.2 is used to determine the strain rate at the stagnation plane in the region between the stagnation plane and fuel outlet. Using the expression, the fuel side strain rate is approximately $33.0 \mathrm{~s}^{-1}$.

$$
a=\frac{2\left|V_{\text {fuel }}\right|}{L}\left(1+\frac{\left|V_{\text {ox }}\right| \sqrt{\rho_{\text {ox }}}}{\left|V_{\text {fuel }}\right| \sqrt{\rho_{\text {fuel }}}}\right)
$$

Where $\mathrm{a}=$ strain rate on the fuel side $\left(\mathrm{s}^{-1}\right)$

$$
\mathrm{L}=\text { distance between the two burner ports }(\mathrm{cm})
$$


$\left|\mathrm{V}_{\text {fuel }}\right|=$ absolute value of the fuel stream velocity at the fuel boundary $(\mathrm{cm} / \mathrm{s})$

$\left|\mathrm{V}_{\mathrm{ox}}\right|=$ absolute value of the oxidizer stream velocity at the oxidizer boundary $(\mathrm{cm} / \mathrm{s})$

$\rho_{\text {fuel }}=$ density of the fuel stream $\left(\mathrm{g} / \mathrm{cm}^{3}\right)$

$\rho_{\mathrm{ox}}=$ density of the oxidizer stream $\left(\mathrm{g} / \mathrm{cm}^{3}\right)$

\subsubsection{Gas Sampling System}

Once a stable flame is established between the opposed-flow diffusion flame burner ports, a sampling system is used to obtain qualitative and quantitative information about the flame's characteristics. Samples of the flame are obtained at various points along the vertical axis to determine species concentration profiles and temperature measurements are made to determine the flame's temperature profile.

\subsubsection{Gas Sampling Apparatus}

Sampling probes are designed to produce a minimum disturbance in the flame. These disturbances occur from sample withdrawal and from the bulk of the probe itself. The gas sampling system consists of a fused silica microprobe, which was designed by Sarathy [54]. In this design, the probe tip is low-cost, reproducible, and easily replaceable in case of breakage or clogging. The fused silica microtubes are coated in a polyamide (graphite-reinforced composite) resin on the outer surface to provide flexibility and to reinforce sealing. This study used a $5 \mathrm{~cm}$ length of $200 \mu \mathrm{m}$ deactivated fused-silica microtubing $(0.20 \mathrm{~mm}$ internal diameter, $0.35 \mathrm{~mm}$ outer diameter $)^{3}$. The microprobe is mounted on a stage and can be inserted between the two burner ports through an opening in the quartz shroud that encloses the burner. The microprobe is connected to a dual-stage KNF heated, single-head diaphragm vacuum pump ${ }^{4}$, with heated

${ }^{3}$ Agilent Deactivated Fused Silica Retention Gap

${ }^{4}$ KNF oil-free heated vacuum pump Model N 036 ST. 11E (vacuum side: 24 in. Hg and pressure side: 20 psig) 
$1 / 4$ inch stainless steel tubing. A schematic of the microprobe is shown in Figure 3.7 to describe how the probe is connected to $1 / 4$ inch stainless steel tubing.

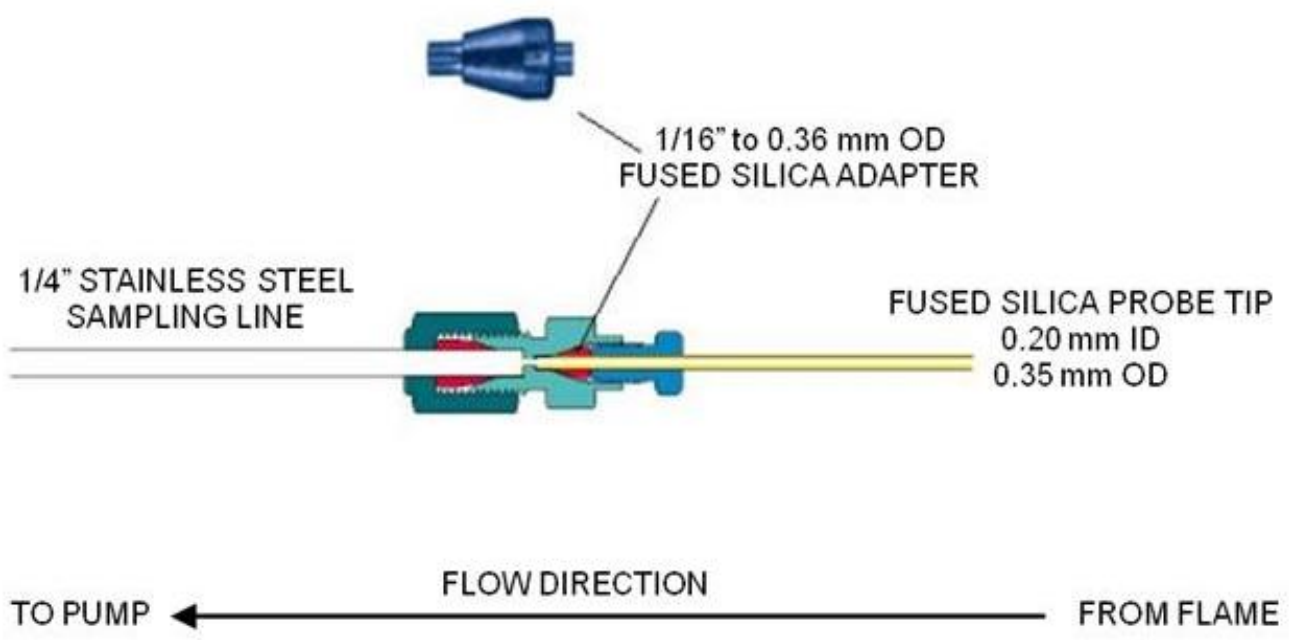

Figure 3.6: Schematic of microprobe setup (not to scale).

The KNF pump is an oil-free pump, so the gas sample being delivered cannot be contaminated. The gas sample is transferred through stainless steel and Teflon parts of the pump. No condensation in the pump head is possible either as it is heated to $240{ }^{\circ} \mathrm{C}$. The elastic diaphragm moves up and down using an eccentric. The first stage (vacuum) of the pump creates suction in the sampling line to withdraw gas samples from the flame through the microprobe. The analytical instruments are connected downstream of the second stage (compressor) of the pump to evaluate these gas samples. The compressor head of the pump delivers gas samples to the analytical instruments through a $1 / 4$ inch stainless steel heated transfer line that is heated to $450 \mathrm{~K}$. A vacuum pressure gauge upstream of the pump is used to monitor the pressure of the sampling line on the vacuum side. A particulate filter ${ }^{5}$ was placed in between the pressure gauge and the vacuum side of the pump to remove any fine particulates that may damage the pump or the analytical equipment downstream. Between the particulate filter and pressure gauge, a high

${ }^{5}$ Swagelok, Model SS-4TF-15; sintered with nominal pore size of $15 \mu \mathrm{m}$ 
temperature two-way ball valve is installed to close off the line when necessary (e.g., for leak detection). The temperature of all heated surfaces is $450 \mathrm{~K}$, which is sufficient to avoid condensation of high molecular weight compounds (e.g., the fuel) in the sampling lines.

When using microprobes for sampling, the main objective is to quench the chemical reactions within the microprobe and sampling line. Fristrom [55] suggests that successful flame sampling does not depend on a rapid temperature drop in the microprobe to quench the reactions. A temperature drop alone would not quench all flame reactions. Thus, a combination of a rapid pressure drop with the destruction of the free radicals on the probe walls will allow for reaction rates to become negligible.

Error is introduced when inserting a microprobe into a flame for sampling. These errors include the potential for disturbance of the flow field, chemical reactions quenching on the outer surface of the microprobe, a poor spatial resolution, and heat absorption by the microprobe. Research by Struckmeier et al. [56] showed good agreement between the quality of species profiles measured using intrusive microprobes (ID = 50 to $700 \mu \mathrm{m}$ ) and optical techniques. Thus, the microprobe sampling is a robust method to collect experimental data of flames with good accuracy. The authors also suggest making minor corrections to the experimental data to account for positional errors caused by the microprobe.

\subsubsection{Leak Detection}

The detection and elimination of leaks of ambient air in the gas sampling line is critical to ensure confidence in flame measurements. Leaks into the sampling line would dilute the gas sample, leading to lower than expected species concentrations. The procedure described was developed by Zabeti [51].

A plug was inserted in place of where the $200 \mu \mathrm{m}$ microtube would be inserted at the end of the probe tip, while the heated vacuum pump is on to create a vacuum in the line. The full vacuum pressure created by the pump read as approximately $81 \mathrm{kPa}$-gauge ( $24 \mathrm{in}$. Hg-gauge). The twoway ball valve is then closed off and the pump was turned off to determine if any leaks existed in the sampling line. If a rapid change in pressure was observed, then a leak must exist in the line. Dry ice (i.e., solid $\mathrm{CO}_{2}$ ), a flow meter, and a non-dispersive infrared (NDIR) analyzer were used 
to determine if a measurable level of $\mathrm{CO}_{2}$ is leaking into the sampling and transfer lines. NDIR analysis is a technique whereby a gas concentration is estimated based on its absorption of a specific wavelength of infrared energy. The NDIR and flow meter are set up in series at the end of the line, downstream of the analytical instruments and just before venting. The dry ice is placed near connection fittings on the line for several minutes. If the NDIR failed to indicate measurable levels of $\mathrm{CO}_{2}$, then no major leaks are present in the sampling line. A verification of the flow meter will indicate that the sampling and transfer lines are leak free if the flow meter shows no flow.

\subsubsection{Sampling Procedure}

The tip of the probe is placed approximately $1.5 \mathrm{~mm}$ behind the central vertical axis that separates the burner ports to allow for samples to be withdrawn from the flame. After initial insertion, the probe is held stationary as the burner assembly is moved vertically by turning the micrometer knob for the translation stage. One complete turn on the micrometer knob in the counterclockwise direction is equivalent to moving the burner assembly downwards by $0.5 \mathrm{~mm}$. To measure the exact position of the microprobe between the two burner ports, the bottom (i.e., fuel) port is taken as the zero height and the top (i.e., oxidizer) port is taken as the maximum height. Each counterclockwise turn of the micrometer knob moves the burner assembly down; thus, increasing the distance between the fuel port and the microprobe (i.e., moving the microprobe upwards in the flame).

When the microprobe is positioned at the desired height, the heated vacuum pump is turned on and product gases are withdrawn from the flame region to fill the sampling line. The sampling lines are purged before any analytical testing occurs. 


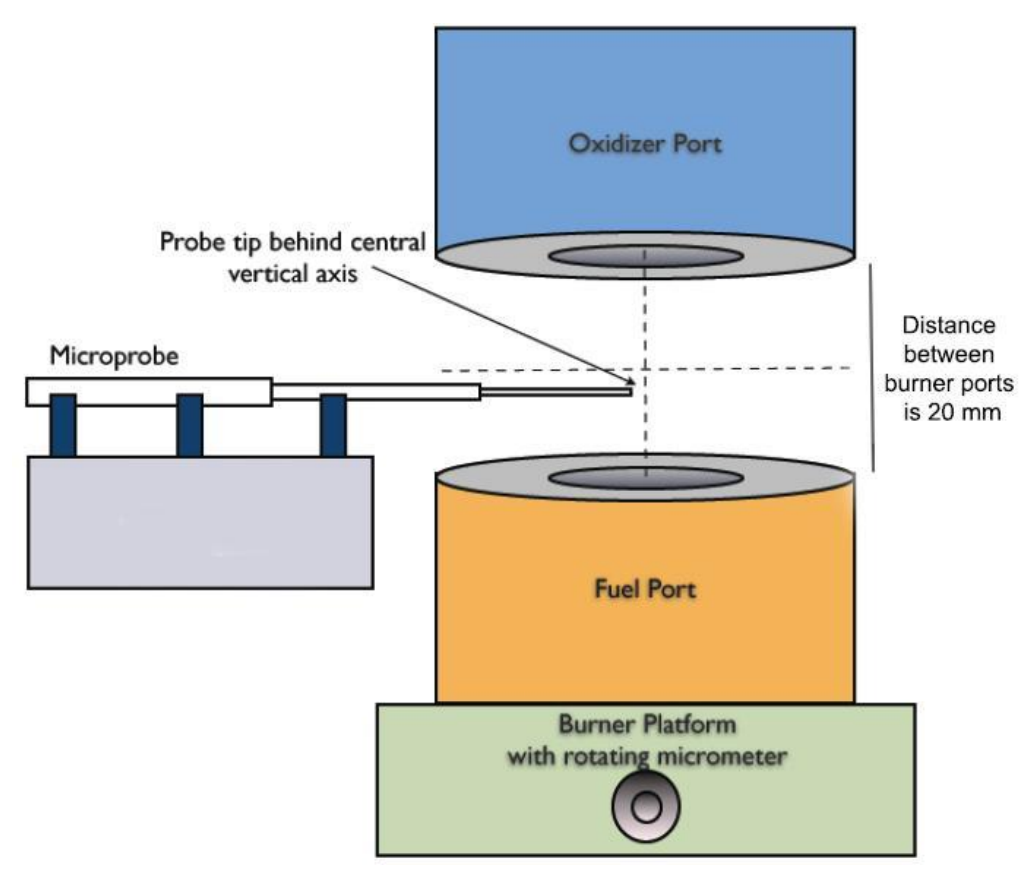

Figure 3.7: Microprobe positioning between the two flat flame burner ports [16].

\subsection{Analytical Techniques}

Gas samples extracted from the flame were analyzed with two gas chromatography machines. The hydrocarbon species and oxygenated compounds were analyzed by a flame ionization detector (FID). Carbon dioxide and carbon monoxide were quantified by a thermal conductivity detector (TCD). The flame temperature was measured by an R-type thermocouple.

\subsubsection{Gas Chromatography}

Gas chromatography (GC) describes a separation process in which volatile organic compounds of a sample partition between a flowing mobile phase (i.e., carrier gas) and a stationary phase (i.e., separation column). The GC method used in this study measured for $\mathrm{CO}, \mathrm{CO}_{2}, \mathrm{C} 1$ to $\mathrm{C} 8$ hydrocarbons and $\mathrm{C} 1$ to $\mathrm{C} 11$ oxygenated compounds. A GC unit includes a flowing mobile phase (carrier gas), a stationary phase (separation column), an injection port, an oven, and a detector. 
The carrier gas carries the sample through a separation column where the compounds in the sample gas partition into the separation column, based on their solubilities at the given temperature. Since partitioning behaviour is strongly dependent on temperature, the separation column is placed in a temperature-controlled oven. Compounds are separated with a range of boiling points by starting at low temperatures and then increasing the temperature until the high boiling point compounds are eluted. The injection port is maintained at a temperature higher than the boiling point of the least volatile compound in the gas mixture.

The retention time is the amount of time a compound spends in the separation column. As each compound of the separated sample gas passes through the detector, a quantitative response in the form of a peak is generated by the detector signal and a collection of these peaks make up a chromatogram. The detector signal is proportional to the quantity of each analyte. Two types of detectors that were utilized in this study - flame ionization detector (FID) and thermal conductivity detector (TCD). The peak retention time is used to identify each compound and the area under the peak is used to quantify the amount of each compound. A sharp peak indicates good separation. The retention times and peaks of each compound were determined using calibration gases of known concentrations. Sample gas chromatograms, generated from the GC/FID and the GC/TCD, are shown in Appendix A and Appendix B, respectively.

\subsubsection{Flame Ionization Detector}

The instrument used in this study is a Varian 3800 GC with electronic flow controllers, a 1079 injector, a methanizer, and two flame ionization detectors (FID). The FID consists of a hydrogen/air flame and a collector plate. As gas components are eluted from the separation column, the flame burns the organic molecules to produce ions. These ions are attracted to the collector plate, which generates a current. This measured current corresponds to the quantity of ions present and is proportional to the quantity of the component in the detector. Since the hydrogen/air flame ionizes the organic molecules, this detection method is destructive. The GC/FID was remotely controlled by the Galaxie Chromatography Data System Ver. 1.9 software. 
A schematic of the GC/FID set up is illustrated in Figure 3.9 and the specific operating conditions are shown in Table 3.1. The injection system is comprised of a gas sample loop, a gas sampling valve (GSV) ${ }^{6}$, and an injector. The heated vacuum pump delivers the gas sample from the flame and fills the $0.25 \mathrm{~mL}$ GC sampling loop.

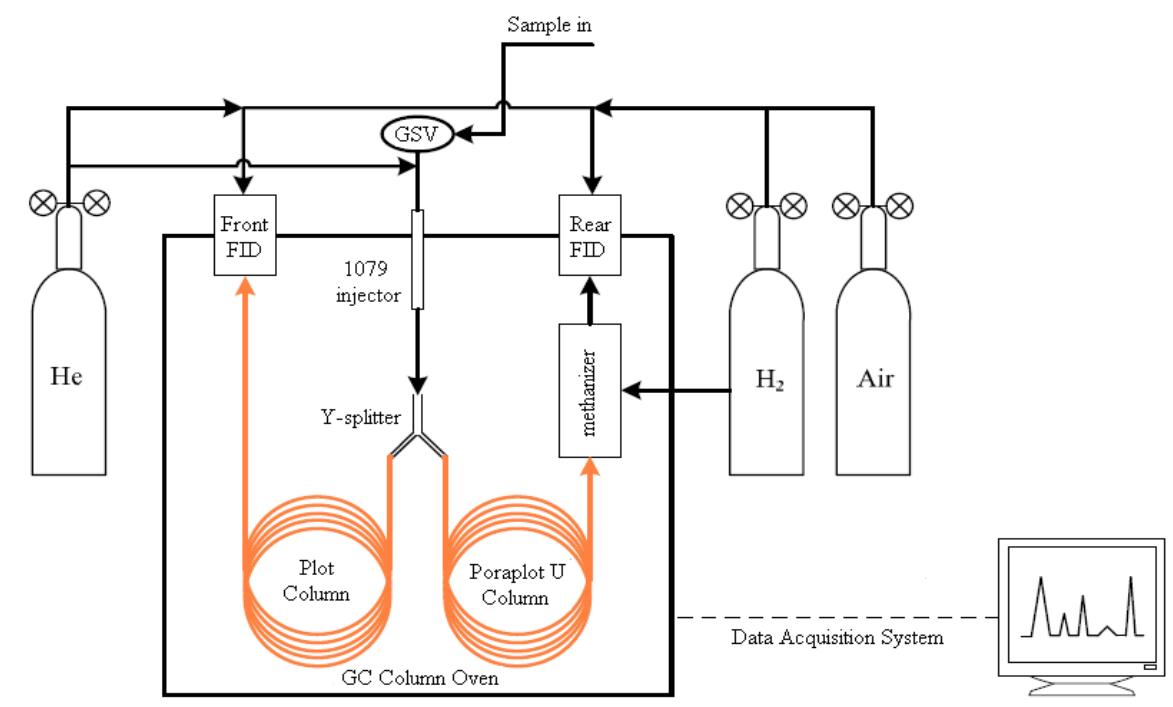

Figure 3.8: Schematic of dual column GC/FID with methanizer setup [51].

The 10 port rotary GSV directs the gas sample and carrier gases into the injector. In the GSV's fill position, the gas sample flow through the sample loop and the carrier gas flow to the injector and separation column. Once the GSV is switched to the load position, the gas sample in the sample loop gets carried with the carrier gas flow through the injector and into the separation column.

The injector is a Varian 1079 universal capillary injector equipped with a splitless insert. A splitless insert allows for the entire gas sample to be loaded into the separation column; thus,

${ }^{6}$ VICI Valco 10 port valve with air actuator 
allowing for trace compounds to be detected. A split insert can be used to load a portion of the gas sample into the separation column.

Once the gas sample passes through the injector, it moves into a $0.5 \mathrm{~m}$ fused-silica retention gap before passing through a $\mathrm{y}$-splitter ${ }^{7}$ where it is split to two columns for separation. $\mathrm{C} 1$ to $\mathrm{C} 8$ hydrocarbons are separated on a non-polar phase HP-Al/S PLOT capillary column ${ }^{8}$ and are detected on the front FID. Oxygenated species, such as aldehydes, ketones, and alcohols, are separated on a polar phase Poraplot U-capillary column ${ }^{9}$, and are passed through a methanizer before detection on the FID. The FID provides a response proportional to the analyte's concentration and number of carbon atoms. For example, the detector signal for 1 mole of ethane $\left(\mathrm{C}_{2} \mathrm{H}_{6}\right)$ would be about double the magnitude for 1 mole of methane $\left(\mathrm{CH}_{4}\right)$, and 1 mole of propane $\left(\mathrm{C}_{3} \mathrm{H}_{8}\right)$ would be about triple that of 1 mole of $\mathrm{CH}_{4}$. Molar response factors have been examined by Schofield for a number of hydrocarbon and oxygenated species [57].

Oxygenated species have lower responses because the FID flame cannot break down carbonoxygen bonds. Thus, species like formaldehyde and carbon monoxide register zero response on the FID, while higher oxygenated hydrocarbons provide weaker responses than their non-oxygenated counterparts. To improve the FID's response to oxygenated compounds, the separated sample gas was passed through a methanizer before being burned in the FID. The methanizer is a 1/16 inch stainless steel tube packed with a powered nickel catalyst. The methanizer is heated to $380{ }^{\circ} \mathrm{C}$ and requires a constant flow of hydrogen gas. As the gas sample flows through the methanizer, the nickel catalyst breaks the carbon-oxygen bonds and then saturates them with hydrogen. Thus, all carbon-oxygen bonds are converted to carbon-hydrogen bonds. For example, formaldehyde appears as methane and acetaldehyde appears as ethane on the FID. In this study, the $\mathrm{C}-\mathrm{O}$ to $\mathrm{C}-\mathrm{H}$ conversion was assumed to be $100 \%$ efficient.

\footnotetext{
${ }^{7}$ Varian universal quick seal splitter

${ }^{8}$ Agilent Technologies HP-Al/S $50 \mathrm{~m}$ x $0.53 \mathrm{~mm}$ (L x ID)

${ }^{9}$ Varian Poraplot U $25 \mathrm{~m}$ x $0.53 \mathrm{~mm}$ (L x ID)
} 
Table 3.1: GC/FID Dual Column Method Parameters.

\begin{tabular}{|c|c|}
\hline Front Injector & $\begin{array}{c}250{ }^{\circ} \mathrm{C} \\
2.0 \mathrm{~mL} / \mathrm{min} \text { He flow to column } \\
\text { Splitless injection }\end{array}$ \\
\hline Gas Sampling Valve & $\begin{array}{l}200{ }^{\circ} \mathrm{C} \\
\text { Switch sampling position for } 2 \mathrm{~min}\end{array}$ \\
\hline Column Oven Program & $\begin{array}{l}50^{\circ} \mathrm{C} \text {, hold for } 3 \mathrm{~min} \\
20^{\circ} \mathrm{C} / \mathrm{min} \text { to } 150{ }^{\circ} \mathrm{C} \text {, hold for } 5 \mathrm{~min} \\
20^{\circ} \mathrm{C} / \mathrm{min} \text { to } 180^{\circ} \mathrm{C} \text {, hold for } 25 \mathrm{~min}\end{array}$ \\
\hline Front FID & $\begin{array}{c}300{ }^{\circ} \mathrm{C} \\
30 \mathrm{~mL} / \mathrm{min}_{2}, 300 \mathrm{~mL} / \mathrm{min} \text { air } \\
26 \mathrm{~mL} / \mathrm{min} \text { He makeup }\end{array}$ \\
\hline Rear FID & $\begin{array}{c}300{ }^{\circ} \mathrm{C} \\
15 \mathrm{~mL} / \mathrm{min} \mathrm{H}_{2}, 300 \mathrm{~mL} / \mathrm{min} \text { air } \\
28 \mathrm{~mL} / \mathrm{min} \text { He makeup }\end{array}$ \\
\hline Methanizer & $\begin{array}{c}380{ }^{\circ} \mathrm{C} \\
20 \mathrm{~mL} / \mathrm{min} \mathrm{H}_{2}\end{array}$ \\
\hline
\end{tabular}

\subsection{GC/FID Carrier Gas}

The main purpose of the carrier gas is to carry the sample through the separation column. It is inert and it does not interact with the sample.

High purity of the carrier gas for a FID is important as impurities like oxygen and water can destroy the stationary phase. Trace amounts of water can desorb other column contaminants and produce a higher detector background or noise. Trace hydrocarbons in the carrier gas can cause a high background with the ionization detector and limit their sensitivity. Thus, the GC/FID was equipped with hydrocarbon, oxygen and moisture traps before the column to remove any contaminants in the carrier gas.

The carrier gas used for the GC/FID was $99.997 \%$ helium. 


\subsubsection{Thermal Conductivity Detector}

The thermal conductivity detector (TCD) measures the changes in thermal conductivity in a reference carrier gas caused by the eluted components from the gas sample. Thermal conductivity describes the rate at which a material can transfer heat and is strongly temperaturedependent. Measurement with a TCD is based on monitoring changes in the electrical resistance of a heated filament caused by variations in its temperature as the eluted components passes through the measuring cell. When a component appears in the carrier gas, the thermal conductivity of the carrier gas is altered, resulting in a change in temperature and resistance of the heated filament. These changes in temperature and resistance produce a corresponding voltage signal. This type of detector is generally sensitive to all substances except the carrier gas. The TCD has the advantage of not destroying the analyte, which happens in a FID. Although a TCD is less sensitive than a FID, a TCD has the ability to detect pure substances such as $\mathrm{O}_{2}, \mathrm{~N}_{2}$, $\mathrm{CO}$, and $\mathrm{CO}_{2}$. The GC/TCD was remotely controlled by the Galaxie Chromatography Data System Ver. 1.9 software.

The instrument used in this part of the study was a Varian 450-GC. Similar to the system found on the GC/FID, this Varian 450-GC consists of a gas sample loop, two GSVs. The gas sample is introduced to the system with an Electronic Flow Control (EFC) pneumatic system for constant pressure control and constant total flow control. The first GSV loads the gas sample into the $1 \mathrm{~mL}$ sample loop and then injects the gas sample into the stream of carrier gas, where the mixture is delivered to the separation columns. The two columns in series are used for separation: a Hayesep Q packed column ${ }^{10}$ and a Molecular sieve packed column ${ }^{11}$. The fraction containing oxygen $\left(\mathrm{O}_{2}\right)$, nitrogen $\left(\mathrm{N}_{2}\right)$, carbon monoxide $(\mathrm{CO})$ and methane $\left(\mathrm{CH}_{4}\right)$ is flushed onto the Molecular Sieve column and are parked there. The remaining fraction, mainly carbon dioxide $\left(\mathrm{CO}_{2}\right)$, $\mathrm{C} 2$ isomers, and water $\left(\mathrm{H}_{2} \mathrm{O}\right)$ bypass the Molecular Sieve column and are eluted to the TCD. The Molecular Sieve column is then set to flow again, allowing for the separation of $\mathrm{O}_{2}, \mathrm{~N}_{2}, \mathrm{CO}$, and $\mathrm{CH}_{4}$ and the detection of these species on the TCD. While the GC/TCD can

\footnotetext{
${ }^{10} 0.5 \mathrm{~m} \times 2 \mathrm{~mm}$ (L x ID), 80-100 mesh

$111.5 \mathrm{~m}$ x 2 mm (L x ID), MolSieve 13X, 80-100 mesh
} 
quantify many species, only the concentrations of $\mathrm{CO}, \mathrm{CO}_{2}$, and $\mathrm{O}_{2}$ were quantified in this study with this technique.

The GC/TCD is equipped with oxygen, moisture and charcoal filters to remove impurities from the carrier gas. Helium gas at an inlet pressure of 80 psig served as the carrier and make up gas. Instrument air at 60 psig was used for valve operation.

The strength of the TCD response signal depends on the concentration of the eluted components that has a different thermal conductivity than that of the carrier gas. Thus, gas components with thermal conductivities close to that of the carrier gas will elicit small responses, while those that differ more from the carrier gas will show larger responses.

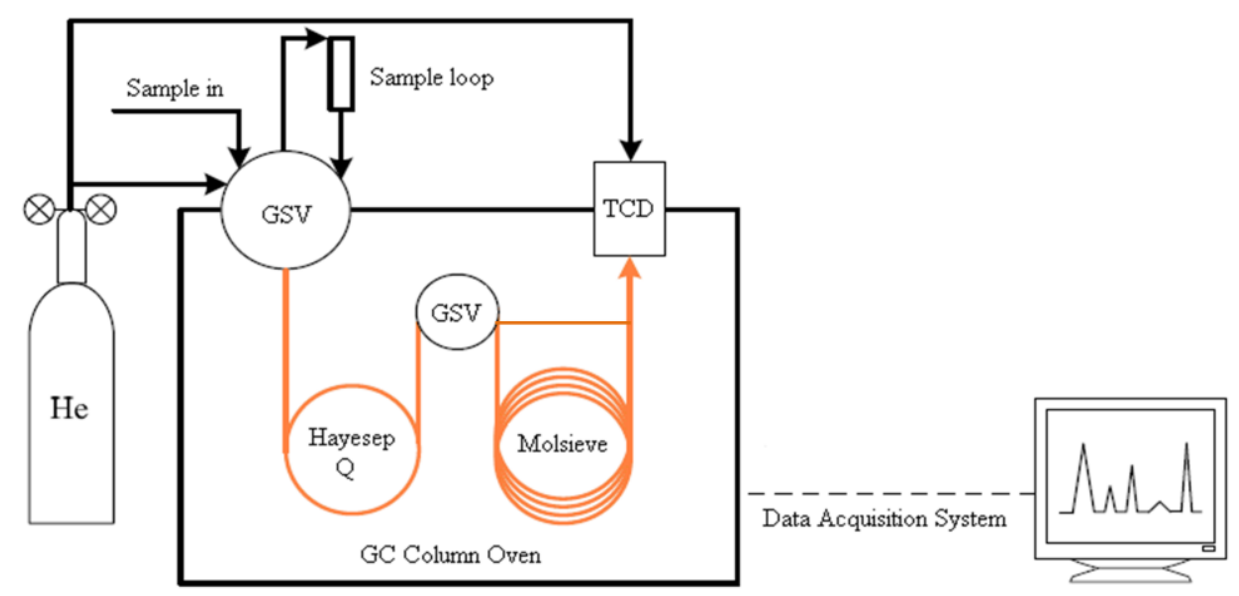

Figure 3.9: Schematic of dual column GC/TCD setup [51].

Table 3.2: GC/TCD Method Parameters.

\begin{tabular}{c|c}
\hline Column Oven Program & $\begin{array}{c}50{ }^{\circ} \mathrm{C}, \text { hold for } 10 \mathrm{~min} \\
8{ }^{\circ} \mathrm{C} / \mathrm{min} \text { to } 90^{\circ} \mathrm{C}, \text { hold for } 1 \mathrm{~min}\end{array}$ \\
\hline TCD Filament Temperature & $300{ }^{\circ} \mathrm{C}$ \\
\hline Carrier Gas (He) Flow Rate & $40 \mathrm{~mL} / \mathrm{min}$ \\
\hline Make-Up Gas (He) Flow Rate & $20 \mathrm{~mL} / \mathrm{min}$ \\
\hline
\end{tabular}




\subsection{GC/TCD Carrier Gas}

In measurements with a TCD, the suitability of the carrier gas depends on its own thermal conductivity as it is the reference gas flow.

Helium is used as the carrier gas for the TCD as it has a higher thermal conductivity compared to most organic compounds; thus, yielding larger TCD responses than nitrogen and argon carrier gases. Given that the thermal conductivity of helium ${ }^{12}$ is similar to the thermal conductivity of hydrogen ${ }^{13}$, the detection of $\mathrm{H}_{2}$ in the He carrier gas was not possible. If argon was used as the carrier gas instead of helium in order to detect hydrogen, then the detection of $\mathrm{CO}$ and $\mathrm{CO}_{2}$ would have to be sacrificed, as their thermal conductivities ${ }^{14}$ are similar to that of $\operatorname{argon}^{15}$. Thus, for a TCD to be effective in analyzing a gas sample, the thermal conductivities of analytes must be significantly different than that of the carrier gas. To resolve this problem, a dual TCD system can be used, whereby one TCD would operate with a He carrier gas, and the second TCD would use Ar carrier gas to measure for $\mathrm{H}_{2}$ [51].

Purity of the carrier gas affects the magnitude of the TCD signal. Thus, ultra-pure helium Grade $5.0(99.999 \%)$ was used.

\subsubsection{Calibration}

Different calibration techniques were used to calibrate the GC/FID and GC/TCD for carbon dioxide, carbon monoxide, stable hydrocarbon species, and oxygenated compounds. Calibration gas mixtures were used for hydrocarbons, carbon dioxide, and carbon monoxide. Permeation tubes were used for the calibration of oxygenated compounds. A table listing the retention time of each species can be found in Appendix C. The list includes species that were looked for but not detected in the flame.

\footnotetext{
${ }^{12} \mathrm{k}_{\mathrm{He}}=0.157 \mathrm{~W} / \mathrm{m} \cdot \mathrm{K}$ at $300 \mathrm{~K}$ [45]

${ }^{13} \mathrm{k}_{\mathrm{H} 2}=0.187 \mathrm{~W} / \mathrm{m} \cdot \mathrm{K}$ at $300 \mathrm{~K}[45]$

${ }^{14} \mathrm{k}_{\mathrm{CO}}=0.025 \mathrm{~W} / \mathrm{m} \cdot \mathrm{K}, \mathrm{k}_{\mathrm{CO}}=0.017 \mathrm{~W} / \mathrm{m} \cdot \mathrm{K}$ at $300 \mathrm{~K}$ [45]

${ }^{15} \mathrm{k}_{\mathrm{Ar}}=0.018 \mathrm{~W} / \mathrm{m} \cdot \mathrm{K}$ at $300 \mathrm{~K}$ [45]
} 


\subsubsection{Hydrocarbons}

Hydrocarbon species from the gas samples were analyzed using the GC/FID. The GC/FID was calibrated for hydrocarbons using Scotty calibration gas mixtures. These gas mixtures included:

- 1,000 ppm C1 - C6 alkanes (methane, ethane, propane, $n$-butane, $n$-pentane, $n$-hexane) in nitrogen

- 1,000 ppm C2 - C6 alkenes (ethylene, propylene, 1-butene, 1-pentene, 1-hexene) in nitrogen

- 100 ppm C2 - C6 alkenes (ethylene, propylene, 1-butene, 1-pentene, 1-hexene) in nitrogen

- 1000 ppm acetylene in nitrogen

- 15 ppm C2 - C4 alkynes (acetylene, propyne, 1-butyne, 2-butyne) in nitrogen

- 15 ppm C4 alkanes, alkenes, and alkynes (isobutane, $n$-butane, trans-2-butene, 1-butene, isobutylene, cis-2-butene, 1,3-butadiene, 1-butyne) in nitrogen

Calibrations were performed at a flow rate typically found during gas sampling of the flame. The operating conditions of the GC/FID during the calibration processes were identical to those used during gas sampling analysis. The retention times for benzene and trans-1,3-pentadiene were obtained by injecting the saturated vapour above the pure component liquid into the sample loop.

Schofield suggested that organic compounds have relative responses on a FID according to their effective FID carbon number (or FID molar response factor) [57]. For example, if the FID's response signal for methane at 1,000 ppm was 5,000 units, then the expected FID response signal for 1,000 ppm of propane would be 15,000 units.

To test the linearity of the GC/FID, the $100 \mathrm{ppm}$ and 1,000 ppm gas mixtures of alkenes were flowed into and detected on the GC/FID at a fixed flow rate. Results showed a less than 5\% difference in linearity between the two gas mixtures. Thus, the precision of the species measurements on the GC/FID is estimated to be approximately $\pm 5 \%$. 


\subsubsection{Oxygenated Compounds}

GC calibration for aldehydes and ketones was challenging, as gas mixtures are not readily available, nor reliable for calibration purposes. These compounds are highly reactive and are prone to degrade when stored in gas cylinders. Thus, calibration of acetaldehyde and formaldehyde was done with a calibration gas generator ${ }^{16}$. A calibration gas generator, as depicted in Figure 3.11, uses a permeation tube to release a fixed rate of a compound of interest into a gas stream at a given temperature. A permeation device is an inert permeable tube that is filled with a pure chemical compound in a gas-liquid or gas-solid equilibrium. The permeation tube is heated to a specified temperature in a passivated glass-coated chamber and the device will emit the chemical compound through the permeable tube wall at a constant mass flow rate. An inert carrier gas flows over permeation tube at a constant flow rate to generate a calibration gas flow rate with a known concentration of the chemical compound. This calibration gas mixture is sent to the GC for analysis. The desired concentration is established or changed by varying the flow rate of the carrier nitrogen.

The permeation tube is placed in an oven that is heated to a constant temperature. The temperature controller for the oven has a reported accuracy of $\pm 0.01{ }^{\circ} \mathrm{C}$. Nitrogen carrier gas is purified and delivered to the oven at a constant flow rate with a mass flow controller. The temperature of the oven and the nitrogen flow rate are specified by the manufacturer.

The concentration of the gas mixture was determined using Equation 3.3.

$$
C=\frac{P \cdot\left(\frac{24.46}{M W}\right)}{F}
$$

Where $\mathrm{C}=$ concentration of chemical compound (ppm)

$\mathrm{MW}=$ molecular weight of chemical compound $(\mathrm{g} / \mathrm{mol})$

$\mathrm{P}=$ permeation rate provided by manufacturer $(\mathrm{ng} / \mathrm{min})$

16 Dyancalibrator Model 150 
$\mathrm{F}=$ carrier gas flow rate $(\mathrm{mL} / \mathrm{min})$

24.46 L = molar volume of nitrogen at STP

For a permeation tube of acetaldehyde, with a release rate of about 26,000 $\mathrm{ng} / \mathrm{min}$, the oven was heated to $90{ }^{\circ} \mathrm{C}$ and the carrier nitrogen flow rate was set to $25 \mathrm{~cm}^{3} / \mathrm{min}$. At these conditions, the concentration of acetaldehyde was expected to be roughly $512 \mathrm{ppm}$. Likewise, for a permeation tube of formaldehyde, with a release rate of about $17,000 \mathrm{ng} / \mathrm{min}$, the oven was heated to $110{ }^{\circ} \mathrm{C}$ and the carrier nitrogen flow rate was set to $20 \mathrm{~cm}^{3} / \mathrm{min}$. At these conditions, the concentration of acetaldehyde was expected to be roughly $685 \mathrm{ppm}$. The report accuracy of these permeation devices is $\pm 2.00 \%$. The flow rate of nitrogen gas was chosen according to the expected magnitude of aldehydes appearing in the 1-hexanol flame.

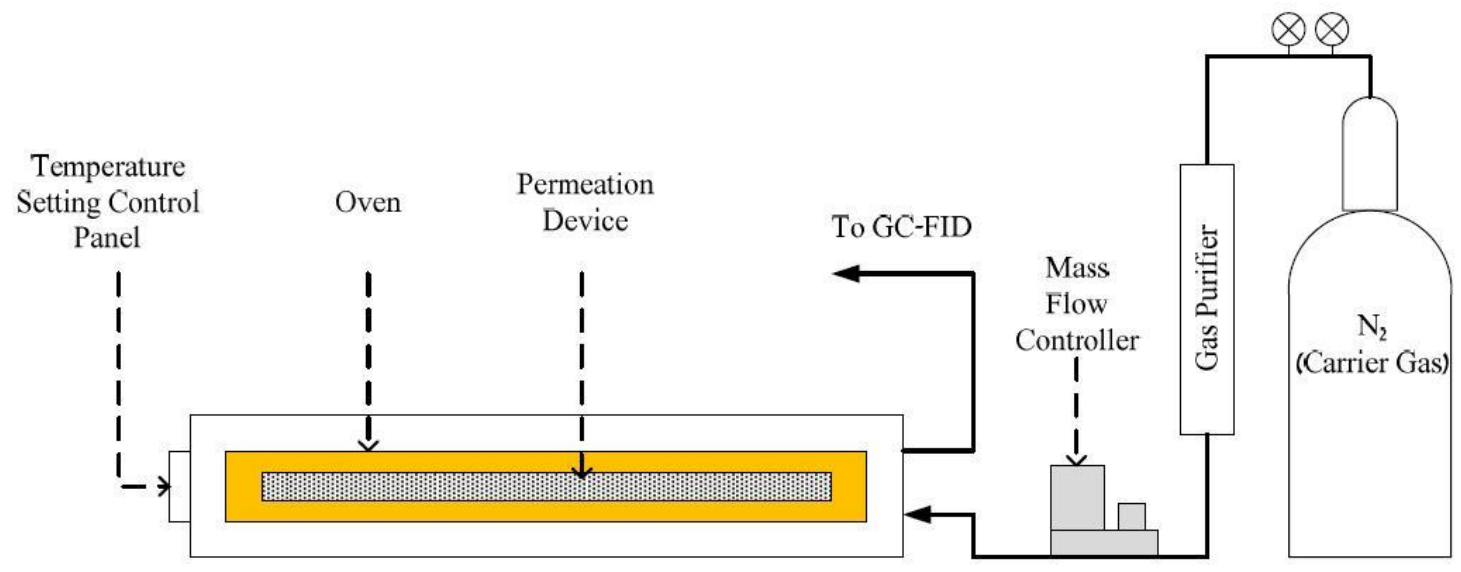

Figure 3.10: Calibration gas generator apparatus for oxygenated compounds [51].

Since gas mixtures or permeation tubes were not available for 1-hexanol, the calibration of the fuel was performed using the fuel vaporization and burner set up. With the fuel vaporization system, the fuel is vaporized and diluted in a stream of nitrogen gas, as previously discussed. The concentration of the fuel in the nitrogen stream was determined from the flow rates of nitrogen gas and liquid fuel that entered the Bronkhorst CEM unit. The fuel mixture was delivered to the bottom burner port of the opposed-flow diffusion flame burner and samples were 
collected using the microprobe sampling apparatus. The GC sampling methods described above were used to calibrate for 1-hexanol.

For other oxygenated compounds, the retention times for crotonaldehyde/2-butenal, 3-buten-1-ol, 4-penten-1-ol, acrolein, n-butanol, methanol, hexanal, and ketene were obtained from sampling the saturated vapour above the pure component liquids to fill the gas sample loop of the GC/FID. The FID's response signal for 1-hexanol was used to calibrate the GC quantitatively. The response signals for equivalent concentrations of the other hydrocarbons were then calculated using Schofield's relative molar response factors for aldehydes and alcohols [57].

\subsubsection{Carbon Dioxide and Carbon Monoxide}

The GC/FID is equipped with a methanizer that would be able to detect $\mathrm{CO}$ and $\mathrm{CO}_{2}$, but at very low concentrations. Thus, the GC/TCD was used to quantify levels of $\mathrm{CO}, \mathrm{CO}_{2}$ and $\mathrm{O}_{2}$. A Scotty gas mixture of $0.5 \%$ each of $\mathrm{CO}, \mathrm{CO}_{2}, \mathrm{O}_{2}$, and $\mathrm{H}_{2}$ in nitrogen was used to calibrate for low concentrations of $\mathrm{CO}, \mathrm{CO}_{2}$, and $\mathrm{O}_{2}$ on the GC/TCD. For higher concentrations, a Linde gas mixture of $9.9 \% \mathrm{CO}$ and $9.9 \% \mathrm{CO}_{2}$ in nitrogen was used for calibration. To calibrate for $\mathrm{O}_{2}$, air was flowed into the sample loop and its composition was assumed to be $21 \% \mathrm{O}_{2}$ and $79 \% \mathrm{~N}_{2}$.

Calibrations for $\mathrm{CO}$ and $\mathrm{CO}_{2}$ on the GC/TCD were performed at flow rates typically found during gas sampling of the flame. The operating conditions of the GC/TCD during the calibration processes are identical to those used during gas sampling analysis. A similar test to verify the calibration error of the GC/FID was done for the GC/TCD as well using the two calibration mixtures as described. From this test, the precision of the species measurements on the $\mathrm{GC} / \mathrm{TCD}$ is estimated to be about $\pm 5 \%$ of the measured value. 


\subsubsection{Temperature Measurement}

The temperature profile of the flame was evaluated by measuring the local temperature at various regions between the two burner ports. Temperature measurements were obtained with an apparatus similar to that used by McEnally et al. [58]. A thin thermocouple wire is small compared to the thickness of a flame front, so the wire would not disturb the flame. The disadvantages of using this measurement method include the aerodynamic wake behind the flame front when the thermocouple is inserted and the possibility of catalytic activity on the thermocouple surface.

A thermocouple consists of two dissimilar metals or conductors that are welded together at one end to form a junction. When any conductor is subjected to a thermal gradient, a voltage is generated along the length of the wire. Thus, both conductor wires experience the same temperature gradient and generate different voltages. This voltage difference is proportional to a specific temperature at the thermocouple junction.

Thermocouples made of thin noble metals, such as platinum and rhodium, are ideal for direct flame measurements because they offer a high resolution, the aerodynamic disturbance of the flame front is minimized, and the materials can withstand high temperature environments. The temperature apparatus used an R-type thermocouple ${ }^{17}$ that satisfied temperature range requirements. An R-type thermocouple is comprised of a positive wire, which is pure platinum, and a negative wire that is $87 \%$ platinum and $13 \%$ rhodium. In addition, the smallest wire diameter available was used to minimize the disturbance of the flame front. The wire diameter of the thermocouple was $75 \mu \mathrm{m}$, with a bead diameter of approximately $180 \mu \mathrm{m}$, which was measured using an inverted microscope.

The thermocouple wires are supported in two ceramic insulator tubes ${ }^{18}$, which are mounted to a plate with bolts. In contrast to the apparatus presented by McEnally et al. [58], a spring was not used in this thermocouple setup to keep the wire taut between the ends of the ceramic tube. It was found that the spring provided excessive force between the two tubes and caused the

\footnotetext{
17 Omega R-Type Unsheathed Fine Gage Microtemp Thermocouple, 12 inch lengths

18 Omega Ceramic Thermocouple Insulators, OD 1/16 inch, ID 1/32 inch
} 
ceramic tubes to bend, which lead to frequent breakage of the thermocouple wire or the ceramic tubes. The thermocouple setup design used in this study was adequate in supporting the thermocouple wire, while keeping it taut during measurements. The junction of the thermocouple did not noticeably sag downwards as the thermocouple thermally expanded in the flame.

The positive and negative wires are connected to an R-type extension wire, which carries the measured signal to a digital thermometer where the temperature is read ${ }^{19}$. Fluctuations of $\pm 50 \mathrm{~K}$ were observed in the hot regions near the flame front (i.e., above $1300 \mathrm{~K}$ ), so a 10 second average was reported. A maximum error of $\pm 10 \%$ was estimated for the temperature measurements.

The modes of heat transfer associated with a thermocouple include surface-induced catalytic reactions, conduction along the thermocouple wires, convection between the thermocouple and surrounding gases, transient heating and cooling of the thermocouple, and radiant heat transfer between the thermocouple and its surroundings [59]. Effects from catalytic reactions and conduction are difficult to quantify in practice, so measures are taken to minimize these heat loss mechanisms. As suggested by Shaddix [59], a non-catalytic coating can be applied to the thermocouple to reduce the catalysis-induced heating and the use of sufficiently long thermocouples will help minimize conduction loss. A thermocouple length-to-diameter ratio of at least 200 is recommended in literature [60]. The ratio of thermocouple length to diameter in this experiment is over 3300. The convective heat transfer from the gas to the thermocouple was estimated assuming that flow was over a sphere, given the physical shape of the junction. In this study, temperature measurements from a coated thermocouple are compared to those from an uncoated (bare) thermocouple.

${ }^{19}$ Digi-sense DualLog R Thermocouple Thermometer 


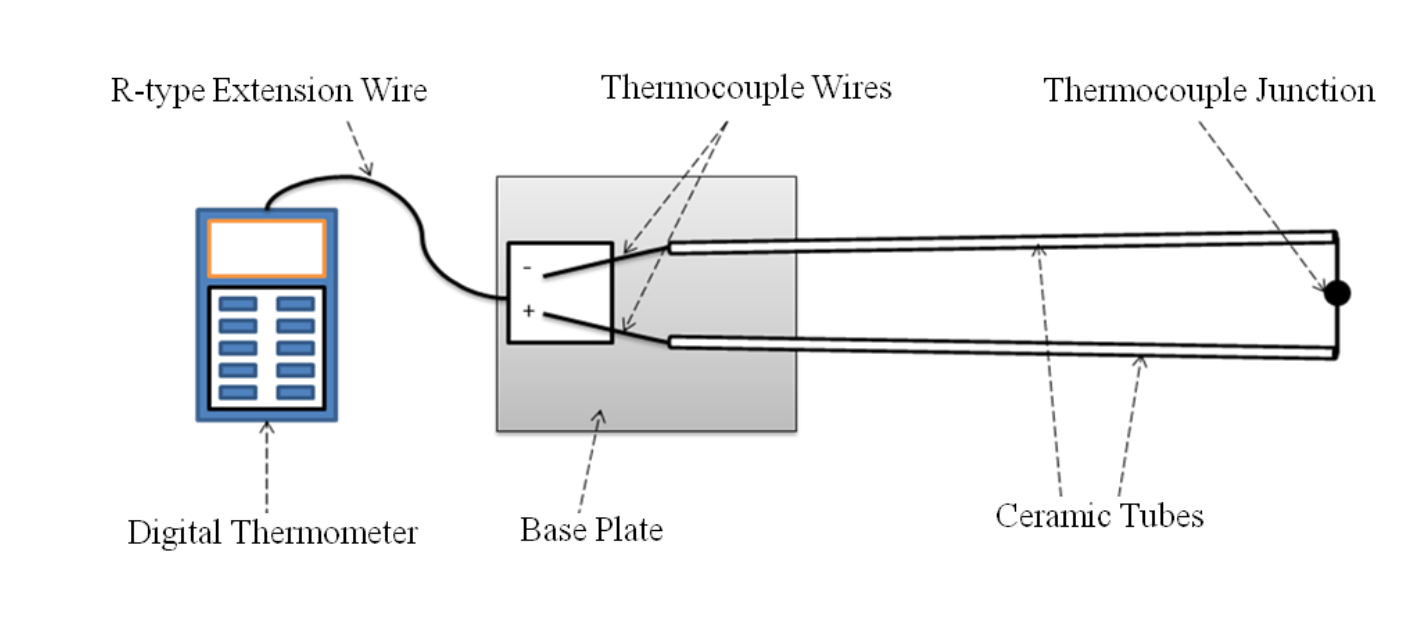

Figure 3.11: Schematic of thermocouple apparatus for temperature measurements (not to scale).

\subsubsection{Coated Thermocouples}

The catalytic heating on the thermocouple has been commonly attributed to the effects of radical recombination near the thermal boundary layer on the wire [60]. Coatings on thermocouples are typically used to reduce or eliminate the effect of catalytic activity on the thermocouple surface. Bare thermocouples attain a higher temperature than their coated counterparts because of their lower emissivity and because of the catalytic heating that occurs on the surface [61]. Platinumrhodium thermocouples need to be coated for flame temperature measurements for two reasons. Firstly, platinum acts as a catalyst in the oxidation of hydrogen. Any reactions on the surface of the junction will increase the temperature, which deviates from the true flame temperature. As described by Kent [62], a catalytically active thermocouple should be insulated from the flame with an inert coating. Secondly, platinum-rhodium alloys may be contaminated at high temperatures by elements, such as hydrogen and carbon, which are naturally found in flames. As a result, contamination may lead to embrittlement of the thermocouple. Furthermore, a suitable coating must be impermeable to gases and a poor conductor of electricity. The coating must be stable at high temperatures and be able to be applied evenly on the surface of a thermocouple wire.

The thermocouple used in the experiments was coated in a layer of silica, as recommended by Shaddix [59]. Fristrom and Westenberg [63] recommend polydimethylsiloxane as the silica 
compound for the coating, as it is inert, non-toxic and non-flammable. The coating was performed following a procedure described by Fristrom and Westenberg [63]. A uniform coat of silica was added to the thermocouple by immersing it in the hot gases of a flame, at approximately $1300 \mathrm{~K}$, where a small amount of polydimethylsiloxane had been burned. It was found that the coating was powdery at too low of a temperature. Vitrification of the silica layer on the thermocouple was then achieved by firing the coated thermocouple in a $1700 \mathrm{~K}$ flame for three hours. The thickness of the coating was measured to be approximately $10 \mu \mathrm{m}$. Thus, the bead diameter after coating was $200 \mu \mathrm{m}$.

\subsubsection{Correction for Radiation Loss}

The temperature measured by the thermocouple will be different from the true flame temperature as a result of aerodynamic, thermal, and/or chemical perturbations.

Fristrom and Westenberg [63] have discussed methods to minimize the effect of these perturbations. However, radiation losses will still occur, even if all disturbances have been minimized.

The measured temperatures were corrected for radiation losses from the surface of the thermocouple using the method described by Shaddix [59]. Correcting for radiation losses is estimated by equating the heat transferred to the thermocouple from the gas to the heat lost by radiation from the wire. The radiation correction correlation given by Shaddix [59] as Equation 3.4 describes the heat balance for a thermocouple:

$$
T_{g}=T_{m}+\frac{\varepsilon \sigma\left(T_{m}{ }^{4}-T_{w}{ }^{4}\right) d}{k \cdot N u}
$$

Where: $\mathrm{T}_{\mathrm{g}}=$ true gas temperature $(\mathrm{K})$

$$
\begin{aligned}
& \mathrm{T}_{\mathrm{m}}=\text { measured gas temperature }(\mathrm{K}) \\
& \mathrm{T}_{\mathrm{w}}=\text { wall (ambient) temperature to which heat is radiated }=300(\mathrm{~K}) \\
& \varepsilon=\text { emissivity of the thermocouple element (dimensionless) } \\
& \sigma=\text { Stefan-Boltzmann Constant }=5.67 \mathrm{E}-08\left(\mathrm{~W} / \mathrm{m}^{2} \cdot \mathrm{K}^{4}\right)
\end{aligned}
$$




$$
\begin{aligned}
& \mathrm{d}=\text { bead diameter of thermocouple }(\mathrm{m}) \\
& \mathrm{Nu}=\text { Nusselt Number } \\
& \mathrm{k}=\text { thermal conductivity of gas }(\mathrm{W} / \mathrm{m} \cdot \mathrm{K})
\end{aligned}
$$

The emissivity was obtained from the study by Bradley and Entwistle [64] for the uncoated (bare) R-type thermocouple, which is a function of temperature. For the coated thermocouple in a silica coating, Kaskan [61] suggests a constant emissivity value of $0.22 \pm 0.02$, which is independent of temperature. The thermal conductivity of air was acquired from the CRC Handbook [45].

The correlation in Equation 3.4 is most affected by two variables: the bead diameter and the Nusselt number. The bead diameter size is proportional to the radiation correction, while the radiation correction is inversely proportional to the Nusselt number. Thus, use of the smallest thermocouple diameter would minimize the magnitude of radiation loss at high temperatures.

The Nusselt number was estimated with the Ranz and Marshall [65] correlation, which is applicable to low-Reynolds number forced convection over a sphere. The correlation was initially derived for evaporating drops with Reynolds numbers between 0 and 200. The Ranz and Marshall correlation for Nusselt number is:

$$
N u_{d, \text { sphere }}=2.0+0.60 \operatorname{Re}_{d}^{1 / 2} \operatorname{Pr}^{1 / 3}
$$

For forced convection, the Nusselt number is a function of the Reynolds number (Re) and the Prandtl number (Pr). The Reynolds number describing the flow field varies across the region between the burner ports, given the opposed-flow configuration. For flow approaching the stagnation plane, the Reynolds number approaches zero and the temperature increases as well. Thus, the Reynolds number was estimated across the region between the two ports, relative to predicted temperature. The predicted temperature is from the chemical kinetic model, which will be discussed later. The dynamic viscosity for nitrogen was used in the estimation of the Reynolds number, as majority of the gas composition across the entire flame was nitrogen. The gas velocity was obtained from the results of the chemical kinetic model as well. 
The Prandtl number is a parameter that describes the relative magnitudes of diffusion of momentum/viscosity and heat in a fluid. Given the opposed-flow diffusion flame configuration, the gas composition varies across the burner ports, in the axial direction. Thus, Prandtl numbers have been estimated across this region using the relationship shown in Equation 3.6. The Prandtl number was estimated using the thermal conductivity of air, and the dynamic viscosity and heat capacity of nitrogen gas, at the predicted temperature.

$$
\operatorname{Pr}=\frac{C_{p} \mu}{k}
$$

Where: $\operatorname{Pr}=$ Prandtl number

$$
\begin{aligned}
& \mathrm{C}_{\mathrm{p}}=\text { heat capacity }(\mathrm{kJ} / \mathrm{kg} \cdot \mathrm{K}) \\
& \mu=\text { dynamic viscosity }(\mathrm{kg} / \mathrm{m} \cdot \mathrm{s}) \\
& \mathrm{k}=\text { thermal conductivity }(\mathrm{kW} / \mathrm{m} \cdot \mathrm{K})
\end{aligned}
$$




\section{$4 \quad$ Modeling}

The chemical kinetic modeling for 1-hexanol was performed using the CHEMKIN PRO modeling package [66]. CHEMKIN PRO contains a number of reactor models that can be used to simulate various real world combustion systems, such as shock tubes, premixed flames, diffusion flames, and partially and perfectly stirred reactors.

In this study, the OPPDIF code was used to simulate the physical experiments of the opposedflow diffusion flame configuration. The OPPDIF code is based on a model developed by Kee et al. [67], for premixed opposed-flow flames. A similarity transformation reduces the axisymmetric flow field to a one-dimensional (1-D) problem, so the dependent variables are only functions of the axial direction. Premixed and non-premixed flames can be simulated with OPPDIF. A brief derivation of the governing equations for the opposed-flow diffusion flame configuration is found in Appendix D, but the complete derivation is given in Kee et al. [67].

The opposed-flow diffusion flame computations were modeled with the OPPDIF code [66]. The OPPDIF code computes the steady-state solution for axisymmetric laminar diffusion flames between two opposing flame burners. As such, the one dimensional model predicts the species, temperature, and velocity profiles in the flow between the burners.

These 1-D laminar diffusion flame models are directly applicable to larger, more complicated flame models. Modeling turbulent combustion is challenging because of the large spatial and temporal fluctuations and complex chemistry with nonlinear reaction rates. To simplify turbulent combustion modeling, a collection of many small laminar flamelets is used to describe a turbulent flame. Furthermore, the species in turbulent flames are calculated from laminar flame data. 


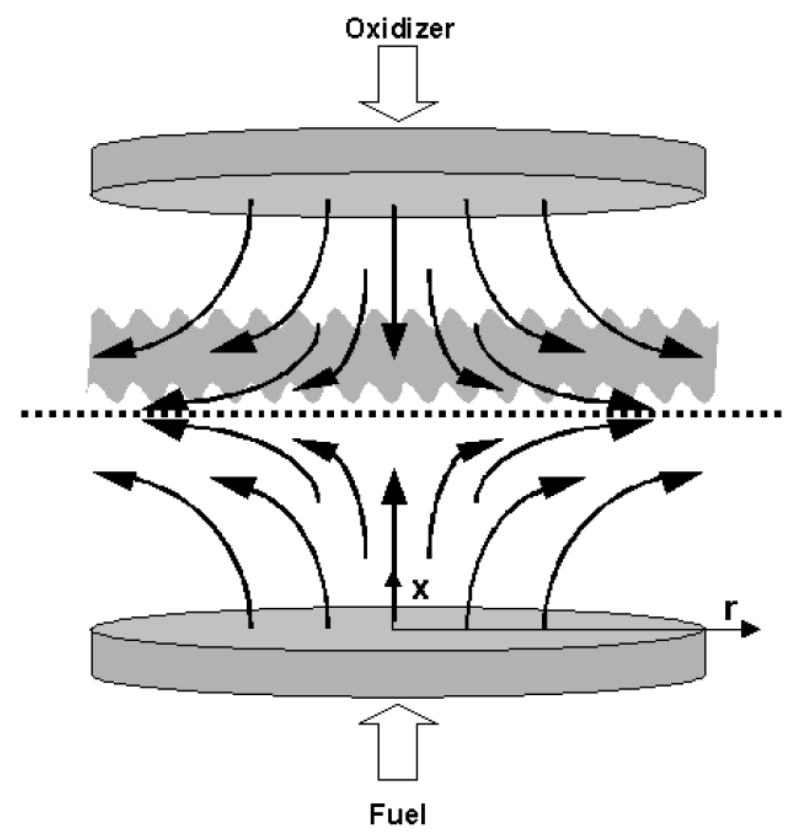

Figure 4.1: Geometry and axis of the axisymmetric opposed-flow diffusion flame configuration [66].

\subsection{Modeling Combustion Chemistry}

Governing equations are solved using CHEMKIN PRO as a numerical solver to evaluate the chemical kinetic, thermodynamic and transport properties in each differential element with respect to time.

The first step to model the combustion setup was to use the graphical user interface of CHEMKIN PRO to create a flow diagram of the experimental apparatus, which included all reactant and product streams. The linking files for the numerical code are then generated with a pre-processor. A pre-processor interprets the three important files: the chemical kinetic database, the thermodynamic database, and the transport database. The "CHEMKIN Gas-Phase Interpreter" reads through the first two files and generates the "CHEMKIN Linking File". The third file is used by the "TRANSPORT Preprocessor" to generate the "Transport Linking File" for modeling systems where transport properties are considered. 
The next step is to define the characteristics of the chemically reacting flow system and inlet flows. These values include the mass flow velocity, initial concentrations, and temperature of each inlet stream, pressure, and a number of solution method options. Table 4.1 shows the boundary conditions and some input parameters of the 1-hexanol flame to be solved with the OPPDIF code in CHEMKIN. The complete input file is presented in detail in Appendix E. The model was run and the numerical simulation output a text file containing the solution. To convert this text file, the "Solution Export Utility" was used to create a readable file for Microsoft Excel.

The inputs to the reactor simulation include a detailed chemical kinetic mechanism, a dataset of thermochemical properties, and a dataset of transport properties.

Table 4.1: Select boundary conditions and input parameters for 1-hexanol flame in OPPDIF code.

\begin{tabular}{c|c}
\hline Fuel Mass Flow Rate & $0.015974 \mathrm{~g} / \mathrm{cm}^{2}-\mathrm{s}$ \\
\hline Fuel Inlet Temperature & $400 \mathrm{~K}$ \\
\hline Fuel Mole Fraction & 1- Hexanol: 0.0245 \\
& Nitrogen: 0.9755 \\
\hline Oxidizer Mass Flow Rate & $0.015423 \mathrm{~g} / \mathrm{cm}^{2}-\mathrm{s}$ \\
\hline Oxidizer Inlet Temperature & $500 \mathrm{~K}$ \\
\hline Oxidizer Mole Fraction & Nitrogen: 0.4009 \\
& Oxygen: 0.5991 \\
\hline Pressure & $1.0 \mathrm{~atm}$ \\
\hline Ending Axial Position & $20 \mathrm{~mm}$ \\
\hline Estimated Zone Width & $25.4 \mathrm{~mm}$ \\
\hline Transport Approach & Mixture-averaged Transport \\
\hline
\end{tabular}




\subsubsection{Chemical Kinetic Database}

The chemical kinetic database provides a user-defined chemical kinetic mechanism for the production and consumption of these species. The chemical kinetic mechanism lists each reaction taking place and the corresponding reaction rate parameters in the modified Arrhenius form:

$$
k_{n}^{f}=A \cdot(T)^{n} \exp \frac{-E_{a}}{R \cdot T}
$$

Where $: \mathrm{k}_{\mathrm{n}}{ }^{\mathrm{f}}=$ reaction rate constant

$$
\begin{aligned}
& A=\text { pre-exponential collision frequency factor }\left(\mathrm{cm}^{3} / \mathrm{mol} \cdot \mathrm{s}\right) \\
& \mathrm{T}=\text { temperature }(\mathrm{K}) \\
& \mathrm{n}=\text { temperature dependence factor } \\
& \mathrm{E}_{\mathrm{a}}=\text { activation energy }(\mathrm{cal} / \mathrm{mol}) \\
& \mathrm{R}=\text { ideal gas constant }(\mathrm{cal} / \mathrm{mol} \cdot \mathrm{K})
\end{aligned}
$$

The chemical kinetic mechanism file format is built as follows, from left to right:

1) The reaction considered

2) The pre-exponential collision frequency factor $\left(1 / \mathrm{s}\right.$ for $1^{\text {st }}$ order, $\mathrm{cm}^{3} / \mathrm{mol} \cdot \mathrm{s}$ for $2^{\text {nd }}$ order $)$

3) The temperature dependence factor

4) The activation energy (cal/mol)

5) After the last number, a comment field can be added

Rate constants for reactions can be found in the NIST Chemical Kinetics Database [68]. This database includes all reported kinetic values for gas-phase chemical reactions.

The chemical kinetic mechanism developed here is based on a previously proposed mechanism for 1-hexanol oxidation in a premixed jet-stirred reactor (JSR) and a combustion bomb [12]. The data files for the simulation were obtained from Togbé et al. [12]. The original chemical kinetic mechanism consists of 2977 reactions involving 600 species. The original kinetic mechanism 
included reactions describing the cool flame chemistry as 1-hexanol exhibited a cool flame and a negative temperature coefficient regime under the JSR conditions. For flame modeling, such as for OPPDIF, the cool flame chemistry was not required, so those chemical reactions related to the cool flame regions were removed. Furthermore, the experiments involving the opposed-flow diffusion flame were conducted at a pressure of $1 \mathrm{~atm}$. Thus, all high pressure (10 atm) reactions, which were used for JSR experiments at $10 \mathrm{~atm}$, were removed from the chemical kinetic mechanism. No additional reactions were added. After the removal of cool flame chemistry and high pressure reactions, the model consists of 2687 reactions involving 361 species.

\subsubsection{Thermochemical Properties}

Thermochemical data are required for CHEMKIN PRO to calculate thermodynamic properties, thermal transport properties and reaction equilibrium constants. The file format containing the thermochemical parameters is as follows:

1) Species' name

2) Elemental composition of the molecule (number of carbon atoms, hydrogen atoms, etc)

3) Electronic charge and phase (solid, liquid or gaseous)

4) Fourteen polynomial fitting coefficients to calculate the constant pressure molar heat capacity $\left(\mathrm{C}_{\mathrm{p}}^{0}\right)$, molar enthalpy of formation $\left(\Delta \mathrm{H}_{\mathrm{f}}{ }^{0}\right)$, and molar entropy of formation $\left(\mathrm{S}_{\mathrm{p}}{ }^{0}\right)$ at any temperature

Thermochemical properties can be found in the "NIST Chemistry WebBook" [52] or estimated using computer programs, such as THERGAS [69] or THERM [70], which are based on Benson's group additivity method [71]. The additivity law determines a desired property of a molecule by adding bond properties for individual groups of atoms in the molecule.

The thermochemical dataset that is used in this study is from Togbé et al. [12], which was initially used to study 1-hexanol oxidation in a JSR and a combustion bomb. 


\subsubsection{Transport Properties}

Transport properties are required when simulating combustion processes that involve the diffusion of multicomponent gaseous mixtures. The molecular transport of species, momentum, and energy in a multicomponent mixture are characterized by the diffusion coefficients, viscosities, thermal conductivities, binary diffusion coefficients, and thermal diffusion coefficients.

The input file containing molecular transport parameters is built via a specified data format for each species, as shown here:

1) An index indicating the geometrical configuration of the molecule - If the index is 0 , the molecule is a single atom. If the index 1 , the molecule is linear, and if it is 2 , the molecule is nonlinear.

2) The Lennard-Jones potential well depth, $\varepsilon / \mathrm{k}_{\mathrm{b}}(\mathrm{K})$

3) The Lennard-Jones collision diameter, $\sigma(\AA)$

4) The dipole moment, $\mu$ (Debyes)

5) The polarizability, $\alpha\left(\AA^{3}\right)$

6) The rotational relaxation collision number, $Z_{\text {rot }}$, at $298 \mathrm{~K}$

7) After the last number, a comment field can be enclosed

The Lennard-Jones (LJ) potential well depth, $\varepsilon / \mathrm{k}_{\mathrm{b}}$, and collision diameter, $\sigma$, can be estimated using the correlations developed by Tee et al. [72]. The coefficients found in these correlations have been optimized for $n$-alkanes (up to $n$-heptane) by Holley et al. [73]. These empirical correlations are shown as Equations 4.3 and 4.4 and are assumed to be independent of temperature. The optimal coefficients for alcohols are not found in literature.

$$
\begin{gathered}
\frac{\varepsilon}{k_{b} T_{c}}=0.8063+0.6802 \omega \\
\sigma\left(\frac{P_{c}}{T_{c}}\right)^{1 / 3}=2.3551-0.3955 \omega
\end{gathered}
$$

The critical temperature $\left(\mathrm{T}_{\mathrm{c}}\right)$, critical pressure $\left(\mathrm{P}_{\mathrm{c}}\right)$ and boiling point $\left(\mathrm{T}_{\mathrm{b}}\right)$ of a molecule can be found using the "NIST Chemistry WebBook" [52]. If these parameters are not available, they 
can be approximated from species with similar molecular structures. The next step was to calculate the acentric factor, $\omega$, using the Lee-Kesler vapor-pressure relation [74]:

$$
\omega=\frac{-\ln \left(P_{c}\right)-5.927+6.096\left(\frac{T_{b}}{T_{c}}\right)^{-1}+1.289 \ln \left(\frac{T_{b}}{T_{c}}\right)-0.169\left(\frac{T_{b}}{T_{c}}\right)^{6}}{15.252-15.688\left(\frac{T_{b}}{T_{c}}\right)^{-1}-13.472 \ln \left(\frac{T_{b}}{T_{c}}\right)+0.436\left(\frac{T_{b}}{T_{c}}\right)^{6}}
$$

Where: $\omega=$ acentric factor

$$
\begin{aligned}
& \mathrm{T}_{\mathrm{b}}=\text { boiling point }(\mathrm{K}) \\
& \mathrm{T}_{\mathrm{c}}=\text { critical temperature }(\mathrm{K}) \\
& \mathrm{P}_{\mathrm{c}}=\text { critical pressure }
\end{aligned}
$$

The dipole moment, $\mu$, is a measure of polarity within a molecule and is defined as a vector sum of individual bond dipole moments. It depends on the difference in electronegativity and the distance between the charges. Thus, non-polar molecules, such as saturated hydrocarbons, have zero dipole moment, while polar molecules, such as oxygenated compounds, have higher dipole moments. The dipole moment of molecules is available in McClellan's “Tables of Experimental Dipole Moments" [75].

The polarizability, $\alpha$, of a molecule describes the tendency of a molecule's charge distribution to be distorted by the presence of an electric field from a nearby ion or dipole. This property can be calculated using an empirical additive formula presented by Bosque and Sales [76] that allows the estimation of polarizability from the molecular formula of hydrocarbons:

$$
\alpha=(1.51 \times \# C)+(0.17 \times \# H)+(0.57 \times \# O)+0.32
$$

The rotational relaxation collision number, Zrot, at $298 \mathrm{~K}$ can be found for each species in the transport database of CHEMKIN PRO [66]. 
To reduce the computational intensity in this study, a mixture-averaged approach was used to estimate gas mixture properties from pure gas mixture properties. A more accurate, yet computationally intensive approach is a multicomponent approach to determine transport properties. The methods of the mixture-averaged approach are documented in Kee et al. [77] and Warnatz [78].

The transport dataset used in this study is from the proposed chemical kinetic model by Togbé et al. [12]. With the transport data, mixture-averaged viscosity, mixture-averaged thermal conductivity, mixture-averaged diffusion coefficients, and thermal diffusion ratios are evaluated.

\subsubsection{Validating Chemical Kinetic Mechanisms}

Once the chemical kinetic, thermochemical, and transport databases are complete, the mechanism can be validated with controlled physical experiments. Figure 4.2 depicts the typical procedure that is followed for the development and validation of chemical kinetic models. The flowchart is adapted from a process that was initially outlined by Frenklach et al. [79] and was summarized by Simmie [80]. It shows that the development and validation of a chemical kinetic mechanism is an iterative process until good agreement between experimental data and simulation results is achieved.

The process can be summarized in the following steps:

1. Conduct controlled experiments that can be used to validate the chemical reactions and rate parameters in the model.

2. Generate a list of elementary chemical reactions that involve all possible reactant, intermediate and product species.

3. Determine the reaction rate constants for each elementary reaction using literature sources or estimation techniques.

4. Provide thermochemical constants to determine equilibrium reaction rate constants for reverse reactions.

5. Model the physical experiment using the reactor code in CHEMKIN PRO.

6. Compare the experimental data with those predicted by computer model. 


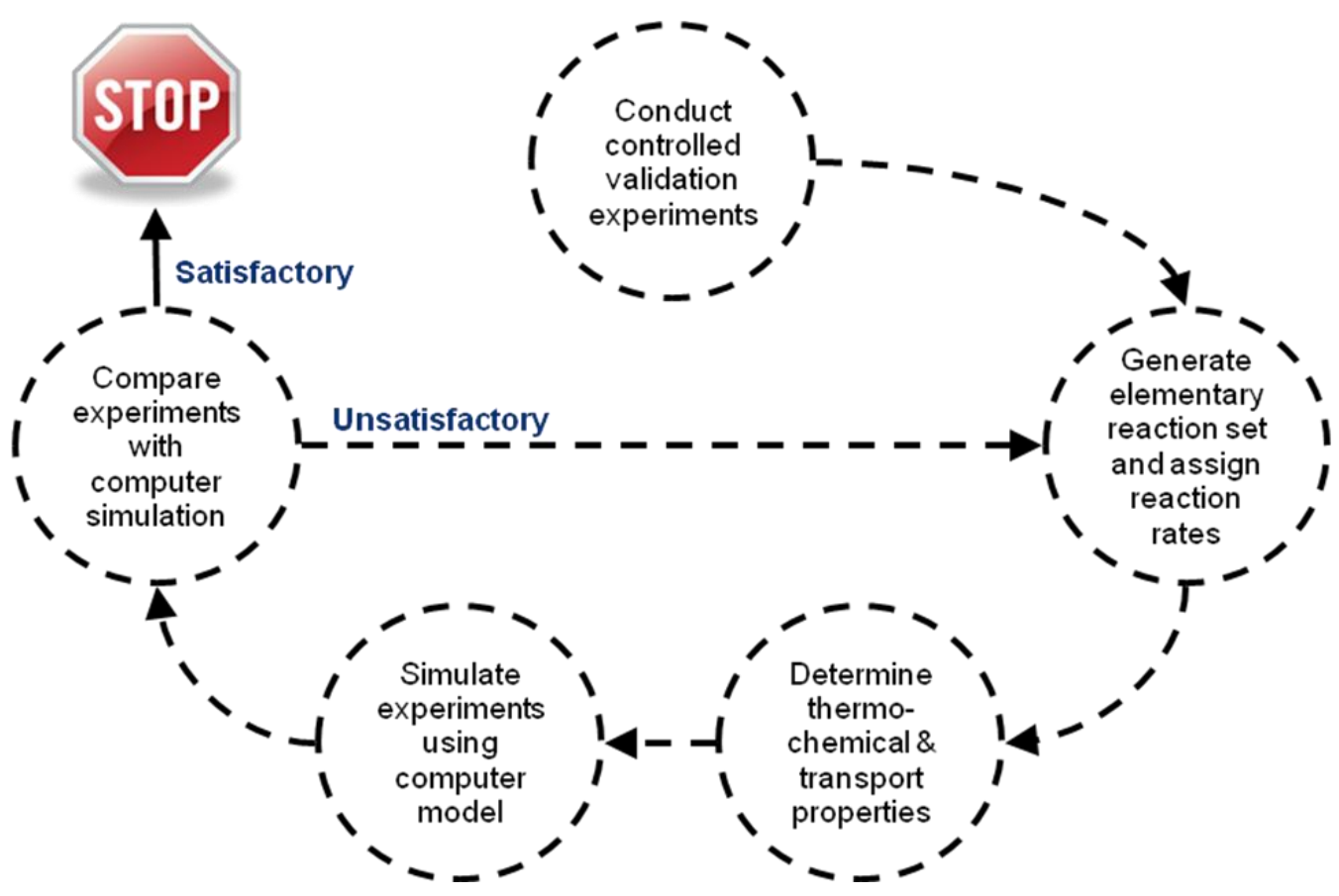

Figure 4.2: Iterative procedure for developing and validating chemical kinetic mechanisms.

Experiments in well defined configurations are required to comprehensively validate the model across different temperatures, pressures, and mixing scenarios found in real combustion systems. Thus, a chemical kinetic mechanism is not considered to be comprehensive if it has only been tested against one experiment as each elementary reaction has its own unique role depending on temperature, pressure, and composition. Elementary reactions with fuel and hydrogen compounds are dominant in fuel rich conditions, while fuel and hydroxyl compounds are mostly found in fuel lean conditions. In addition, there are many reactions that only take part in low temperature chemistry, while others are important at high temperatures. 


\section{Results and Discussion}

The proposed model for the oxidation of 1-hexanol was validated against experimental data from an opposed-flow diffusion flame. The opposed-flow diffusion flame offers a non-premixed environment to study the oxidation of 1-hexanol. Gas samples were extracted in the flame region between the two burner ports and were analyzed using various analytical techniques. The measured species included 1-hexanol (HXOL), carbon dioxide $\left(\mathrm{CO}_{2}\right)$, carbon monoxide $(\mathrm{CO})$, methane $\left(\mathrm{CH}_{4}\right)$, acetylene $\left(\mathrm{C}_{2} \mathrm{H}_{2}\right)$, ethylene $\left(\mathrm{C}_{2} \mathrm{H}_{4}\right)$, ethane $\left(\mathrm{C}_{2} \mathrm{H}_{6}\right)$, formaldehyde $\left(\mathrm{CH}_{2} \mathrm{O}\right)$, acetaldehyde $\left(\mathrm{CH}_{3} \mathrm{HCO}\right)$, propylene $\left(\mathrm{C}_{3} \mathrm{H}_{6}\right)$, 1-pentene $\left(1-\mathrm{C}_{5} \mathrm{H}_{10}\right)$, and 1-hexene $\left(1-\mathrm{C}_{6} \mathrm{H}_{12}\right)$. The gas chromatography method could not separate 1-butene $\left(\mathrm{C}_{4} \mathrm{H}_{8}\right)$ from 1,2-propadiene $\left(\mathrm{aC}_{3} \mathrm{H}_{4}\right)$, so we report the combined concentration of these two species. The same was done for 1,3-butadiene $\left(\mathrm{C}_{4} \mathrm{H}_{6}\right)$ and propyne $\left(\mathrm{pC}_{3} \mathrm{H}_{4}\right)$. Measurable levels (i.e., $\left.>100 \mathrm{ppm}\right)$ of unsaturated aldehydes and alcohols (i.e., 4-pentan-1-ol, 3-butan-1-ol, crotonaldehyde/2-butenal) were not detected in the flame. Given the opposed-flow diffusion flame configuration, whereby diffusion of species is involved, a carbon balance of the system cannot be estimated at a particular location in the flame.

To assist in the discussion, Figure 5.1 indicates the carbon number for each carbon atom in 1-hexanol to help identify its position in the chain.

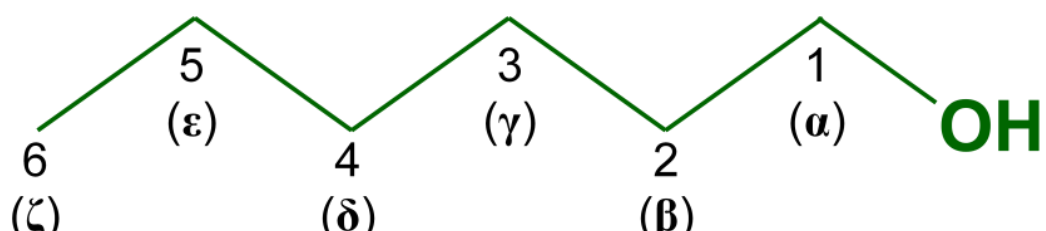

Figure 5.1: Carbon sites for 1-hexanol oxidation 


\subsection{Temperature, Fuel, and Species Concentrations}

The measured and predicted species concentration and temperature profiles obtained in the opposed-flow diffusion flame are illustrated in Figures 5.2 and 5.3. The experimental results are represented by the symbols, while the predicted results are represented by lines.

The reported temperature and species concentration profiles were shifted by $0.3 \mathrm{~mm}$ away from the fuel port. This shift from the fuel port was to account for a positioning uncertainty that is a human error introduced when zeroing the sampling probe against the fuel port surface. The thermocouple height is determined by matching it to the height of the sampling probe.

\subsubsection{Temperature}

Measurements of the temperature were made using an uncoated (bare) thermocouple and a coated thermocouple. The temperature profiles measured by the uncoated thermocouple and the coated thermocouple are plotted on the same axis in Figure 5.2, for comparison. A correction was applied to the measured results to account for radiation loss. Thus, the plot displays the measured and corrected temperature profiles for both thermocouples. The peak temperature predicted by the model is $1733 \mathrm{~K}$. This predicted maximum temperature is greater than the measured maximum temperature with both thermocouples. This discrepancy may be due to poor resolution of the thermocouple in the flame at a given location.

The correction for radiation loss did not provide significant adjustments to the measured temperatures. The maximum radiation loss correction for the uncoated thermocouple was an increase of $38 \mathrm{~K}$ at the peak temperature. Similarly, the maximum temperature correction for the coated thermocouple was $35 \mathrm{~K}$ at the peak temperature. The effect of the correction is greatest near the peak temperature of the profile, as greater losses are exhibited at higher temperatures. Hence, no or a very small amount of radiation loss is observed near the boundaries of the flame.

After radiation loss correction, the peak temperatures measured by the uncoated and coated thermocouples were $1695 \mathrm{~K}$ and $1592 \mathrm{~K}$, respectively. This $103 \mathrm{~K}$ discrepancy between the uncoated and coated thermocouple should suggest that there may be catalytic heating on the surface of the uncoated thermocouple. While the coating on thermocouple will lower the surface 
temperature by reducing catalytic activity, the peak temperature with the uncoated thermocouple is closer to the predicted peak temperature of $1733 \mathrm{~K}$, than is the coated thermocouple. A thin layer of coating was applied to the thermocouple, as suggested (i.e., approximately $10 \mu \mathrm{m}$ thick). As discussed by Kent [62], the thickness of a thermocouple coating should be thin to avoid significant losses through conduction. It is possible that a correction may be required to account for the conduction through the coating layer. In the study by Grana et al. [18], the maximum temperature measured by an uncoated thermocouple for an $n$-butanol flame was about $200 \mathrm{~K}$ higher than that measured with a coated thermocouple. The peak temperature measured with the coated thermocouple is shown to be about $100 \mathrm{~K}$ lower than the predicted temperature. Thus, the discrepancy between the experimental data and predicted results seen in this study are considered to be within reason. 


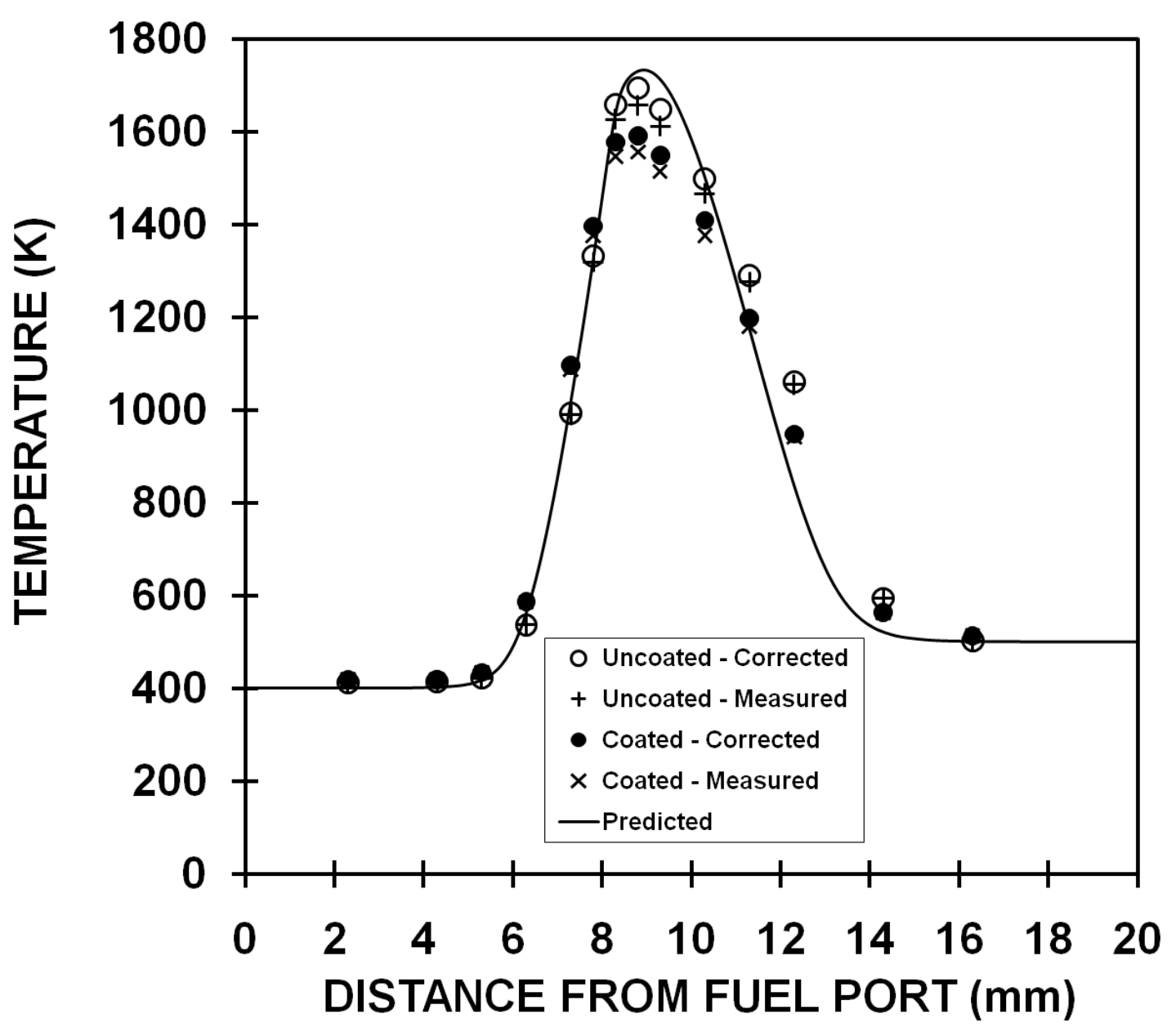

Figure 5.2: Comparison of experimental temperature profiles of 1-hexanol flame using a uncoated (bare) thermocouple and a coated thermocouple. Measured temperatures and corrected temperatures for both thermocouples are shown.

\subsubsection{Fuel and Species Concentrations}

Experimental data was collected over a course of three days to determine the amount of daily scatter throughout the measurements, which may be the result of positioning accuracy. Scatter bars are marked on the species concentration profiles in Figure 5.3 to indicate the day to day variation. The percent scatter for each species was estimated using the peak concentration of the dataset used to plot the results in Figure 5.3 and the peak concentrations measured on the other two days. Table 5.1 presents the peak measured and predicted mole fractions in the 1-hexanol flame. 
The reactivity of 1-hexanol is well predicted by the model. The experimental results show that the concentration of 1-hexanol significantly decreases after a distance of $6.0 \mathrm{~mm}$ from the fuel port. As the 1-hexanol is consumed, the concentrations of $\mathrm{CO}$ and $\mathrm{CO}_{2}$ begin to increase. The fuel is completely consumed at a distance of approximately $8.0 \mathrm{~mm}$ from the fuel port, where the flame front is observed. Just before the flame front, the concentrations of hydrocarbon species reach their peak. Along with $\mathrm{CO}$ and $\mathrm{CO}_{2}$, the most abundant measured species are $\mathrm{C}_{2} \mathrm{H}_{4}, \mathrm{C}_{2} \mathrm{H}_{2}$, $\mathrm{CH}_{4}$, and $\mathrm{C}_{3} \mathrm{H}_{6}$. The peak measured concentration of $\mathrm{CO}$ is seen at a distance of $7.5 \mathrm{~mm}$ from the fuel port, followed by the peak concentration of $\mathrm{CO}_{2}$ at approximately $9.0 \mathrm{~mm}$ from the fuel port. The maximum concentrations of $\mathrm{CO}_{2}$ and $\mathrm{CO}$ are considered to be well predicted. The maximum concentration of $\mathrm{CO}_{2}$ is over predicted by the mode by about $2 \%$, while the maximum concentration of $\mathrm{CO}$ is under predicted by approximately $4 \%$. As for $\mathrm{O}_{2}$, there is good agreement between the experimental data and predicted results as well.

In the following discussion, the model's quantitative prediction is considered good if the predicted maximum mole fraction or percent is within a factor 1.5 of the measured maximum mole fraction or percent. The model performs well in predicting the maximum concentrations of $\mathrm{CH}_{4}, \mathrm{C}_{2} \mathrm{H}_{2}, \mathrm{C}_{2} \mathrm{H}_{6}, \mathrm{C}_{3} \mathrm{H}_{6}, \mathrm{aC}_{3} \mathrm{H}_{4}+\mathrm{C}_{4} \mathrm{H}_{8}, \mathrm{pC}_{3} \mathrm{H}_{4}+\mathrm{C}_{4} \mathrm{H}_{6}, \mathrm{CH}_{2} \mathrm{O}$, and $\mathrm{CH}_{3} \mathrm{HCO}$. The model moderately (i.e., 1.6 to 2 times) under predicts the maximum concentration of $1-\mathrm{C}_{5} \mathrm{H}_{10}$. There are large (i.e., more than 2 times) under predictions of $\mathrm{C}_{2} \mathrm{H}_{4}$, and $1-\mathrm{C}_{6} \mathrm{H}_{12}$ by the model. Analysis of the 1-hexanol mechanism against experimental data in a JSR presented by Togbé et al. [12] also showed a large discrepancy for $\mathrm{C}_{2} \mathrm{H}_{4}$ at $10 \mathrm{~atm}$ and fuel rich conditions. The model was only able to accurately predict $\mathrm{C}_{2} \mathrm{H}_{4}$ in fuel lean conditions (i.e., $\varphi=0.5$ ). In fuel rich conditions, In fuel rich conditions, the proposed chemical kinetic mechanism showed an under prediction of the peak concentration by as much as $33 \%$. Weaknesses in predicting levels of $\mathrm{C}_{2} \mathrm{H}_{4}$ were also found in literature for $n$-butanol combustion in an opposed-flow diffusion flame and a JSR [16].

While formaldehyde, hexanal, acetaldehyde, and acrolein were the main aldehydes produced during the oxidation of 1-hexanol in a JSR [12], the main aldehydes predicted in an opposedflow diffusion flame are formaldehyde, acetaldehyde, crotonaldehyde, and acrolein. Only a trace amount (peak concentration of $\sim 12 \mathrm{ppm}$ ) of hexanal was predicted by the model under the opposed-flow diffusion flame configuration. 
The experimental concentration profiles of $\mathrm{CH}_{2} \mathrm{O}$ and $\mathrm{CH}_{3} \mathrm{HCO}$ shown in Figure 5.3(f) are narrower than the predicted concentration profiles. The over prediction of $\mathrm{CH}_{2} \mathrm{O}$ has been apparent in literature and one group has suggested that the discrepancy may be due to the polymerization of $\mathrm{CH}_{2} \mathrm{O}$ in the sampling lines [81].

Appreciable levels (i.e., hundreds of ppm) of unsaturated straight-chain aldehydes and alcohols, such as crotonaldehyde, acrolein, 3-buten-1-ol, and 4-penten-1-ol, are predicted by the model, but were not detected in the opposed-flow diffusion flame despite having the necessary analytical systems in place. It is hypothesized that in the flame experiments, these species are decomposing upon contact with hot surfaces in the high pressure side of the sampling line. Further investigation is required to test this hypothesis. 

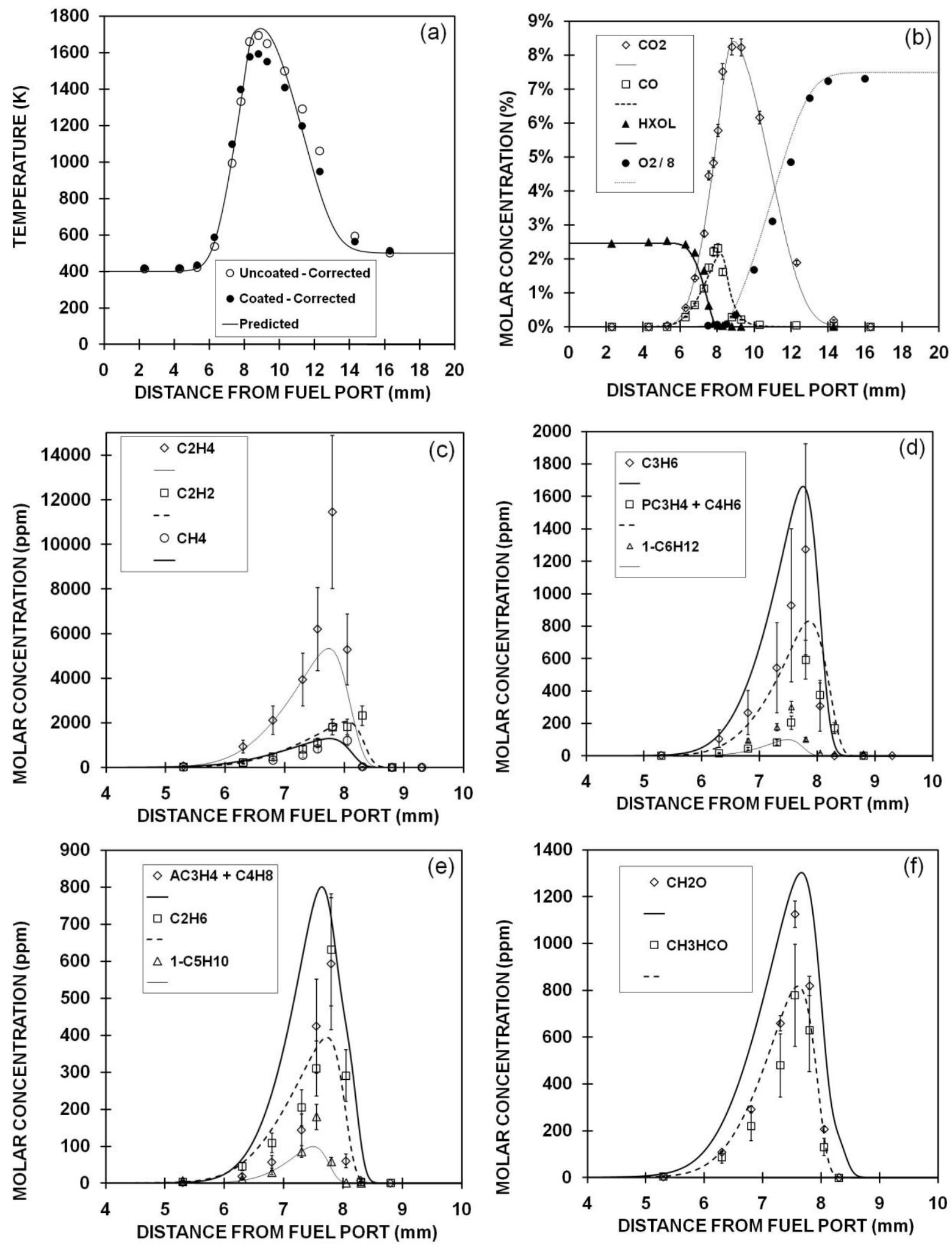

Figure 5.3: Experimental (symbols) and predicted (lines) profiles obtained from the oxidation of 1-hexanol in an atmospheric opposed-flow diffusion flame (2.45\% fuel, $60 \%$ $\left.\mathbf{O}_{2}\right)$. 
Table 5.1: Measured and predicted peak temperatures and species concentrations in the opposed-flow diffusion flame. Italicized numbers are measured values, bold numbers are predicted values, and underlined values are the ratio of measured to predicted.

\begin{tabular}{|c|c|}
\hline \multicolumn{2}{|l|}{ Parameter } \\
\hline Temperature $(\mathrm{K})$ & $\begin{array}{c}1714 \\
\mathbf{1 7 3 3} \\
1.0 \\
\end{array}$ \\
\hline $\mathrm{CO}_{2} /$ carbon dioxide $(\%)$ & $\begin{array}{c}8.24 \\
\mathbf{8 . 4} \\
1.0 \\
\end{array}$ \\
\hline $\mathrm{CO} /$ carbon monoxide $(\%)$ & $\begin{array}{c}2.31 \\
\mathbf{2 . 1 3} \\
\underline{1.1} \\
\end{array}$ \\
\hline $\mathrm{CH}_{4} /$ methane (ppm) & $\begin{array}{c}1833 \\
\mathbf{1 2 9 1} \\
\underline{1.4} \\
\end{array}$ \\
\hline $\mathrm{C}_{2} \mathrm{H}_{2}$ /acetylene (ppm) & $\begin{array}{c}2381 \\
\mathbf{2 0 7 3} \\
1.1 \\
\end{array}$ \\
\hline $\mathrm{C}_{2} \mathrm{H}_{4} /$ ethylene (ppm) & $\begin{array}{c}11457 \\
\mathbf{5 3 2 5} \\
\underline{2.2} \\
\end{array}$ \\
\hline $\mathrm{C}_{2} \mathrm{H}_{6} /$ ethane $(\mathrm{ppm})$ & $\begin{array}{l}574 \\
\mathbf{3 9 4} \\
1.5 \\
\end{array}$ \\
\hline $\mathrm{C}_{3} \mathrm{H}_{6} /$ propylene $(\mathrm{ppm})$ & $\begin{array}{c}1274 \\
\mathbf{1 6 6 2} \\
\underline{0.8} \\
\end{array}$ \\
\hline $\mathrm{C}_{4} \mathrm{H}_{8}+\mathrm{aC}_{3} \mathrm{H}_{4} / 1$-butene+1,2-propadiene (ppm) & $\begin{array}{l}593 \\
\mathbf{8 0 0} \\
0.7 \\
\end{array}$ \\
\hline $\mathrm{C}_{4} \mathrm{H}_{6}+\mathrm{pC}_{3} \mathrm{H}_{4} / 1,3$-butadiene+propyne (ppm) & $\begin{array}{c}594 \\
831 \\
0.7 \\
\end{array}$ \\
\hline $1-\mathrm{C}_{5} \mathrm{H}_{10} / 1$-pentene (ppm) & $\begin{array}{c}179 \\
\mathbf{9 9} \\
1.8 \\
\end{array}$ \\
\hline $1-\mathrm{C}_{6} \mathrm{H}_{12} / 1$-hexene (ppm) & $\begin{array}{l}302 \\
\mathbf{1 0 1} \\
\underline{3.0} \\
\end{array}$ \\
\hline $\mathrm{CH}_{2} \mathrm{O} /$ formaldehyde (ppm) & $\begin{array}{c}1126 \\
\mathbf{1 3 0 2} \\
0.9 \\
\end{array}$ \\
\hline $\mathrm{CH}_{3} \mathrm{HCO} /$ acetaldehyde (ppm) & $\begin{array}{l}779 \\
\mathbf{8 1 7} \\
1.0 \\
\end{array}$ \\
\hline AC3H5HCO/crotonaldehyde (ppm) & $\begin{array}{l}\overline{N / A} \\
913 \\
\text { N/A } \\
\end{array}$ \\
\hline B1OL3E/3-buten-1-ol (ppm) & $\begin{array}{l}\text { N/A } \\
\mathbf{2 7 8} \\
\text { N/A } \\
\end{array}$ \\
\hline PE1OL4E/4-penten-1-ol (ppm) & $\begin{array}{l}\text { N/A } \\
122 \\
\text { N/A } \\
\end{array}$ \\
\hline
\end{tabular}




\subsection{Reaction Pathway Analysis}

A reaction pathway analysis was performed to interpret the modeling results of the oxidation of 1-hexanol in the opposed-flow diffusion flame.

Figure 5.4 displays the primary reaction pathways involved in the consumption of 1-hexanol at $1000 \mathrm{~K}$, which corresponds to approximately $7.27 \mathrm{~mm}$ from the fuel port and where $50 \%$ of the fuel is consumed. This location offers insight into how fuel consumption occurs in the flame. The percentages, which correspond to each pathway, are rounded to the nearest whole number.

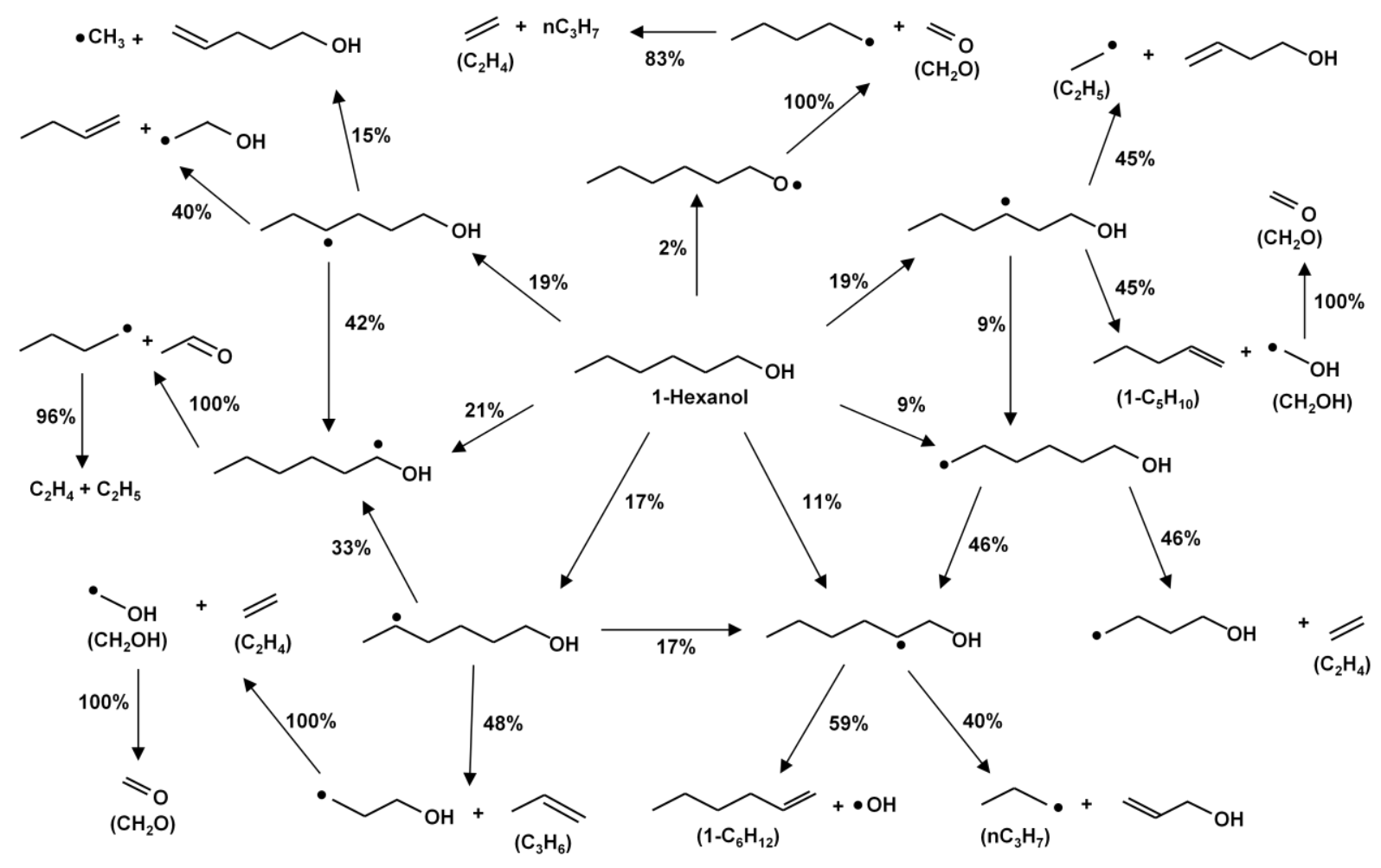

Figure 5.4: Reaction pathway diagram for 1-hexanol oxidation in an opposed-flow diffusion flame at $\mathrm{T}=1000 \mathrm{~K}$.

Seven different radicals, as tabulated in Table 5.2, are formed via H-atom abstraction reactions from 1-hexanol. The branching ratios for these seven radicals are consistent with the expected bond dissociation energies of 1-hexanol. The bond dissociation energies of $n$-butanol have been 
presented by Black et al. [17] and are presented in Figure 5.5. The trend of the bond energies of $n$-butanol are expected to be similar to those found in 1-hexanol, as both molecules are straightchain alcohols. Some bond dissociation energies for 1-hexanol are shown in Figure 5.6 [82]. The $\mathrm{C}-\mathrm{C}$ bond closest to the $\mathrm{OH}$ group is typically the weakest $\mathrm{C}-\mathrm{C}$ bond of a straight-chain alcohol. As for the weakest $\mathrm{C}-\mathrm{H}$ bond, it is typically found on the $\alpha$-carbon as a result of the presence of the $\mathrm{OH}$ group.

Table 5.2: Seven radicals produced from $\mathrm{H}$-atom abstraction of 1-hexanol.

HXOL Radicals

At this select temperature of $1000 \mathrm{~K}, \mathrm{H}$-atom abstraction from a $\mathrm{C}$-atom is the predominant route for initiation because the $\mathrm{C}-\mathrm{H}$ bonds are weaker than the $\mathrm{O}-\mathrm{H}$ bond. The most dominant route of $\mathrm{H}$-atom abstraction is the formation of HXOL1J (21\%), followed closely by the formation of radicals HXOL3J (20\%), HXOL4J (20\%), and HXOL5J (18\%). According to Figure 5.4, the 
weakest $\mathrm{C}-\mathrm{H}$ bond is typically found on the $\alpha$-carbon, as a result of the adjacent $\mathrm{C}-\mathrm{O}$ bond. The strongest $\mathrm{C}-\mathrm{H}$ bond is found on the primary $(\zeta)$ carbon, so small quantities (9\%) of HXOL6J are formed. And only $2 \%$ of $\mathrm{H}$-atom abstraction occurs on the hydroxyl group because of the strong O-H bond.

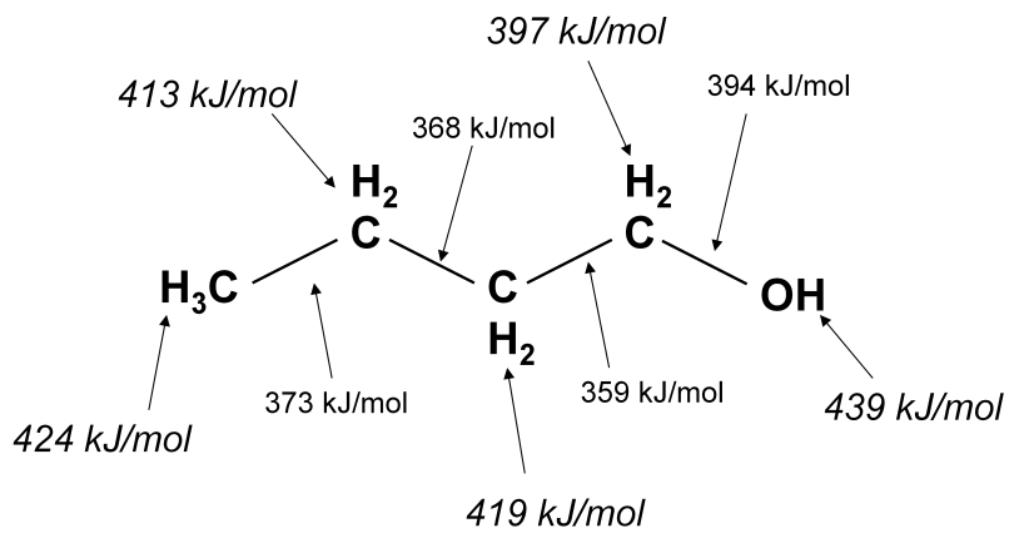

Figure 5.5: Bond dissociation energies of $n$-butanol, with an accuracy of $\pm 1 \mathrm{~kJ} / \mathrm{mol}[17]$.

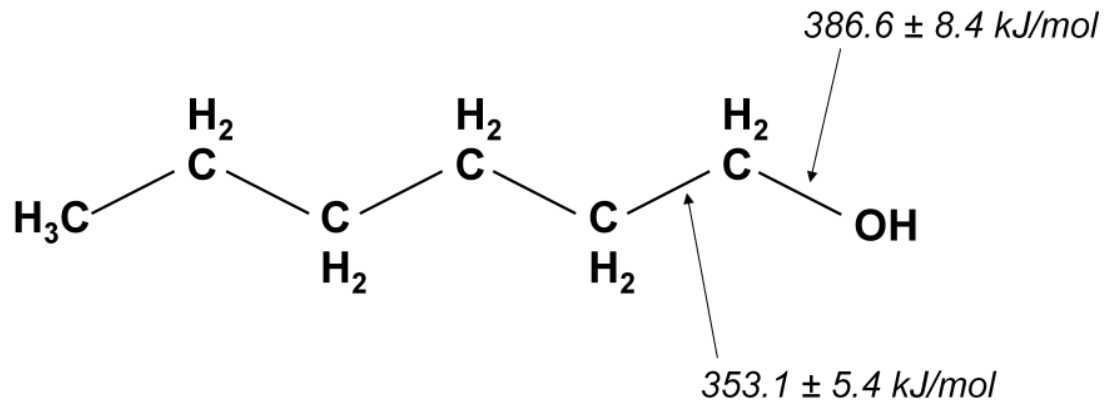

Figure 5.6: Bond dissociation energies of 1-hexanol reported by Luo [82].

Subsequently, these fuel radicals isomerize and decompose via $\beta$-scission. According to the proposed model, $\mathrm{H}$-atom abstraction accounts for more than $99 \%$ of the fuel consumption at this temperature, which is expected because radical species that are produced near the flame front can diffuse into the fuel stream to consume more fuel. The abstractions are predominantly initiated by $\mathrm{H}$ atoms $(49 \%), \mathrm{OH}$ radicals $(33 \%)$, and $\mathrm{CH}_{3}$ radicals $(12 \%)$. At higher temperatures in regions near the flame (e.g., $1500 \mathrm{~K}$ ), unimolecular decomposition reactions are dominant, as 
$\mathrm{H}$-atom abstraction reactions become negligible due to low levels of $\mathrm{H}$-atoms near the flame. However, the amount of fuel that reaches these conditions is small, so these reactions do not contribute significantly to the formation of product species. The dominant initiation step of 1-hexanol decomposition via $\mathrm{H}$-atom abstraction is consistent with literature for other straight chain alcohols, like $n$-butanol and 1-pentanol [16,23]. In addition, the study by Togbé et al. [12] showed that 1-hexanol oxidation in a JSR at 10 atm reacts mostly by $\mathrm{H}$-atom abstraction at low, intermediate, and high temperatures as well.

From the reaction pathway diagram, the fuel radicals formed by means of $\mathrm{H}$-atom abstraction are primarily consumed via $\beta$-scission. For fuel radicals with a radical site on a secondary carbon, $\beta$-scission reactions produce $\mathrm{C}_{2} \mathrm{H}_{4}, \mathrm{C}_{3} \mathrm{H}_{6}, 1-\mathrm{C}_{5} \mathrm{H}_{10}, 1-\mathrm{C}_{6} \mathrm{H}_{12}, 2$-propen-1-ol, 3-buten-1-ol, and 4-penten-1-ol. $\mathrm{C}_{2} \mathrm{H}_{4}$ appears to be formed through most pathways, either directly, or through ethyl $\left(\mathrm{C}_{2} \mathrm{H}_{5}\right)$ and $n$-propyl $\left(\mathrm{nC}_{3} \mathrm{H}_{7}\right)$ radicals.

The branching ratio of the $\beta$-scission reaction of HXOL2J to form $1-\mathrm{C}_{6} \mathrm{H}_{12}$ (with an $\mathrm{OH}$ radical) or 2-propen-1-ol (with an $n$-propyl radical) is unexpected. The model shows that $1-\mathrm{C}_{6} \mathrm{H}_{12}$ is formed in larger fraction than 2-propen-1-ol (59\% to 40\%), even though the bond dissociation energy of the $\mathrm{C}-\mathrm{O}$ bond is expected to be higher than the $\mathrm{C}-\mathrm{C}$ bond between the $\gamma$ and $\delta$ carbons. According to the estimates for $n$-butanol in Figure 5.5, the C-O bond dissociation energy is $394 \mathrm{~kJ} / \mathrm{mol}$, while the bond dissociation energy between $\gamma$ and $\delta$ carbons is $373 \mathrm{~kJ} / \mathrm{mol}$.

The branching ratio of the decomposition of HXOL3J is also interesting to note. At the temperature of $1000 \mathrm{~K}$, the model predicts that HXOL3J will undergo $\beta$-scission in both directions in equal fractions $(45 \%)$ to produce $1-\mathrm{C}_{5} \mathrm{H}_{10}$ (with a $\mathrm{CH}_{2} \mathrm{OH}$ radical) and 4-buten-1-ol (with a $\mathrm{C}_{2} \mathrm{H}_{5}$ radical). Considering the bond dissociation energies between the $\alpha$ and $\beta$ carbons, and the $\delta$ and $\varepsilon$ carbons, it would be expected that $\beta$-scission would occur between the $\alpha$ and $\beta$ carbons more frequently. For $n$-butanol, the bond dissociation energy between the $\alpha$ and $\beta$ carbons is the lowest amongst the other $\mathrm{C}-\mathrm{C}$ bonds, as a result of the strong $\mathrm{OH}$ group on the $\alpha$ carbon.

One reaction that appears to be missing from the chemical kinetic mechanism is the decomposition of HXOL4J through $\beta$-scission to form 1-butene $\left(1-\mathrm{C}_{6} \mathrm{H}_{12}\right)$ and an ethanol radical $\left(\mathrm{C}_{2} \mathrm{H}_{4} \mathrm{OH}\right)$. Although the results here have shown that the measured peak concentration of 1 -butene is lower than the predicted peak, the addition of this $\beta$-scission reaction may result in an 
increase of 1-butene in the system. From the reaction pathway analysis at $1000 \mathrm{~K}$, the predominant route of 1-butene formation is through a direct combination reaction between allyl $\left(\mathrm{C}_{3} \mathrm{H}_{5}\right)$ and methyl $\left(\mathrm{CH}_{3}\right)$ radicals.

\subsubsection{Oxygenated Species}

According to the reaction pathway analysis, the main oxygenated species produced were formaldehyde, acetaldehyde, acrolein, 2-butenal/crotonaldehyde, 3-buten-1-ol, 4-penten-1-ol, $n$-butanol, and methanol. This section will take a closer look at the reaction pathways of the more unique alcohol compounds that are formed from the oxidation of 1-hexanol.

From the reaction pathway diagram, 2-propen-1-ol is formed with an $n$-propyl radical via $\mathrm{H}$ atom abstraction from the 1-hexanol radical on the $\beta$ (or second) carbon. As shown in Figure 5.7, majority of the 2-propen-1-ol (97\%) undergoes unimolecular decomposition to form allyl and hydroxyl radicals, while the remaining form acrolein. Acrolein was not measured in the opposedflow diffusion flame, although the model predicted a peak concentration of $96 \mathrm{ppm}$. The predicted peak concentration of 2-propen-1-ol is $19 \mathrm{ppm}$.

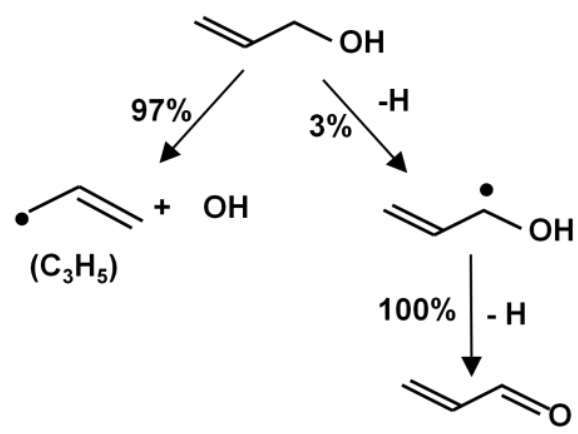

Figure 5.7: Reaction pathway diagram for consumption of 2-propen-1-ol in the opposedflow diffusion flame at $1000 \mathrm{~K}$.

Figure 5.8 shows the fate of the $n$-butanol radical, B1OL4J, formed via $\mathrm{H}$-atom abstraction from the 1-hexanol radical on the sixth carbon. Majority of this $n$-butanol radical (83\%) isomerizes into another $n$-butanol radical that forms formaldehyde and $n$-propyl radicals from $\beta$-scission. 
The remainder of the $n$-butanol radical also undergoes isomerization, followed by $\beta$-scission to form acetaldehyde and an ethyl radical.

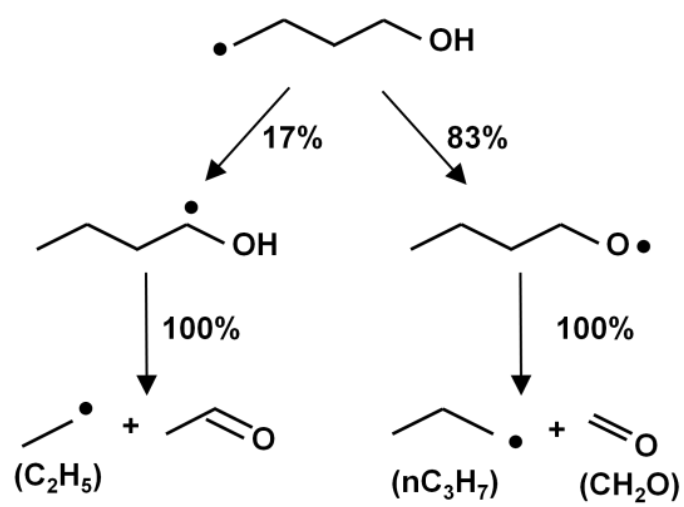

Figure 5.8: Reaction pathway diagram for consumption of butanol radical, B1OL4J, in the opposed-flow diffusion flame at $1000 \mathrm{~K}$.

As shown in Figure 5.9, the model predicts that 3-buten-1-ol is consumed via H-atom abstraction on the hydroxyl site to form a radical that isomerizes into 2-butenal/crotonaldehyde and on the fourth carbon of the four carbon alcohol to form a radical that produces 1,3-butadiene from $\beta$-scission. The predicted peak concentration of 3-buten-1-ol is $278 \mathrm{ppm}$.

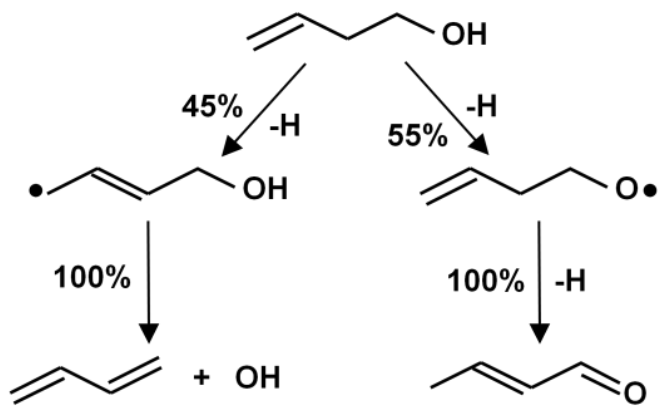

Figure 5.9: Reaction pathway diagram for consumption of 3-buten-1-ol in the opposed-flow diffusion flame at $1000 \mathrm{~K}$. 
The reaction pathway shows that 4-penten-1-ol is produced from $\beta$-scission of the 1-hexanol radical on the $\delta$ (fourth) carbon. Figure 5.10 illustrates that this alcohol compound is consumed via $\mathrm{H}$-atom abstraction to form radicals that undergo $\beta$-scission to 1,3-butadiene, acetaldehyde, and hydroxymethyl and allyl radicals. The predicted peak concentration of 4-penten-1-ol is $122 \mathrm{ppm}$.

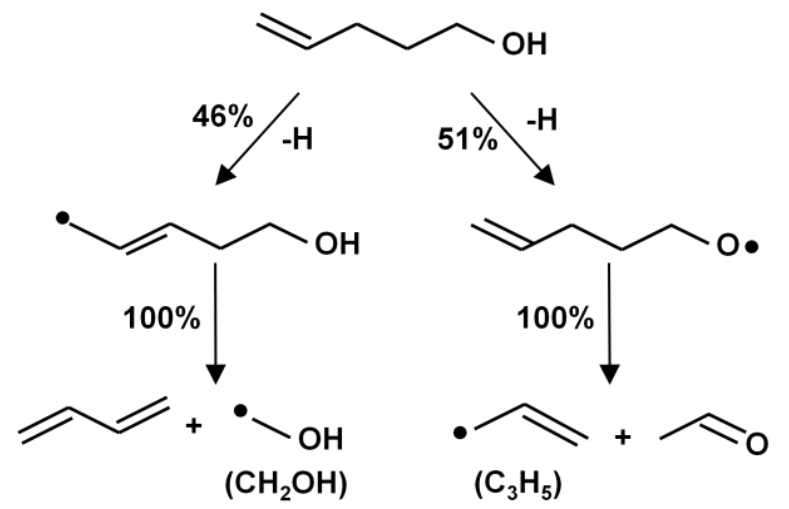

Figure 5.10: Reaction pathway diagram for consumption of 4-penten-1-ol in the opposedflow diffusion flame at $1000 \mathrm{~K}$.

The isomerization of enols to ketos (i.e., ketones or aldehhydes) has been discussed in previous studies that have identified enols as important species in the combustion of hydrocarbons and oxygenates $[83,84,85,86]$. In chemistry, enols and ketos are tautomers of each other, whereby a keto and an enol are in chemical equilibrium with one another via a shift in a proton and bonding electrons. The unsaturated alcohols expressed in this section (i.e., 2-propan-1-ol, 3-buten-1-ol, and 4-penten-1-ol) are not classified as enols because they lack the double carbon bond $(\mathrm{C}=\mathrm{C})$ that is adjacent to a hydroxyl $(\mathrm{OH})$ group. An enol is alkene with a hydroxyl group that is bonded to a carbon atom of a double carbon bond. Thus, the stability of enols is often assessed in literature, but the concern is unrelated to the unsaturated alcohols found in this study. Furthermore, enols (i.e., 1-hexen-1-ol, 1-penten-1-ol, and 1-buten-1-ol) and their reactions are not included in the proposed chemical kinetic mechanism by Togbé et al. [12] to describe the combustion of 1-hexanol. 


\subsection{Sensitivity Analysis}

A sensitivity analysis was conducted to determine the quantitative effects of various parameters on the model. A reaction with a strong positive sensitivity coefficient indicates that an increase in the forward rate will increase the concentration of the species of interest. Likewise, strong negative coefficients represent a decrease in concentration of the species with an increase in the forward rate of reaction.

A sensitivity analysis was conducted for 1-hexanol at $840 \mathrm{~K}$, which corresponds to approximately $6.97 \mathrm{~mm}$ from the fuel port and where $30 \%$ of the fuel has been consumed. Analysis at this low temperature offers an insight to how fuel consumption is initiated in the flame. Figure 5.11 displays the reactions that the 1-hexanol concentration is most sensitive to under these conditions and at $1000 \mathrm{~K}$, the temperature at which $50 \%$ of the fuel is consumed. At both temperatures, strong negative sensitivity coefficients are observed for unimolecular decomposition reactions. The predicted fuel concentrations are also influenced by $\mathrm{H}$-atom abstractions from the $\gamma$ and $\varepsilon$ carbons, which were determined to be major pathways for fuel consumption in the reaction pathway analysis. The positive sensitivity coefficients are observed for radical recombination, $\beta$-scission, and chain propagating reactions. 


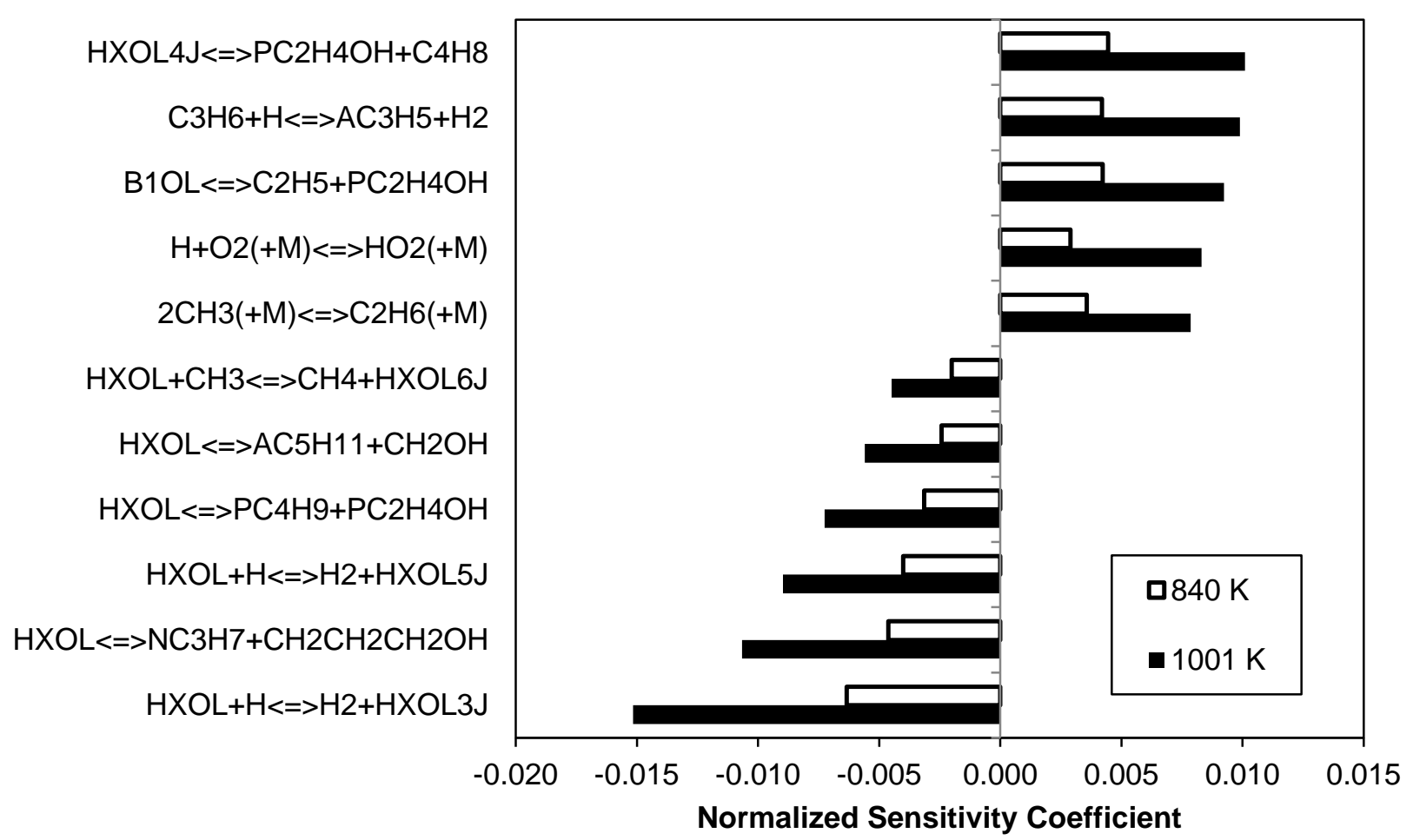

Figure 5.11: Sensitivity of 1-hexanol concentration to select reactions in the atmospheric opposed-flow diffusion flame $\left(2.45 \%\right.$ fuel, $\left.60 \% \mathrm{O}_{2}\right)$.

From the comparisons between the experimental results and model predictions, it was found that the greatest discrepancies in the results were for $\mathrm{C}_{2} \mathrm{H}_{4}$ and 1- $\mathrm{C}_{6} \mathrm{H}_{12}$. Thus, a sensitivity analysis was performed for each species at the location whereby $50 \%$ of the fuel is consumed (i.e., $7.27 \mathrm{~mm}$ from the fuel port at $1000 \mathrm{~K}$ ) and at the location at which the predicted peak concentration occurs (i.e., $7.73 \mathrm{~mm}$ from the fuel port at $1279 \mathrm{~K}$ for $\mathrm{C}_{2} \mathrm{H}_{4}$ and $7.48 \mathrm{~mm}$ from the fuel port at $1127 \mathrm{~K}$ for $1-\mathrm{C}_{6} \mathrm{H}_{12}$ ).

Figure 5.12 displays the sensitivity of $\mathrm{C}_{2} \mathrm{H}_{4}$ concentration to select reactions under these conditions in the opposed-flow diffusion flame. At both temperatures, $\mathrm{C}_{2} \mathrm{H}_{4}$ is predominantly produced from the decomposition of ethyl $\left(\mathrm{C}_{2} \mathrm{H}_{5}\right)$ and 1-butyl radicals $\left(\mathrm{pC}_{4} \mathrm{H}_{9}\right)$ and the $\beta$-scission of radicals (i.e., HXOL6J, B1OL4J). In contrast, strong negative sensitivity coefficients show that $\mathrm{C}_{2} \mathrm{H}_{4}$ is mostly consumed through $\mathrm{H}$-atom abstractions with $\mathrm{OH}, \mathrm{H}$, and $\mathrm{CH}_{3}$ radicals, and thermal decomposition of a fuel radical (HXOL4J). Also, a strong negative sensitivity coefficient 
is observed for the competing $\beta$-scission reaction of $\mathrm{pC}_{4} \mathrm{H}_{9}$ to form a methyl radical and propylene.

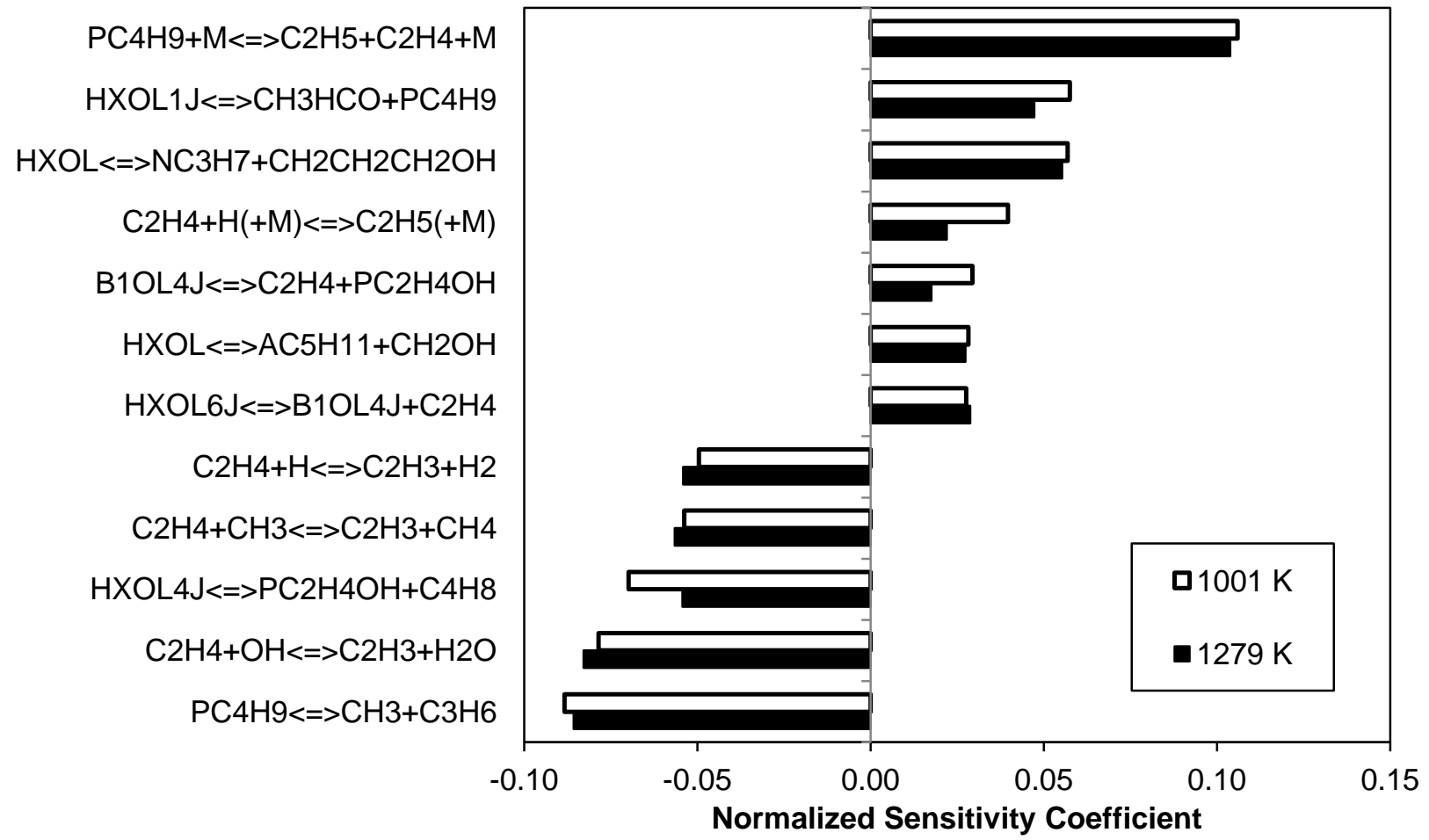

Figure 5.12: Sensitivity of $\mathrm{C}_{2} \mathrm{H}_{4}$ concentration to select reactions in the atmospheric opposed-flow diffusion flame $\left(2.45 \%\right.$ fuel, $\left.60 \% \mathrm{O}_{2}\right)$.

In Figure 5.13, the sensitivity analysis shows that the production of $1-\mathrm{C}_{6} \mathrm{H}_{12}(\mathrm{AC} 6 \mathrm{H} 12)$ is predominantly influenced by the decomposition of the HXOL2J radical, which is the main route of $1-\mathrm{C}_{6} \mathrm{H}_{12}$ formation shown in the reaction pathway analysis. Likewise, strong positive sensitivity coefficients were observed for reactions that produce the HXOL2J radical, which leads to the formation of $1-\mathrm{C}_{6} \mathrm{H}_{12}$ in the reverse rate. The strongest negative sensitivity coefficient was for the thermal decomposition of $1-\mathrm{C}_{6} \mathrm{H}_{12}$ to produce an $n$-propyl radical $(\mathrm{NC} 3 \mathrm{H} 7)$ and an allyl radical $(\mathrm{AC} 3 \mathrm{H} 5)$. As expected, $1-\mathrm{C}_{6} \mathrm{H}_{12}$ is also influenced by the competing $\beta$-scission reaction from HXOL2J to produce 2-propen-1-ol $(\mathrm{C} 2 \mathrm{H} 3 \mathrm{CH} 2 \mathrm{OH})$ and an $n$-propyl radical and by the $\beta$-scission reactions of 1 -hexanol radicals that can isomerize into HXOL2J for $1-\mathrm{C}_{6} \mathrm{H}_{12}$ formation. 


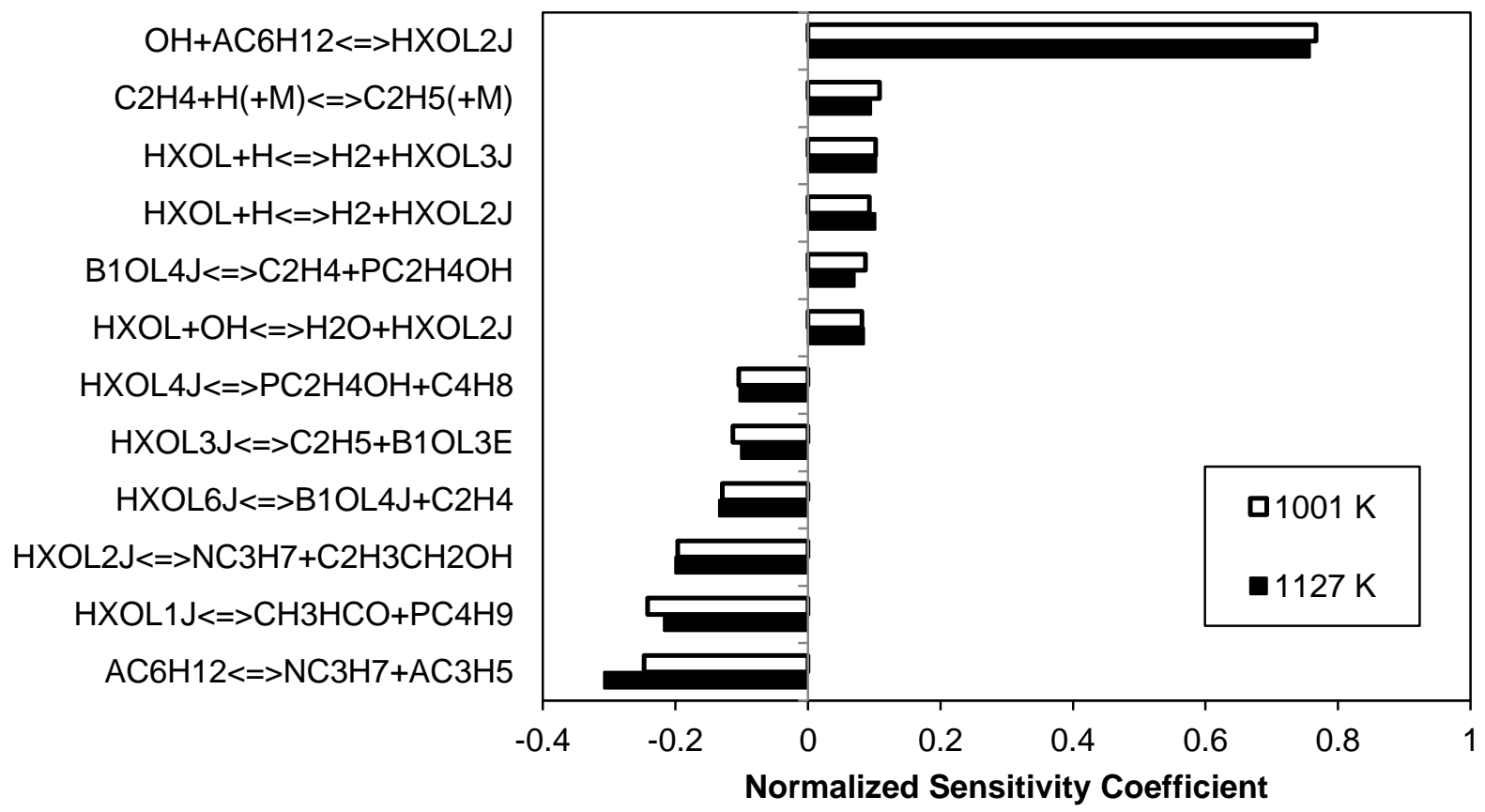

Figure 5.13: Sensitivity of $1-\mathrm{C}_{6} \mathrm{H}_{12}$ concentration to select reactions in the atmospheric opposed-flow diffusion flame $\left(2.45 \%\right.$ fuel, $\left.60 \% \mathrm{O}_{2}\right)$.

\subsection{Reaction Rate Sensitivity of the Proposed Chemical Kinetic Mechanism}

From the results of the model prediction and experimental data, significant discrepancies were observed for $\mathrm{C}_{2} \mathrm{H}_{4}$ and 1- $\mathrm{C}_{6} \mathrm{H}_{12}$. Sensitivity analyses were completed for these two species to identify the reactions that are most influential on the species' concentration. One method to improve the agreement between the predicted model and experimental results is to modify the rate constants of important reactions. Nonetheless, any modifications made to a reaction rate constant cannot adversely affect the prediction of temperature and other species. The analyses described in this section discuss the sensitivity of the reaction rate constants on the modeling results. A detailed calculation of the reaction rate constants is not attempted here. For both species, the A-factor or pre-exponential factor of the most sensitive reactions were modified and tested. The pre-exponential factor describes the frequency of collisions between reactant molecules and it is related to the kinetic collision theory and transition state theory. The activation barriers of the reactions were not modified. 


\subsubsection{Reaction Rate Sensitivity for Ethylene}

The task of optimizing the proposed chemical kinetic mechanism for $\mathrm{C}_{2} \mathrm{H}_{4}$ can be a challenging one because as shown in the reaction pathway analysis, most pathways lead to the formation of $\mathrm{C}_{2} \mathrm{H}_{4}$. The sensitivity analysis showed small sensitivity coefficients for the reactions determined to be most influential on the concentration of $\mathrm{C}_{2} \mathrm{H}_{4}$. Thus, a significant change in the rate constants of the most sensitive reaction may not yield the significant improvement that is desired.

The reaction HXOL1J $\leftrightarrow \mathrm{CH} 3 \mathrm{HCO}+\mathrm{PC} 4 \mathrm{H} 9$ was shown to be one of the more influential reactions of $\mathrm{C}_{2} \mathrm{H}_{4}$ concentration. The A-factor (pre-exponential collision frequency factor) for this reaction proposed by Togbé et al. [12] is $2 \times 10^{13} \mathrm{~s}^{-1}$. From the results of the chemical kinetic modeling, $\mathrm{C}_{2} \mathrm{H}_{4}$ was under predicted by more than a factor of 2 . Thus, to increase the production of PC4H9, which leads to the formation of $\mathrm{C}_{2} \mathrm{H}_{4}$, the A-factor is increased by an order of magnitude to $2 \times 10^{12} \mathrm{~s}^{-1}$. However, this significant increase in the A-factor did not result in a significant increase in the predicted peak concentration of $\mathrm{C}_{2} \mathrm{H}_{4}$. The increase in the A-factor by a factor of 10 only increased the predicted peak concentration by $378 \mathrm{ppm}$ to $5703 \mathrm{ppm}$, which is still a large under prediction from the peak measured concentration of almost 11,500 ppm. Thus, this small increase in $\mathrm{C}_{2} \mathrm{H}_{4}$ would not make this modification of the A-factor practical.

The $\beta$-scission of the 1-butyl radical, $\mathrm{PC} 4 \mathrm{H} 9$, can occur in two locations. These two reactions were identified from the sensitivity analysis to be most influential on the concentration of $\mathrm{C}_{2} \mathrm{H}_{4}$. One $\beta$-scission reaction undergoes with a third body (i.e., $\mathrm{PC} 4 \mathrm{H} 9+\mathrm{M} \leftrightarrow \mathrm{C} 2 \mathrm{H} 5+\mathrm{C} 2 \mathrm{H} 4+\mathrm{M}$ ), while the second reaction breaks on its own (i.e., PC4H9 $\leftrightarrow \mathrm{CH} 3+\mathrm{C} 3 \mathrm{H} 6$ ). From the reaction pathway analysis, it showed the branching ratio to be in large favour (i.e., > 96\%) of $\mathrm{C}_{2} \mathrm{H}_{4}$ formation. The A-factor proposed in Togbé et al. [12] for reaction PC4H9+ M $\leftrightarrow \mathrm{C} 2 \mathrm{H} 5+\mathrm{C} 2 \mathrm{H} 4$ $+\mathrm{M}$ is $1.9 \times 10^{55} \mathrm{~s}^{-1}$. A study by Curran [87] proposed an A-factor for the reaction as $4.92 \times 10^{13}$, which is much smaller. Other A-factors for the reaction in the NIST Chemical Kinetic Database [68] are within the same magnitude of the A-factor proposed by Curran. A test using the A-factor by Curran did not show any improvement in the prediction of $\mathrm{C}_{2} \mathrm{H}_{4}$, as the predicted peak concentration was found to be $3764 \mathrm{ppm}$. The A-factor for reaction PC4H9 $\leftrightarrow \mathrm{CH} 3+\mathrm{C} 3 \mathrm{H} 6$ proposed in Togbé et al. [12] (i.e., $1.26 \times 10^{12} \mathrm{~s}^{-1}$ ) is from a study by 
Kerr and Trotman-Dickenson [88] and it is the only reported value in the NIST Chemical Kinetic Database.

To bring the agreement between the predicted results and the experimental data within a factor of 2 and to stress the branching ratio of $\mathrm{pC}_{4} \mathrm{H}_{9}$, the A-factor of reaction $\mathrm{PC} 4 \mathrm{H} 9+\mathrm{M} \leftrightarrow \mathrm{C} 2 \mathrm{H} 5+$ $\mathrm{C} 2 \mathrm{H} 4+\mathrm{M}$ was increase by a factor of 10 to $1.9 \times 10^{56} \mathrm{~s}^{-1}$ and the A-factor of reaction PC4H9 $\leftrightarrow \mathrm{CH} 3+\mathrm{C} 3 \mathrm{H} 6$ was decreased by a factor of 5 . The result of these changes only increased the predicted peak concentration to $6190 \mathrm{ppm}$, but is within a factor of 2 from the measured peak concentration. The effect of these significant changes on the reaction rate constants improved the agreements for more than half of the measured parameters (e.g., temperature, $\mathrm{CO}_{2}, \mathrm{C}_{3} \mathrm{H}_{6}, \mathrm{C}_{4} \mathrm{H}_{6}+\mathrm{pC}_{3} \mathrm{H}_{4}, 1-\mathrm{C}_{5} \mathrm{H}_{10}, 1-\mathrm{C}_{6} \mathrm{H}_{12}$, and $\mathrm{CH}_{2} \mathrm{O}$ ). Using these new A-factors for the two reactions must be used with caution. Further studies should optimize the branching ratio of the $\mathrm{pC}_{4} \mathrm{H}_{9}$ to improve the prediction of $\mathrm{C}_{2} \mathrm{H}_{4}$, while avoiding negative effects on other measure parameters. An A-factor of $1.9 \times 10^{56} \mathrm{~s}^{-1}$ is not physically possible, nor is the magnitude typical for pre-exponential factors. A typical magnitude of a pre-exponential factor derived from the collision theory and transition state theory is in the order of $10^{11}$ to $10^{14}$.

\subsubsection{Reaction Rate Sensitivity for 1-Hexene}

The proposed chemical kinetic model showed a large under prediction of $1-\mathrm{C}_{6} \mathrm{H}_{12}$ from the 1-hexanol flame in the opposed-flow configuration. From the sensitivity analysis on $1-\mathrm{C}_{6} \mathrm{H}_{12}$, it was shown that the species is most sensitive to the decomposition reaction of the fuel radical, HXOL2J (i.e., OH $+\mathrm{AC6H12} \leftrightarrow \mathrm{HXOL} 2 \mathrm{~J})$. Thus, to improve the agreement between the experimental result and model prediction, the reaction rate constants of this reaction can be modified. However, an improvement in the agreement of 1- $\mathrm{C}_{6} \mathrm{H}_{12}$ must not significantly affect the results for temperature and other species concentration predictions. The reaction described above is not found in the NIST Chemical Kinetics Database [68].

The A-factor for the reaction $\mathrm{OH}+\mathrm{AC6H} 12 \leftrightarrow \mathrm{HXOL} 2 \mathrm{~J}$ in the proposed chemical kinetic mechanism from Togbé et al. [12] is reported to be $9.93 \times 10^{11} \mathrm{~cm}^{3} / \mathrm{mol}-\mathrm{s}$. When the A-factor value is increased, by a factor of 3 , to $29.79 \times 10^{11} \mathrm{~cm}^{3} / \mathrm{mol}-\mathrm{s}$, the peak concentration of $1-\mathrm{C}_{6} \mathrm{H}_{12}$ is $204 \mathrm{ppm}$, which is within a factor of 1.5 from the experimentally measured peak concentration 
of $303 \mathrm{ppm}$. As previously discussed, a model's prediction is considered good if the predicted maximum concentration is within a factor 1.5 of the measured maximum concentration. While the modification of the A-factor did generally improve the agreement for most of the other species as well, the agreements for $\mathrm{C}_{3} \mathrm{H}_{6}, \mathrm{C}_{4} \mathrm{H}_{8}+\mathrm{aC}_{3} \mathrm{H}_{4}$, and 1- $\mathrm{C}_{5} \mathrm{H}_{10}$ were made worse with the A-factor change. Thus, the modification made to the A-factor for the reaction should be used with caution.

\subsection{Uncertainty Analysis}

Discrepancies between the experiment and model predictions may have been the result of several sources of error.

\subsubsection{Experimental Uncertainties}

For the measured and predicted temperatures, the potential for catalytic reactions on the thermocouple wire have been acknowledged, but this was not investigated in the present study. It was assumed the silica coating on the thermocouple would reduce or eliminate any catalytic heating on the surface of the thermocouple.

The microprobe and sampling line apparatus used in the experiment may have introduced errors through flame perturbation and chemical reactions in the sampling line. With the microprobe, no perturbations to the flame sheet were visually observed during the experiment. It is hypothesized that errors in the flame experiment result in these species decomposing upon contact with hot surfaces in the high pressure side of the sampling line. This hypothesis has not been tested.

In order to quench the reactions the reactions in the sampling line, the sampling apparatus was designed to allow for supersonic expansion of the gas sample by pumping it through a small orifice (200 $\mu \mathrm{m}$ diameter microprobe) and into a low pressure environment, whereby the gas is cooled to $400 \mathrm{~K}$ and the local gas density of gas molecules and their collision rates are significantly reduced. 


\subsubsection{Modeling Uncertainties}

Errors in the proposed model may result from missing reaction pathways, uncertainties in reaction rate constants, thermochemical data, or transport properties.

As discussed by Sarathy et al. [89], research in opposed-flow diffusion flames has shown that fuel reactivity is more sensitive to diffusion estimates than to kinetic rate parameters because transport processes are rate controlling in these systems [89]. The influence of uncertainties in the molecular transport on model predictions have been examined by Smallbone et al. [90] and Holley et al. [73]. The authors argue that the molecular diffusion model used in flame simulations is inaccurate because it assumes that a molecule's spherical potential is valid at high temperatures. Thus, they imply that LJ transport parameters obtained at low temperatures are not accurate at high temperature diffusion. Holley et al. [73] suggest that the molecular geometry of large $n$-alkanes is non-spherical and that the spherical potential represents an average of the molecular orientations over the different temperature and pressure ranges. Furthermore, Chae and Violi [91] suggest that large $n$-alkanes resemble "stick-like" structures, rather than spherical ones.

As a sensitivity analysis, the LJ potential well depth, $\varepsilon / \mathrm{k}_{\mathrm{b}}$, and collision diameter, $\sigma$, of 1-hexanol was recalculated using the correlations presented by Holley et al. [73] as presented in Section 4.1.3. Using the correlations from Holley et al., the LJ potential well depth is estimated to be 731.306 K (previously 391.000 K from Togbé et al. [12]) and the collision diameter is estimated to be $5.584 \AA$ (previously reported as $4.455 \AA$ in Togbé et al. [12]). The original transport database provided by Togbé et al. [12] showed that the transport of 1-hexanol was identical to $n$-butanol, which can be argued otherwise as the two molecules differ in chain length.

This new LJ potential well depth increased by 87\%., while the new LJ collision diameter increased by about 25\%. The results of this modification, shown in Figure 5.14, indicate some improvements in the agreement between the experiment results and model predictions. The predicted reactivity of the fuel shows a better agreement with the experimentally measured profile, especially between $6 \mathrm{~mm}$ and $7 \mathrm{~mm}$ from the fuel port. The comparison between the model predictions and experimental results is influenced by the modifications in the transport parameters. Table 5.3 displays the percent changes in peak temperature and species concentrations after the transport parameters were modified. In addition, Table 5.4 compares the 
peak temperatures and species concentrations from the model prediction using the original transport dataset from Togbé et al. [12] and those using the modified transport parameters for 1-hexanol.

The peak temperature from experiments now matches more closely with the model prediction. The increase in transport parameters caused the peak temperature to drop by about $2 \%$. The effect of the modifications on peak temperature and species concentrations varies in both directions. The predicted peak $\mathrm{CO}$ and $\mathrm{CO}_{2}$ concentrations were reduced by about $6.6 \%$ and $2.9 \%$, respectively. The comparison between the experimental results and model predictions was improved for $\mathrm{CO}_{2}$, but not for $\mathrm{CO}$. Significant increases (i.e., $>+10 \%$ ) in peak concentrations are observed for $1-\mathrm{C}_{5} \mathrm{H}_{10}$ and $1-\mathrm{C}_{6} \mathrm{H}_{12}$, while significant decreases (i.e., > $-10 \%$ ) in peak concentrations for $\mathrm{C}_{2} \mathrm{H}_{2}$ and $\mathrm{CH}_{4}$. Although most species concentrations decreased as the collision diameter and potential well depth were increased, there were species whose peak concentrations experienced an increase. $1-\mathrm{C}_{5} \mathrm{H}_{10}, 1-\mathrm{C}_{6} \mathrm{H}_{12}$, and $\mathrm{CH}_{3} \mathrm{HCO}$ all showed growth in their peak concentrations after the modification of the transport parameters of 1-hexanol. In terms of the agreement between the new predicted peak concentrations and the measured peak concentrations, the agreement was improved for only half of the species measured. 

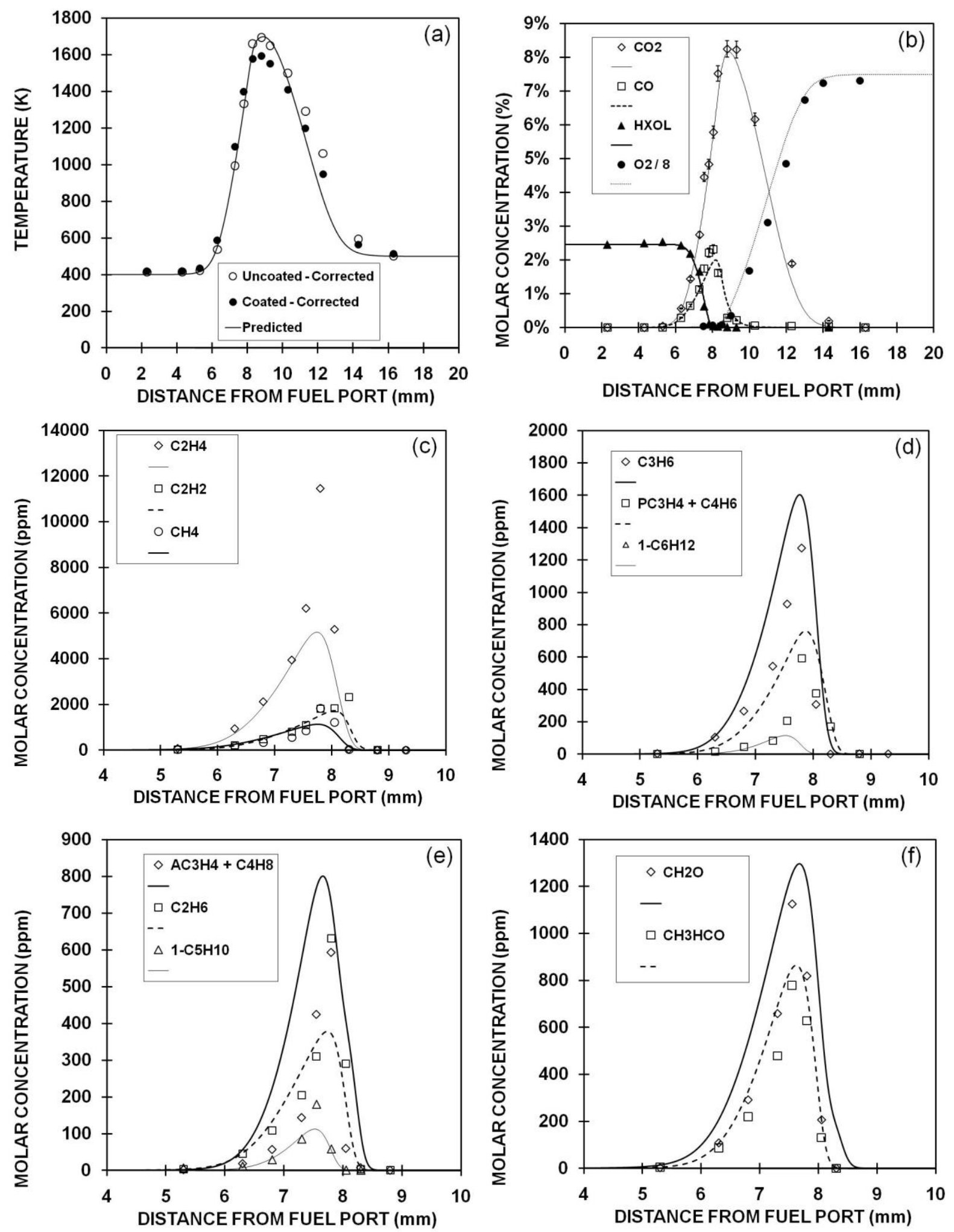

Figure 5.14: Experimental and predicted profiles obtained from the oxidation of 1-hexanol in an atmospheric opposed-flow diffusion flame $\left(2.45 \%\right.$ fuel, $\left.60 \% \quad \mathrm{O}_{2}\right)$ with an $87 \%$ increase in $\mathrm{LJ}$ potential well depth and a $25 \%$ increase in $\mathrm{LJ}$ collision diameter. 
Table 5.3: Change in peak temperature and species concentrations after a $25 \%$ increase in LJ collision diameter and an $87 \%$ increase in $\mathrm{LJ}$ potential well depth of 1-hexanol.

\begin{tabular}{|c|c|}
\hline Parameter & Change in peak value \\
\hline Temperature (K) & $-2.0 \%$ \\
\hline $\mathrm{CO}_{2} /$ carbon dioxide $(\%)$ & $-2.9 \%$ \\
\hline $\mathrm{CO} /$ carbon monoxide $(\%)$ & $-6.6 \%$ \\
\hline $\mathrm{CH}_{4} /$ methane (ppm) & $-11.5 \%$ \\
\hline $\mathrm{C}_{2} \mathrm{H}_{2}$ /acetylene (ppm) & $-16.3 \%$ \\
\hline $\mathrm{C}_{2} \mathrm{H}_{4} /$ ethylene (ppm) & $-2.8 \%$ \\
\hline $\mathrm{C}_{2} \mathrm{H}_{6} /$ ethane (ppm) & $-4.1 \%$ \\
\hline $\mathrm{C}_{3} \mathrm{H}_{6} /$ propylene (ppm) & $-3.4 \%$ \\
\hline $\mathrm{C}_{4} \mathrm{H}_{8}+\mathrm{aC}_{3} \mathrm{H}_{4} / 1$-butene+1,2-propadiene (ppm) & $+0.1 \%$ \\
\hline $\mathrm{C}_{4} \mathrm{H}_{6}+\mathrm{pC}_{3} \mathrm{H}_{4} / 1,3$-butadiene+propyne (ppm) & $-8.2 \%$ \\
\hline 1- $\mathrm{C}_{5} \mathrm{H}_{10} / 1$-pentene (ppm) & $+14.1 \%$ \\
\hline 1- $\mathrm{C}_{6} \mathrm{H}_{12} / 1$-hexene (ppm) & $+15.8 \%$ \\
\hline $\mathrm{CH}_{2} \mathrm{O} /$ formaldehyde (ppm) & $-0.4 \%$ \\
\hline $\mathrm{CH}_{3} \mathrm{HCO} /$ acetaldehyde (ppm) & $+5.9 \%$ \\
\hline AC3H5HCO/crotonaldehyde (ppm) & $-0.2 \%$ \\
\hline B1OL3E/3-buten-1-ol (ppm) & $-4.3 \%$ \\
\hline PE1OL4E/4-penten-1-ol (ppm) & $-3.3 \%$ \\
\hline
\end{tabular}


Table 5.4: Comparison of measured and predicted peak temperatures and species concentrations in the opposed-flow diffusion flame with the original transport data and the modified transport data. Italicized numbers are measured values, bold numbers are predicted values, and underlined values are the ratio of measured to predicted.

\begin{tabular}{|c|c|c|}
\hline Parameter & Original & Modified \\
\hline \multirow[t]{2}{*}{ Temperature (K) } & \multicolumn{2}{|c|}{1695} \\
\hline & $\begin{array}{c}\mathbf{1 7 3 3} \\
1.0\end{array}$ & $\begin{array}{c}\mathbf{1 6 9 9} \\
1.0\end{array}$ \\
\hline \multirow[t]{2}{*}{$\mathrm{CO} 2 /$ carbon dioxide $(\%)$} & \multicolumn{2}{|c|}{8.24} \\
\hline & $\begin{array}{l}8.4 \\
1.0\end{array}$ & $\begin{array}{c}8.16 \\
1.0\end{array}$ \\
\hline \multirow[t]{2}{*}{$\mathrm{CO} /$ carbon monoxide $(\%)$} & \multicolumn{2}{|c|}{2.31} \\
\hline & $\begin{array}{c}2.13 \\
1.1\end{array}$ & $\begin{array}{c}1.99 \\
1.2 \\
\end{array}$ \\
\hline \multirow[t]{2}{*}{$\mathrm{CH} 4 /$ methane (ppm) } & \multicolumn{2}{|c|}{1833} \\
\hline & $\begin{array}{c}1291 \\
1.4 \\
\end{array}$ & $\begin{array}{c}1143 \\
1.6 \\
\end{array}$ \\
\hline \multirow[t]{2}{*}{ C2H2/acetylene (ppm) } & \multicolumn{2}{|c|}{2381} \\
\hline & $\begin{array}{c}2073 \\
1.1\end{array}$ & $\begin{array}{c}1736 \\
1.4\end{array}$ \\
\hline \multirow[t]{2}{*}{ C2H4/ethylene (ppm) } & \multicolumn{2}{|c|}{11457} \\
\hline & $\begin{array}{c}\mathbf{5 3 2 5} \\
2.2 \\
\end{array}$ & $\begin{array}{c}\mathbf{5 1 7 8} \\
2.2 \\
\end{array}$ \\
\hline \multirow[t]{2}{*}{ C2H6/ethane (ppm) } & \multicolumn{2}{|c|}{574} \\
\hline & 394 & 378 \\
\hline \multirow[t]{2}{*}{ C3H6/propylene (ppm) } & \multicolumn{2}{|c|}{1274} \\
\hline & $\begin{array}{c}1662 \\
0.8 \\
\end{array}$ & $\begin{array}{c}1605 \\
0.8 \\
\end{array}$ \\
\hline \multirow[t]{3}{*}{$\mathrm{C} 4 \mathrm{H} 8+\mathrm{aC} 3 \mathrm{H} 4 / 1$-butene+1,2-propadiene (ppm) } & \multicolumn{2}{|c|}{593} \\
\hline & 800 & 801 \\
\hline & $\underline{0.7}$ & $\underline{0.7}$ \\
\hline \multirow[t]{3}{*}{$\mathrm{C} 4 \mathrm{H} 6+\mathrm{pC} 3 \mathrm{H} 4 / 1,3$-butadiene+propyne (ppm) } & \multicolumn{2}{|c|}{594} \\
\hline & 831 & 763 \\
\hline & $\underline{0.7}$ & $\underline{0.8}$ \\
\hline \multirow[t]{3}{*}{ aC5H10 /1-pentene (ppm) } & \multicolumn{2}{|c|}{179} \\
\hline & 99 & 113 \\
\hline & $\underline{1.8}$ & $\underline{1.6}$ \\
\hline \multirow[t]{3}{*}{ aC6H12 /1-hexene (ppm) } & \multicolumn{2}{|c|}{301} \\
\hline & 101 & 117 \\
\hline & $\underline{\underline{3.0}}$ & $\underline{2.6}$ \\
\hline \multirow[t]{3}{*}{$\mathrm{CH} 2 \mathrm{O} /$ formaldehyde (ppm) } & \multicolumn{2}{|c|}{1126} \\
\hline & 1302 & 1297 \\
\hline & $\underline{0.9}$ & $\underline{0.9}$ \\
\hline $\mathrm{CH} 3 \mathrm{HCO} /$ acetaldehyde (ppm) & & \\
\hline & 817 & 865 \\
\hline & $\underline{1.0}$ & $\underline{0.9}$ \\
\hline AC3H5HCO/crotonaldehyde (ppm) & & \\
\hline & 913 & 915 \\
\hline & $\underline{N} / \mathrm{A}$ & $\underline{N} / \mathrm{A}$ \\
\hline B1OL3E/3-buten-1-ol (ppm) & & \\
\hline & 278 & 290 \\
\hline & $\underline{\text { N/A }}$ & N/A \\
\hline & 122 & 126 \\
\hline & $\underline{\mathrm{N} / \mathrm{A}}$ & $\underline{\mathrm{N} / \mathrm{A}}$ \\
\hline
\end{tabular}


The effect of modifying the transport parameters of 1-hexanol and its radicals cannot be investigated in the JSR, as the JSR does not consider transport parameters in its premixed configuration.

Transport properties are required to model the laminar flame speed of fuel-air mixtures. The laminar flame speed of 1-hexanol-air mixtures was modeled using the PREMIX code in CHEMKIN PRO with the modified transport parameters. The effect of the modified transport parameters on laminar flame speeds of 1-hexanol-air mixtures are illustrated in Figure 5.14, where the results are compared to those using the original transport dataset from Togbe et al. [12]. From the comparison, the modifications made on the transport parameters had the greatest effect on the laminar flame speeds in fuel rich conditions at both pressures, with increases in laminar flame speeds between 2 to $5 \mathrm{~cm} / \mathrm{s}$. Under fuel lean conditions, the laminar flame speeds were not significantly influenced by the changes in the transport parameters.

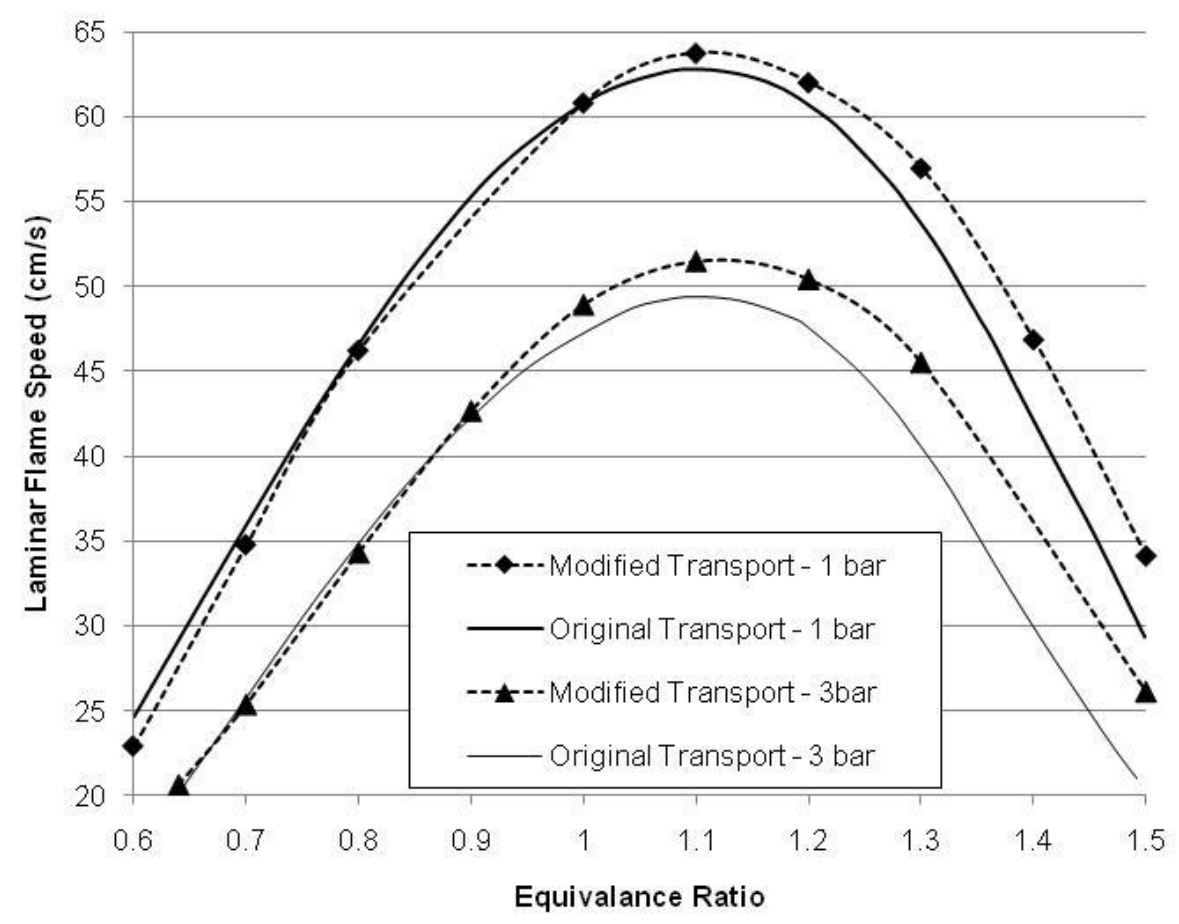

Figure 5.15: Laminar flame speed of 1-hexanol-air mixtures at $423 \mathrm{~K}$ and at 1 and 3 bar. The effect of the modified transport parameters on laminar flame speed is compared to the original results from Togbé et al. [12]. 


\section{Conclusions and Recommendations}

\subsection{Conclusions}

New experimental results were obtained for the oxidation of 1-hexanol in an opposed-flow diffusion flame at $0.101 \mathrm{MPa}$ to validate a high temperature chemical kinetic mechanism proposed by Togbé et al. [12] . The results from this study extend the validation of the proposed chemical kinetic model to a 1-D counterflow configuration, which is the midpoint between a 0-D JSR and turbulent flames. These 1-D laminar diffusion flame models are applicable to modeling turbulent flames through flamelet models, which use laminar flame data to handle the chemistry. The proposed chemical kinetic mechanism was previously validated in a JSR and a combustion bomb [12]; however, a study of 1-hexanol combustion in an opposed-flow diffusion flame further validated the transport properties expressed in the proposed model.

The predicted temperature profile of the 1-hexanol flame was shown to be closely matched to the experimental temperature profile produced with the uncoated thermocouple. The peak temperature measured with the silica-coated thermocouple was found to be lower than the peak measured with the uncoated thermocouple. The proposed chemical kinetic mechanism exhibited good agreement with most of the experimental data. The most abundant measured species from the experimental data were $\mathrm{CO}, \mathrm{CO}_{2}, \mathrm{C}_{2} \mathrm{H}_{2}, \mathrm{C}_{2} \mathrm{H}_{4}$, and $\mathrm{C}_{3} \mathrm{H}_{6}$. Several other $n$-alkenes (e.g., $\mathrm{C}_{4} \mathrm{H}_{8}$, 1- $\mathrm{C}_{5} \mathrm{H}_{10}$, and 1- $\mathrm{C}_{6} \mathrm{H}_{12}$ ) were observed and measured in the 1-hexanol flame. As for oxygenated species, $\mathrm{CH}_{2} \mathrm{O}$ and $\mathrm{CH}_{3} \mathrm{HCO}$ were measured in the flame as well. The greatest discrepancies between the predicted and measured results were observed for $\mathrm{C}_{2} \mathrm{H}_{4}$, and $1-\mathrm{C}_{6} \mathrm{H}_{12}$.

The reaction pathway analysis at $1000 \mathrm{~K}$, which corresponds to the temperature at which $50 \%$ of fuel is consumed, showed that $\mathrm{H}$-atom abstraction was the main route of fuel consumption. The fuel radicals produced from $\mathrm{H}$-atom abstraction decomposed via $\beta$-scission to the form the species observed experimentally. From the proposed mechanism, isomerization of the fuel radical was shown to be important. The pathways also predicted the production of unsaturated aldehydes and alcohols, such as acrolein, 2-butenal/crotonaldehyde, 3-buten-1-ol, and 4-penten-1-ol. However, these unsaturated aldehydes and alcohols were not observed in the flame. 
Sensitivity analyses were conducted for 1-hexanol, $\mathrm{C}_{2} \mathrm{H}_{4}$, and $1-\mathrm{C}_{6} \mathrm{H}_{12}$ at several temperatures. The predicted fuel concentrations are shown to be mostly influenced by H-atom abstraction reactions initiated with $\mathrm{H}$ atoms. As for $\mathrm{C}_{2} \mathrm{H}_{4}$, its formation is most sensitive to the unimolecular decomposition of the 1-butyl radical $\left(\mathrm{pC}_{4} \mathrm{H}_{9}\right)$. Also, the concentration of 1- $\mathrm{C}_{6} \mathrm{H}_{12}$ is observed to be primarily affected by the $\beta$-scission decomposition of the fuel radical, HXOL2J, which is shown from the reaction pathway analysis to be the major path of $1-\mathrm{C}_{6} \mathrm{H}_{12}$ production. Attempts to optimize the predictions of $\mathrm{C}_{2} \mathrm{H}_{4}$, and $1-\mathrm{C}_{6} \mathrm{H}_{12}$ were made by changing the rate constants of the most sensitive reactions. Hence, modifications of the A-factor for reactions that the species were most influenced by, according to the sensitivity analyses, were considered. However, it is important that any changes made to a rate constant of a reaction cannot negatively affect the agreements of the other species.

The uncertainty analysis on the LJ collision diameter and potential well depth of the fuel indicates that predicted species and temperature profiles were sensitive to fuel diffusion. It was found that an $87 \%$ increase in the LJ potential well depth and a $25 \%$ increase in the LJ collision diameter only improved about half of the agreements between the experimental results and model predictions. The modifications in the LJ transport parameters were used to predict the laminar flame speeds of 1-hexanol-air mixtures at $423 \mathrm{~K}$ and at 1 and 3 bar. The laminar flame speeds in fuel rich conditions appeared to increase between 2 to $5 \mathrm{~cm} / \mathrm{s}$ after the changes in the LJ parameters, in comparison to the results reported in Togbé et al. [12]. 


\subsection{Recommendations}

A number of recommendations are suggested to improve the quality of the results discussed in this study and for future work.

\subsubsection{1-Hexanol Studies}

Autoignition characteristics of 1-hexanol are not available in literature. These properties are typical characteristics that describe the combustion behaviour of a fuel and they are studied using shock tubes, flow reactor, or rapid compression machines.

\subsubsection{Analytical Techniques}

There are limitations related to the species that the GC/TCD can detect given the choice of carrier gas. Thus, if hydrogen is of interest, the GC/TCD can be equipped with another detector running argon as the carrier gas. Using argon will not interfere with the detection of hydrogen as their thermal conductivities are sufficiently different.

\subsubsection{Thermocouple Coatings}

A silica coating was attempted on the thermocouples used to measure flame temperature in the experiments. However, silica coatings have been reported to react with hydrogen at high temperatures $(>1400 \mathrm{~K})$ to form platinum silicide on the thermocouple surface and this silicide causes embrittlement of the thermocouple wire [62]. There are other types of coating materials that could be used, such as a beryllium- yttrium oxide $\left(\mathrm{BeO} / \mathrm{Y}_{2} \mathrm{O}_{3}\right)$ ceramic coating and an alumina-based ceramic.

The $\mathrm{BeO} / \mathrm{Y}_{2} \mathrm{O}_{3}$ coating was suggested by Kent [62], which requires dissolving yttrium chloride and beryllium oxide in hydrochloric acid. A disadvantage of this coating is that beryllium oxide is highly toxic and poisonous. The emissivity of a $\mathrm{BeO} / \mathrm{Y}_{2} \mathrm{O}_{3}$ has been determined to be 0.60 by Peterson and Laurendeau [92], which is higher than the emissivity of 0.22 for the silica coating. 
Alumina-based coatings have also been used on $\mathrm{R}$ type thermocouples as discussed by Heitor and Moreira [60]. Burton et al. [93] applied an aluminum oxide/potassium silicate $\left(\mathrm{Al}_{2} \mathrm{O}_{3} / \mathrm{K}_{2} \mathrm{SiO}_{3}\right)$ coating, which is non-toxic, stable at high temperatures and shown to eliminate catalytic heating. However, these ingredients produce a thick coating, which damps the response of the thermocouple and increases the emissivity and the magnitude of radiation correction [59].

\subsubsection{Chemical Kinetic Mechanism}

Based the chemical kinetic modeling results in the opposed-flow diffusion flame, there were some discrepancies that could be addressed in future work.

A discrepancy between the measured and predicted peak concentrations of $\mathrm{C}_{2} \mathrm{H}_{4}$ was observed in the opposed-flow diffusion flame, but the proposed chemical kinetic mechanism from Togbé et al. [12] showed weaknesses in predicting $\mathrm{C}_{2} \mathrm{H}_{4}$ concentrations in a JSR under fuel rich conditions as well. Although attempts to improve the chemical kinetic mechanism for $\mathrm{C}_{2} \mathrm{H}_{4}$ were made in this study, more extensive fundamental reaction rate studies may be required on the 1-hexanol decomposition reactions at high temperatures. Moreover, the reaction rate studies may also improve some branching ratios from the decomposition of 1-hexanol radicals and clarify some isomerizations of 1-hexanol radicals. The branching ratio of the 1-butyl radical, $\mathrm{pC}_{4} \mathrm{H}_{9}$, should be further investigated as well, as it is a precursor for $\mathrm{C}_{2} \mathrm{H}_{4}$ formation.

A large under prediction was observed for $1-\mathrm{C}_{6} \mathrm{H}_{12}$. Similar to $\mathrm{C}_{2} \mathrm{H}_{4}$, modification of the A-factor for the most sensitive reaction was tested but did not provide results that could be used with confidence. Thus, further reaction rate studies on the reaction $\mathrm{OH}+\mathrm{AC6H} 12 \leftrightarrow \mathrm{HXOL} 2 \mathrm{~J}$ may be beneficial. However, as stressed, any changes in reaction rate constants cannot adversely affect the predictions of other species.

Enols appear to be missing from the proposed chemical kinetic mechanism by Togbé et al. [12]. Thus, the reactions for enols should be added to the proposed chemical kinetic mechanism to better describe the flame chemistry of 1-hexanol. These reactions should include the isomerization reactions of enols to ketones or aldehydes and the decomposition of enols and enol radicals. 


\subsubsection{Transport Properties}

Further analysis on the uncertainty of transport properties is required as the modified LJ collision diameter and potential well depth for 1-hexanol were obtained from empirical correlations. The empirical correlations used in the modification of these transport parameters were originally derived for large $n$-alkanes, but were assumed to be sufficient for 1-hexanol. As of yet, no such empirical correlations are available in literature to estimate the LJ collision diameter and potential well depth for alcohols. Methods described in Tee et al. [72] show that empirical correlations for any fluid can be estimated using a least-squares analysis of viscosity data and second viral coefficients. However, these parameters must be applicable to high temperature conditions in order to be valid.

Furthermore, the transport dataset proposed by Togbé et al. [12] should be verified as well, especially for the larger alcohols (i.e., $n$-butanol, 1-pentanol, 1-hexanol) and their radicals. 


\section{Bibliography}

[1] Exxon Mobil, "The Outlook for Energy: A View to 2030.," 2010.

[2] U.S. Department of Commerce, National Oceanic and Atmospheric Administration, Earth System Research Laboratory, Global Monitoring Division. (2011, June) Trends in Atmospheric Carbon Dioxide. [Online]. http://www.esrl.noaa.gov/gmd/ccgg/trends/index.html

[3] BP p.l.c., "The BP Energy Outlook 2030," London, UK, 2011.

[4] L. D. D. Harvey, Energy and the New Reality - Carbon-free Energy Supply. London, UK : Earthscan Ltd. , 2010.

[5] Canada Gazette. (2010, April 10) Renewable Fuels Regulations. [Online]. http://www.gazette.gc.ca/rp-pr/p1/2010/2010-04-10/html/reg1-eng.html\#1

[6] United Nations Environment Programme. (2009, July ) G8 leaders agree to global warming goals. [Online].

http://hqweb.unep.org/NewsCentre/Default.aspx?DocumentID=593\&ArticleID=6245

[7] Envrionment Canada. (2011, February ) Measuring Sustainability: Canadian Environmental Sustainability Indicators. [Online]. http://www.ec.gc.ca/indicateursindicators/default.asp?lang=En\&n=995C74D1-1

[8] M. Vaughn, "All aboard the ethanol bandwagon," The Globe and Mail, December 282010.

[9] M. Lantsman, "Canada's Environment Minister Announces Start Date for Biodiesel Requirement," Environment Canada, Saskatoon, SK, Press Release - June 29, 2011.

[10] C. K. Westbrook and F. L. Dryer, "Chemical kinetic modeling of hydrocarbon combustion," Progress in Energy and Combustion Science, vol. 10, no. 1, pp. 1-57, 1984. 
[11] EIA, "International Energy Outlook 2006," Energy Information Administration, Office of Integrated Analysis and Forecasting, U.S. Department of Energy, Washington, D.C. , June 2006.

[12] C. Togbé et al., "Experimental and detailed kinetic modeling study of 1-hexanol oxidation in a pressurized jet-stirred reactor and a combustion bomb," Energy and Fuels, vol. 24, no. 11, pp. 5859-5875, 2010.

[13] BP. (2006, June) BP-DuPont biofuels fact sheet.

[14] J. T. Moss et al., "An Experimental and Kinetic Modeling Study of the Oxidation of the Four Isomers of Butanol," Journal of Physical Chemistry A, vol. 112, no. 43, pp. 1084310855, 2008.

[15] P. Dagaut, S. M. Sarathy, and M. J. Thomson, "A chemical kinetic study of n-butanol oxidation at elevated pressure in a jet stirred reactor," Proceedings of the Combustion Insitute, vol. 32, no. 1, pp. 229-237, 2009.

[16] S. M. Sarathy et al., "An experimental and kinetic modeling study of n-butanol combustion," Combustion and Flame, vol. 156, no. 4, pp. 852-864, 2009.

[17] G. Black, H. J. Curran, S. Pichon, J. M. Simmie, and V. Zhukov, "Bio-butanol: Combustion properties and detailed chemical kinetic model," Combustion and Flame, vol. 157, no. 2, pp. 363-373, 2010.

[18] R. Grana et al., "An experimental and kinetic modeling study of combustion of isomers of butanol," Combustion and Flame, vol. 157, no. 11, pp. 2137-2154, November 2010.

[19] P. S. Veloo, Y. L. Wang, F. N. Egolfopoulos, and C. K. Westbrook, "A comparative experimental and computational study of methanol, ethanol, and n-butanol flames," Combustion and Flame, vol. 157, no. 10, pp. 1989-2004, October 2010.

[20] P. S. Veloo and F. N. Egolfopoulos, "Flame propagation of butanol isomers/air mixtures," 
Proceedings of the Combustion Institute, vol. 33, no. 1, pp. 987-993, 2011.

[21] C. M. Gowen and S. S. Fong, "Exploring Biodiversity for Cellulosic Biofuel Production," Chemistry \& Biodiversity, vol. 7, no. 5, pp. 1086-1097, 2010.

[22] M. Gautam and D. M. Martin, "Combustion characteristics of higher-alcohol/gasoline blends," Proceedings of the Institution of Mechanical Engineers, Part A: Journal of Power and Energy, vol. 214, no. A5, pp. 497-511, 2000.

[23] C. Togbé, F. Halter, F. Foucher, C. Mounaim-Rouselle, and P. Dagaut, "Experimental and detailed kinetic modeling study of 1-pentanol oxidation in a JSR and combustion in a bomb," Proceedings of the Combustion Institute, vol. 33, no. 1, pp. 367-374, 2011.

[24] A. F. Cann and J. C. Liao, "Pentanol isomer synthesis in engineered microorganisms ," Applied Microbiology and Biotechnology, vol. 85, pp. 893-899, 2010.

[25] A. P. Sathiyagnanam, C. G. Saravanan, and M. Gopalakrishnan, "Hexanol-Ethanol Diesel Blends on DI-Diesel Engine to Study the Combustion and Emission," in World Congress on Engineering, International Association of Engineers, London, 2010.

[26] I. Glassman and R. A. Yetter, Combustion, 4th ed. San Diego, CA: Academic Press, 2008.

[27] T. Le Cong and P. Dagaut, "Kinetics of natural gas, natural gas/syngas mixtures oxidation and effect of burnt gas recirculation: experimental and detailed modeling," Proceedings of the ASME Turbo Expo 2007: Power for Land, Sea and Air, pp. 1-9, May 2007.

[28] P. Dagaut, "On the kinetics of hydrocarbons oxidation from natural gas to kerosene and diesel fuel," Physical Chemistry Chemical Physics, vol. 4, no. 11, pp. 2079-2094 , 2002.

[29] F. Battin-LeClerc et al., "EXGAS-ALKANES, a software for the automatic generation of mechanisms for the oxidation of alkanes," CNRS-DCPR, 2004.

[30] A. Frassoldati et al., "An experimental and kinetic modeling study of n-propanol and isopropanol combustion," Combustion and Flame, vol. 157, no. 1, pp. 2-16, January 2010. 
[31] N. Peters, Turbulent Combustion. Cambridge, England: Cambridge University Press, 2000.

[32] D. Aloko, G. A. Adebayo, and O. E. Oke, "Evaluation of Diesel-Hexanol Blend as Diesel Fuel," Leonardo Journal of Sciences, vol. 6, no. 10, pp. 151-156, 2007.

[33] C. S. Raj, I. R. Edward, J. Nimosh, G. N. Mon, and Y. M. Rameez, "Performance of a Constant Speed Diesel Engine with Hexanol Blended Fuels," International Journal of Applied Engineering Research, vol. 5, no. 7, pp. 1215-1222, 2010.

[34] P. Dagaut and C. Togbe, "Experimental and modeling study of the kinetics of oxidation of ethanol-gasoline surrogate mixtures (E85 surrogate) in a jet-stirred reactor," Energy and Fuels, vol. 22, no. 5, pp. 3499-3505, 2008.

[35] C. Togbé, A. M. Ahmed, and P. Dagaut, "Experimental and modeling study of the kinetics of oxidation of methanol-gasoline surrogate mixtures (m85 surrogate) in a jet-stirred reactor," Energy and Fuels, vol. 23, no. 4, pp. 1936-1941, 2009.

[36] K. Zhang, M. R. Sawaya, D. S. Eisenberg, and J. C. Liao, "Expanding metabolism for biosynthesis of nonnatural alcohols ," Proceedings of the National Academy of Sciences of the United States of America, vol. 105, no. 52, pp. 20653-20658, 2008.

[37] M. Xiang et al., "Synthesis of higher alcohols from syngas over Fischer-Tropsch elements modified K/b-Mo2C catalysts," Fuel, vol. 87, pp. 599-603, 2008.

[38] V. R. Surisetty, A. K. Dalai, and J. Kozinski, "Alkali-Promoted Trimetallic Co-Rh-Mo Sulfide Catalysts for Higher Alcohols Synthesis from Synthesis Gas: Comparison of MWCNT and Activated Carbon Supports," Industrial \& Engineering Chemistry Research, vol. 49, no. 15, pp. 6956-6963, 2010.

[39] V. R. Surisetty, A. K. Dalai, and J. Kozinski, "Intrinsic Reaction Kinetics of Higher Alcohol Synthesis from Synthesis Gas over a Sulfided Alkali-Promoted Co-Rh-Mo Trimetallic Catalyst Supported on Multiwalled Carbon Nanotubes (MWCNTs)," Energy \& Fuels, vol. 24, pp. 4130-4137, 2010. 
[40] D. W. Lachenmeier, S. Haupt, and K. Schulz, "Defining maximum levels of higher alcohols in alcoholic beverages and surrogate alcohol products," Regulatory Toxicology and Pharmacology, vol. 50, no. 3, pp. 313-321, 2008.

[41] D. W. Verser, "Indirect production of butanol and hexanol," PCT/US2009/033561, August $13,2009$.

[42] R. N. Patel, C. T. Hou, A. I. Laskin, A. Felix, and P. Derelanko, "Microbial Oxidation of Gaseous Hydrocarbons: Production of Secondary Alcohols from Corresponding n-Alkanes by Methane-Utilizing Bacteria," Applied and Environmental Microbiology, vol. 39, no. 4, pp. 720-726, April 1980.

[43] D. B. Levin, Production of Hexanol, February 2011, E-mail communication.

[44] L. Starck et al., "ALFA-BIRD - Alternative Fuels and Biofuels for Aircraft Development," International Association for Stability, Handling and Use of Liquid Fuels, no. 42, June 2010.

[45] D. R. Lide, Ed., CRC Handbook of Chemistry and Physics, 87th ed. Boca Raton, FL: Taylor and Francis, 2007.

[46] Environment Canada - Environmental Technology Centre. (2011) Oil Properties - Diesel Fuel Oil (Canada). [Online]. http://www.etc-

cte.ec.gc.ca/databases/oilproperties/pdf/web_diesel_fuel_oil_(canada).pdf

[47] J. F. Larivé et al. R. Edwards, "Well-to-Wheels analysis of future automotive fuels and powertrains in the European context," CONCAWE, EUCAR, European Commission, 2007.

[48] S. R. Turns, An introduction to combustion: concepts and applications, 2nd ed. University Park, PA, USA: McGraw-Hill, 2000.

[49] Holthuis \& Associates. HOLTHUIS \& ASSOCIATES. [Online]. http://www.flatflame.com/index.htm 
[50] R. Battino, T. R. Rettich, and T. Tominaga, "The solubility of nitrogen and air in liquids," Journal of Physical Chemistry Reference Data, vol. 13, no. 2, pp. 563-600, 1984.

[51] P. Zabeti, "Gaseous Species Measurements of Alternative Jet Fuels in Sooting Laminar Coflow Diffusion Flames," University of Toronto , M.A.Sc. Thesis 2010.

[52] P. Linstrom and W. Mallard. (2011) NIST Chemistry WebBook, NIST Standard Reference Database Number 69. [Online]. http://webbook.nist.gov/chemistry/

[53] K. Seshadri and F. A. Williams, "Laminar flow between two parallel plates with injection of a reactant at a high Reynolds number," International Journal of Heat and Mass Transfer, vol. 21, no. 2, pp. 251-253, 1978.

[54] S. M. Sarathy, "Chemical kinetic modeling of biofuel combustion," University of Toronto, Ph.D. Thesis 2009.

[55] R. M. Fristrom, "Comments of quenching mechanisms in the microprobe sampling of flames," Combustion \& Flame, vol. 50, pp. 239-242, 1983.

[56] U. Struckmeier et al., "Sampling Probe Influences on Temperature and Species Concentrations in Molecular Beam Mass Spectroscopic Investigations of Flat Premixed Low-pressure Flames," Zeitschrift für Physikalische Chemie - International Journal of Research in Physical Chemistry \& Chemical Physics, vol. 223, no. 4-5, pp. 503-537, 2009.

[57] K. Schofield, "The enigmatic mechanism of the flame ionization detector: Its overlooked implications for fossil fuel combustion modeling," Progress in Energy \& Combustion Science, vol. 34, no. 3, pp. 330-350, June 2008.

[58] C. McEnally, U. Koylu, L. Pfefferle, and D. Rosner, "Soot volume fraction and temperature measurements in laminar nonpremixed flames using thermocouples," Combustion and Flame, vol. 109, no. 4, pp. 701-720, June 1997.

[59] C. R. Shaddix, "Correcting Thermocouple Measurements For Radiation Loss: A Critical 
Review," Proceedings of the 33rd National Heat Transfer Conference, August 1999.

[60] M. V. Heitor and A. L. N. Moreira, "Thermocouples and sample probes for combustion studies," Progress in Energy and Combustion Science, vol. 19, no. 3, pp. 259-278, January 1993.

[61] W. E. Kaskan, "The dependence of flame temperature on mass burning velocity," Symposium (International) on Combustion, vol. 6, no. 1, pp. 134-143, 1957.

[62] J. H. Kent, "A Noncatalytic Coating for Platinum-Rhodium Thermocouples," Combustion and Flame, vol. 14, pp. 279-281, April 1970.

[63] R. M. Fristorm and A. Westenberg, Flame Structure. NewYork: McGraw-Hill, 1965.

[64] D. Bradley and A. Entwistle, "Determination of the emissivitiy, for total radiation, of small diameter platinum-10\% rhodium wires in the temperature range 600-1450 degrees C," British Journal of Applied Physics, vol. 12, pp. 708-711, December 1961.

[65] W. E. Ranz and W. R., Jr. Marshall, "Evaporation from drops. Parts 1 \& 2," Chemical Engineering Progress, vol. 48, pp. 141-146, 173-180, 1952.

[66] R. J. Kee et al., CHEMKIN-PRO Release 15101. San Diego, California, 2010.

[67] R. J. Kee, J. A. Miller, G. H. Evans, and G. Dixon-Lewis, "A computational model of the structure and extinction of strained, opposed flow, premixed methane-air flames," in Proceedings of the Twenty-Second Symposium (International) on Combustion, The Combustion Institute, Pittsburgh, Pennsylvania, 1988, pp. 1479-1494.

[68] J. A. Manion et al. (2011) NIST Chemical Kinetics Database, Standard Reference Database 17, Version 7.0 (Web Version), Release 1.6.3. [Online]. http://kinetics.nist.gov/kinetics/index.jsp

[69] C. Muller, V. Michel, G. Scacchi, and G. Come, "THERGAS - a computer-program for the evaluation of thermochemical data of molecules and free-radicals in the gas phase"," 
Journal de Chimie Physique et de Physico-Chimie Biologique, vol. 92, no. 5, pp. 11541178, May 1995.

[70] E.R. Ritter and J.W. Bozzelli, "THERM: Thermodynamic property estimation for gas phase radicals and molcule," International Journal of Chemical Kinetics , vol. 23, pp. 767-778, 1991.

[71] S. Benson, Thermochemical Kinetics, 2nd ed. New York : Wiley, 1976.

[72] L. S. Tee, S. Gotoh, and W. E. Stewart, "Molecular Parameters for Normal Fluids - The Lennard-Jones 12-6 Potential," Industrial \& Engineering Chemistry Fundamentals, vol. 5, no. 3, pp. 356-363, August 1966.

[73] A. T. Holley, X. Q. You, E. Dames, H. Wang, and F. N. Egolfopoulos, "Sensitivity of propagation and extinction of large hydrocarbon flames to fuel diffusion," Proceedings of the Combustion Institute, vol. 32, pp. 1157-1163, 2009.

[74] B. Lee and M. Kesler, "A generalized thermodynamic correlation based on the threeparameter corresponding states," American Institute of Chemical Engineers (AIChE) Journal, vol. 21, pp. 510-527, 1975.

[75] A. McClellan, Tables of Experimental Dipole Moments. San Francisco : Freeman, 1963.

[76] R. Bosque and J. Sales, "Polarizabilities of Solvents from the Chemical Composition," Journal of Chemical Information and Computer Sciences, vol. 42, no. 5, pp. 1154-1163, 2002.

[77] R. J. Kee, J. Warnatz, and J. A. Miller, "A Fortran Computer Code Package for the Evaluation of Gas-Phase Viscosities, Conductivities, and Diffusion Coefficients," Sandia National Laboratories, SAND83-8209, 1983.

[78] J. Warnatz, "Numerical Methods in Flame Propagation," 1982.

[79] M. Frenklach, H. Wang, and M. Rabinowitz, "Optimization and analysis of large chemical 
kinetic mechanisms using the solution mapping method: combustion of methane," Progress in Energy and Combustion Science, vol. 18, pp. 47-73, 1992.

[80] J. M. Simmie, "Detailed chemical kinetic models for the combustion of hydrocarbon fuels ," Progress in Energy and Combustion Science, vol. 29, no. 6, pp. 599-634, 2003.

[81] M. S. Kurman, R. H. Natelson, N. P. Cernansky, and D. L. Miller, "Preignition oxidation chemistry of the major JP-8 surrogate component: n-dodecane," in 47th AIAA Aerospace Sciences Meeting including the New Horizons Forum and Aerospace Exposition, Orlando, FL, 2009.

[82] Y. R. Luo, Comprehensive Handbook of Chemical Bond Energies.: CRC Press, 2007.

[83] C. A. Taatjes et al., "Enols Are Common Intermediates in Hydrocarbon Oxidation," Science, vol. 308, no. 5730, pp. 1887-1889, June 2005.

[84] C. A. Taatjes et al., "Combustion Chemistry of Enols: Possible Ethenol Precursors in Flames," Journal of Physical Chemistry A, vol. 110, no. 9, pp. 3254-3260, March 2006.

[85] B. Yang et al., "Identification of combustion intermediates in isomeric fuel-rich premixed butanol-oxygen flames at low pressure," Combustion and Flame, vol. 148, no. 8, pp. 198209, March 2007.

[86] Y. Li et al., "A comprehensive experimental study of low-pressure premixed C3-oxygenated hydrocarbon flames with tunable synchrotron photoionization," Combustion and Flame, vol. 152, no. 3, pp. 336-359, February 2008.

[87] H. J. Curran, "Rate constant estimation for C-1 to C-4 alkyl and alkoxyl radical decomposition," International Journal of Chemical Kinetics, vol. 38, pp. 250 - 275, 2006.

[88] J. A. Kerr and A. F. Trotman-Dickenson, "The reactions of alkyl radicals. Part III. n-Butyl radicals from the photolysis of n-Valeraldehyde," Journal of the Chemical Society, 1960.

[89] S. M. Sarathy et al., "An experimental and kinetic modeling study of n-octane and 2- 
methylheptane in an opposed-flow diffusion flame," Combustion and Flame, vol. 158, no. 7, pp. 1277-1287, July 2011.

[90] A. J. Smallbone, W. Liu, C. K. Law, X. Q. You, and H. Wang, "Experimental and modeling study of laminar flame speed and non-premixed counterflow ignition of n-heptane," Proceedings of the Combustion Institute, vol. 32, pp. 1245-1252, 2009.

[91] K. Chae and A. Violi, "Binary mass diffusion coefficients of straight chain alkanes," in 6th U.S. National Combustion Meeting, Ann Arbor, Michigan, 2009.

[92] R. C. Peterson and N. M. Laurendeau, "The Emittance of Yttrium-Beryllium Oxide Thermocouple Coating," Combustion and Flame, vol. 60, pp. 279-284, 1985.

[93] K. A. Burton, H. D. Ladouceur, and J. W. Fleming, "An Improved Noncatalytic Coating for Thermocouples," Combustion Science and Technology, vol. 81, no. 1-3, pp. 141-145, 1992.

[94] R. J. Kee, M. E. Coltrin, and P. Glarborg, Chemically Reacting Flow: Theory and Practice.: John Wiley and Sons, 2005.

[95] H. Wang and M. Frenklach, "Transport Properties of Polycyclic Aromatic Hydrocarbons for Flame Modeling ," Combustion and Flame , vol. 96, no. 1-2, pp. 163-170, January 1994.

[96] M. Kassem, M. Qun, and S. M. Senkan, "Chemical Structure of Fuel-Rich 1,2$\mathrm{C} 2 \mathrm{H} 4 \mathrm{Cl} 2 / \mathrm{CH} 4 / \mathrm{O} 2 / A r$ Flames: Effects of Micro-Probe Cooling on the Sampling of Flames of Chlorinated Hydrocarbons," Combustion Science and Technology, vol. 67, no. 4-6, pp. 147-157, 1989. 
Appendices 


\section{Appendix A - Sample Gas Chromatogram from GC/FID}

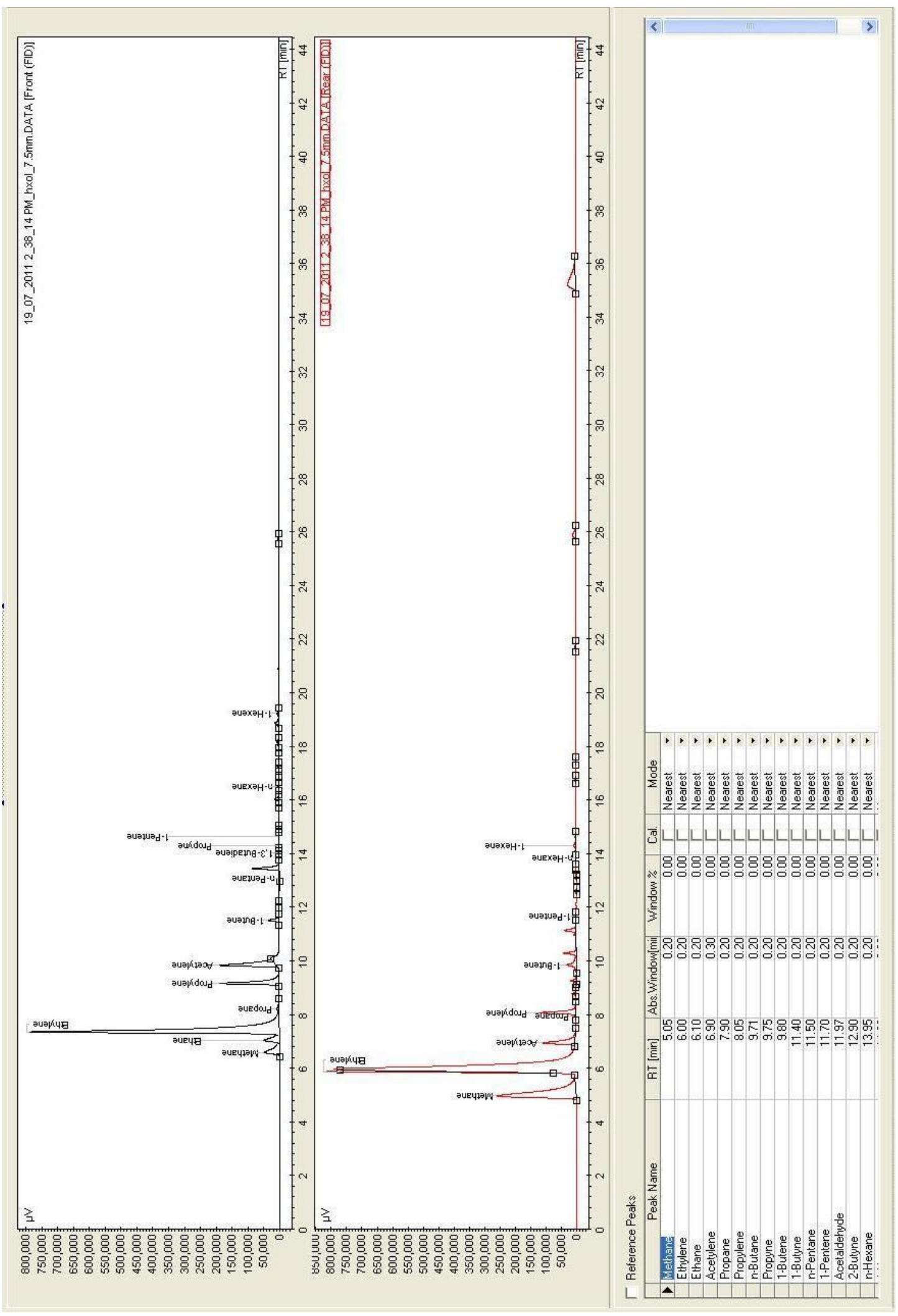


Appendix B - Sample Gas Chromatogram from GC/TCD

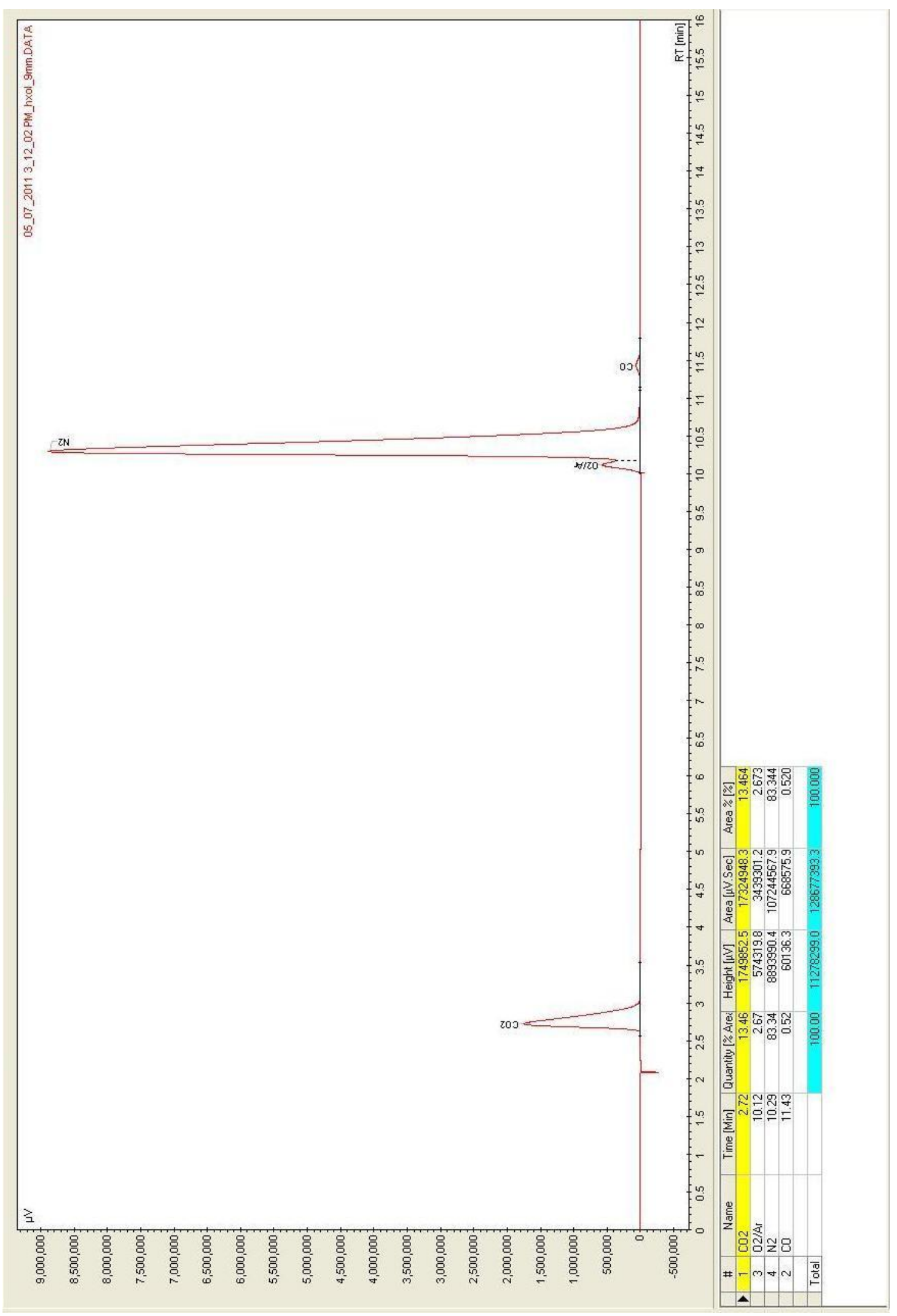




\section{Appendix C - Retention Times of Measured Species}

Retention times for hydrocarbons detected on the front FID of the GC/FID:

\begin{tabular}{c|c}
\hline Species & $\begin{array}{c}\text { Retention Time } \\
(\mathbf{m i n})\end{array}$ \\
\hline Methane & 6.6 \\
\hline Ethane & 7.1 \\
\hline Ethylene & 7.4 \\
\hline Propane & 8.2 \\
\hline Propylene & 9.2 \\
\hline Acetylene & 9.7 \\
\hline Butane & 10.3 \\
\hline 1-Butene & 11.5 \\
\hline Pentane & 13.2 \\
\hline Propyne & 13.4 \\
\hline 1-Pentene & 14.6 \\
\hline 1-Butyne & 15.7 \\
\hline 2-Butyne & 16.3 \\
\hline Trans-1,3-pentadiene & 16.5 \\
\hline Hexane & 16.6 \\
\hline 1-Hexene & 18.7 \\
\hline Benzene & 23.5 \\
\hline
\end{tabular}

Retention times for oxygenated species detected on the rear FID of the GC/FID:

\begin{tabular}{c|c}
\hline Species & $\begin{array}{c}\text { Retention Time } \\
(\mathbf{m i n})\end{array}$ \\
\hline Ketene & 14.1 \\
\hline Crotonaldehyde & 18.2 \\
\hline 3-Buten-1-ol & 19.7 \\
\hline Butanol & 19.9 \\
\hline Hexanal & 24.2 \\
\hline 4-Penten-1-ol & 26.0 \\
\hline 1-Hexanol & 33.3 \\
\hline
\end{tabular}


Retention times for $\mathrm{CO}, \mathrm{CO}_{2}$, and $\mathrm{O}_{2}$ detected on the TCD of the GC/TCD:

\begin{tabular}{c|c}
\hline Species & $\begin{array}{c}\text { Retention Time } \\
(\mathbf{m i n})\end{array}$ \\
\hline Carbon Dioxide & 2.7 \\
\hline Oxygen & 10.1 \\
\hline Carbon Monoxide & 11.4 \\
\hline
\end{tabular}




\section{Appendix D - Governing Equations for the Opposed-Flow Diffusion Flame}

To solve chemically reaction flow systems, the governing equations relating to the system's conservation of mass, momentum, energy and species mass are required [94].

\section{Conservation of Mass}

Mass continuity equation shows that mass is always conserved in a system. The rate at which mass enters a system (or control volume) is equal to the rate at which mass leaves the system (or control volume). Derived from fluid dynamics, the conservation of mass associated with a fixed point in a flow is expressed as:

$$
\frac{\partial \rho}{\partial t}+\nabla \cdot(\rho \vec{v})=0
$$

At steady state, the conservation of mass in cylindrical coordinates is:

$$
\frac{\partial\left(\rho v_{x}\right)}{\partial x}+\frac{1}{r} \frac{\partial}{\partial r}\left(\rho v_{r} r\right)=0
$$

Where: $v_{x}=$ axial velocity

$$
\begin{aligned}
& v_{r}=\text { radial velocity } \\
& \rho=\text { fluid density } \\
& \mathrm{r}=\text { radial position } \\
& \mathrm{t}=\text { time }
\end{aligned}
$$

And for a one-dimensional flame, the conservation of mass reduces to:

$$
\frac{\partial\left(\rho v_{x}\right)}{\partial x}=0
$$




\section{Conservation of Momentum}

Flowing mass has momentum. The conservation of linear momentum describes that the sum of all forces acting in a given direction on a control volume is equal to the net flow of momentum out of the control volume in the same direction. The general differential form of the NavierStokes equation is used to describe a flowing fluid is:

$$
\rho \frac{D \vec{v}}{D t}=\mu \nabla^{2} \vec{v}-\vec{\nabla}+p \vec{g}
$$

Where: $\rho$ = fluid density

$$
\begin{aligned}
& \mathrm{t}=\text { time } \\
& \vec{v}=\text { fluid velocity vector } \\
& \mathrm{p}=\text { pressure } \\
& \vec{g}=\text { gravitational force constant } \\
& \mu=\text { dynamic viscosity }
\end{aligned}
$$

For a one-dimensional laminar flame, the conservation of momentum becomes:

$$
\rho v_{x} \frac{\partial v_{x}}{\partial x}=-\frac{\partial p}{\partial x}+\frac{\partial}{\partial x}\left(\mu \frac{\partial v_{x}}{\partial x}\right)
$$




\section{Conservation of Energy}

The conservation of energy states that the total amount of energy in a system is constant over time. The energy equation is used to describe the temperature profile of a chemically reacting flow, which affects chemical reactions, convection, and molecular diffusion. Using the first law of thermodynamics, assuming ideal gas conditions and low Mach numbers, and using Fourier's law of heat conduction, the thermal energy equation is:

$$
\rho C_{p} \frac{\partial T}{\partial t}+\rho C_{p} \bar{u}_{k} \cdot \nabla T=\nabla \cdot(\lambda \nabla T)-\rho \sum_{k=1}^{K} C_{p, k} Y_{k} \bar{u}_{k} \cdot \nabla T-\sum_{k=1}^{K} h_{k} \dot{w}_{k} W_{k}+q_{r a d}
$$

Where: $\rho$ = fluid density

$$
\begin{aligned}
& C_{p}=\text { heat capacity of } \mathrm{k}^{\text {th }} \text { species } \\
& \mathrm{t}=\text { time } \\
& \mathrm{T}=\text { temperature } \\
& \lambda=\text { thermal conductivity } \\
& \mathrm{Y}_{\mathrm{k}}=\text { mass fraction of the } \mathrm{k}^{\text {th }} \text { species } \\
& \mathrm{Vk}_{\mathrm{k}}=\text { fluid velocity vector of the } \mathrm{k}^{\text {th }} \text { species } \\
& \omega_{\mathrm{k}}=\text { net molar production rate of the } \mathrm{k}^{\text {th }} \text { species } \\
& \mathrm{h}_{\mathrm{k}}=\text { enthalpy of formation of the } \mathrm{k}^{\text {th }} \text { species } \\
& \mathrm{W}_{\mathrm{k}}=\text { molecular weight of the } \mathrm{k}^{\mathrm{th}} \text { species } \\
& \mathrm{q}_{\mathrm{rad}}=\text { radiative heat transfer }
\end{aligned}
$$

For a one-dimensional laminar flame, the conservation of energy becomes:

$$
\rho u \frac{d T}{d x}-\frac{1}{C_{p}} \frac{d}{d x}\left(\lambda \frac{d T}{d x}\right)+\frac{\rho}{C_{p}} \sum_{k=1}^{K} C_{p, k} Y_{k} \bar{u}_{k} \frac{d T}{d x}-\frac{1}{C_{p}} \sum_{k=1}^{K} h_{k} \dot{W}_{k}=0
$$




\section{Conservation of Species Mass}

A species mass conservation equation is developed with the rate law of species transport (Fick's law). For a one dimensional control volume, a species $\mathrm{K}$ flows into and out of the control volume as a result of the bulk flow and diffusion. Within the control volume, species $\mathrm{K}$ may be created or destroyed from chemical reaction. Thus, the mass conservation of a species is important in chemically reacting flow systems involving a multicomponent gas mixture. The mass fraction of a species $\mathrm{K}$ is:

$$
Y_{k}=\frac{\rho_{k}}{\rho}
$$

Where: $\mathrm{Y}_{\mathrm{k}}=$ mass fraction of the $\mathrm{k}^{\text {th }}$ species

$$
\begin{aligned}
& \rho=\text { total fluid density } \\
& \rho_{\mathrm{k}}=\text { mass density of the } \mathrm{k}^{\text {th }} \text { species }
\end{aligned}
$$

The mass conservation of the $\mathrm{k}^{\text {th }}$ species in a control volume is influenced by homogeneous chemical reactions, molecular diffusion, and convection:

Where: $\rho=$ fluid density

$$
\rho \frac{\partial Y_{k}}{\partial t}+\rho \bar{v} \cdot \nabla Y_{k}=\dot{\omega}_{k} W_{k}-\nabla \bar{J}_{k}
$$

$$
\begin{aligned}
& \mathrm{t}=\text { time } \\
& \mathrm{Y}_{\mathrm{k}}=\text { mass fraction of the } \mathrm{k}^{\text {th }} \text { species } \\
& \vec{v}=\text { fluid velocity vector } \\
& \bar{J}_{k}=\text { diffusive mass flux vector of the } \mathrm{k}^{\text {th }} \text { species } \\
& \omega_{\mathrm{k}}=\text { net molar production rate of the } \mathrm{k}^{\text {th }} \text { species } \\
& \mathrm{W}_{\mathrm{k}}=\text { molecular weight of the } \mathrm{k}^{\text {th }} \text { species }
\end{aligned}
$$

The diffusivity or diffusive mass flux of a species is described with Fick's law. Fick's law related the diffusive flux with concentration, by proposing that the flux goes from a region of 
high concentration to a region of low concentration with a magnitude proportional to the concentration gradient. A diffusivity coefficient is a proportionality constant used to link the concentration gradient and the diffusivity:

$$
\bar{J}_{k}=-\rho \frac{Y_{k}}{X_{k}} D_{k} \nabla X_{k}=-\rho \frac{W_{k}}{\bar{W}} D_{k} \nabla X_{k}
$$

Where: $\bar{J}_{k}=$ diffusive mass flux vector of the $\mathrm{k}^{\text {th }}$ species

$$
\begin{aligned}
& \rho=\text { fluid density } \\
& Y_{k}=\text { mass fraction of the } k^{\text {th }} \text { species } \\
& \mathrm{X}_{\mathrm{k}}=\text { mole fraction of the } \mathrm{k}^{\text {th }} \text { species } \\
& \mathrm{D}_{\mathrm{k}}=\text { binary diffusivity coefficient } \\
& \mathrm{W}_{\mathrm{k}}=\text { molecular weight of the } \mathrm{k}^{\text {th }} \text { species } \\
& \bar{W}=\text { mean molecular weight of the mixture }
\end{aligned}
$$




\section{Appendix E - Input File for OPPDIF Code}

\section{Keyword input file for the OPPDIF code to run the chemical kinetic mechanism for 1-hexanol.}

RDKEY: READING THE KEYWORD INPUT.

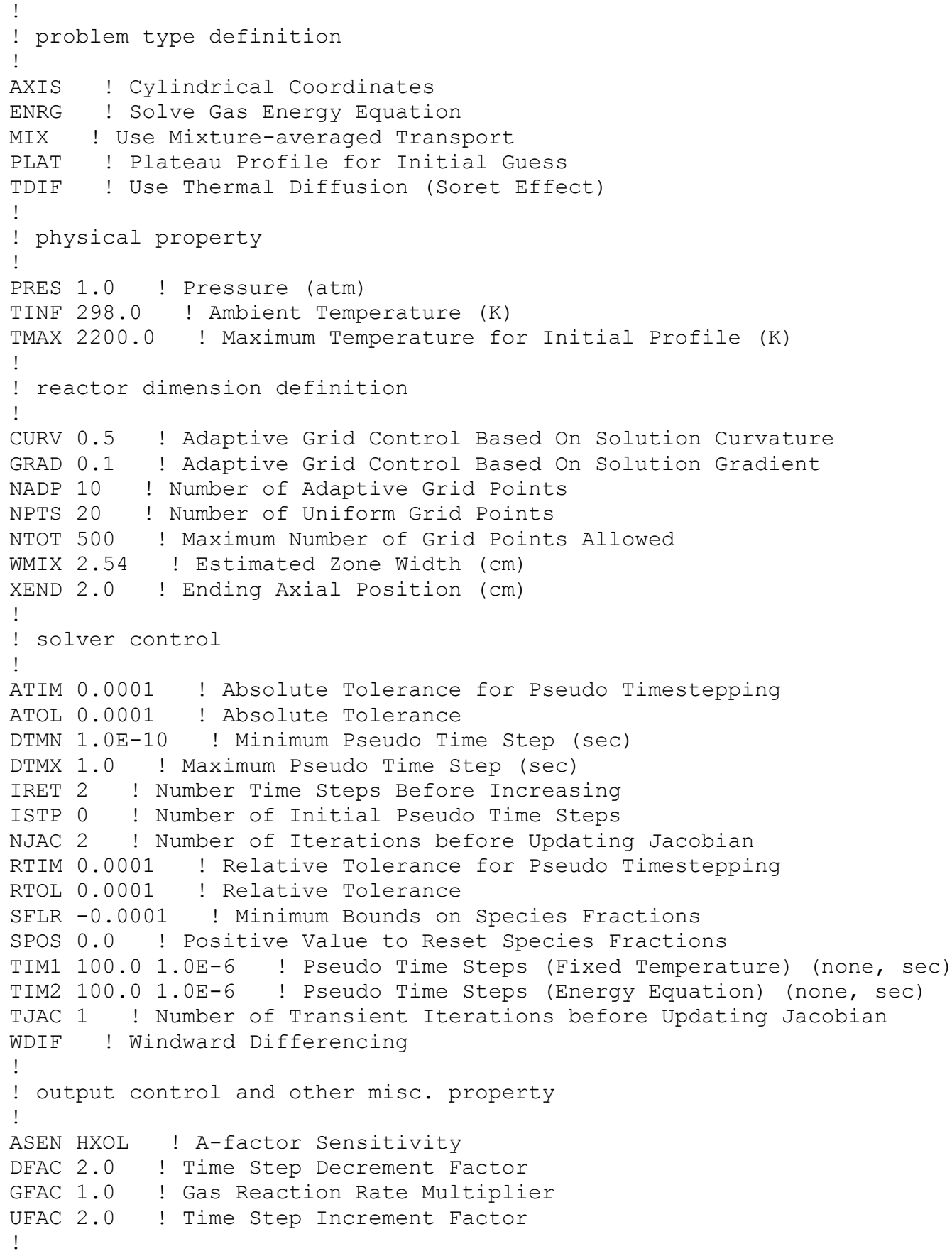




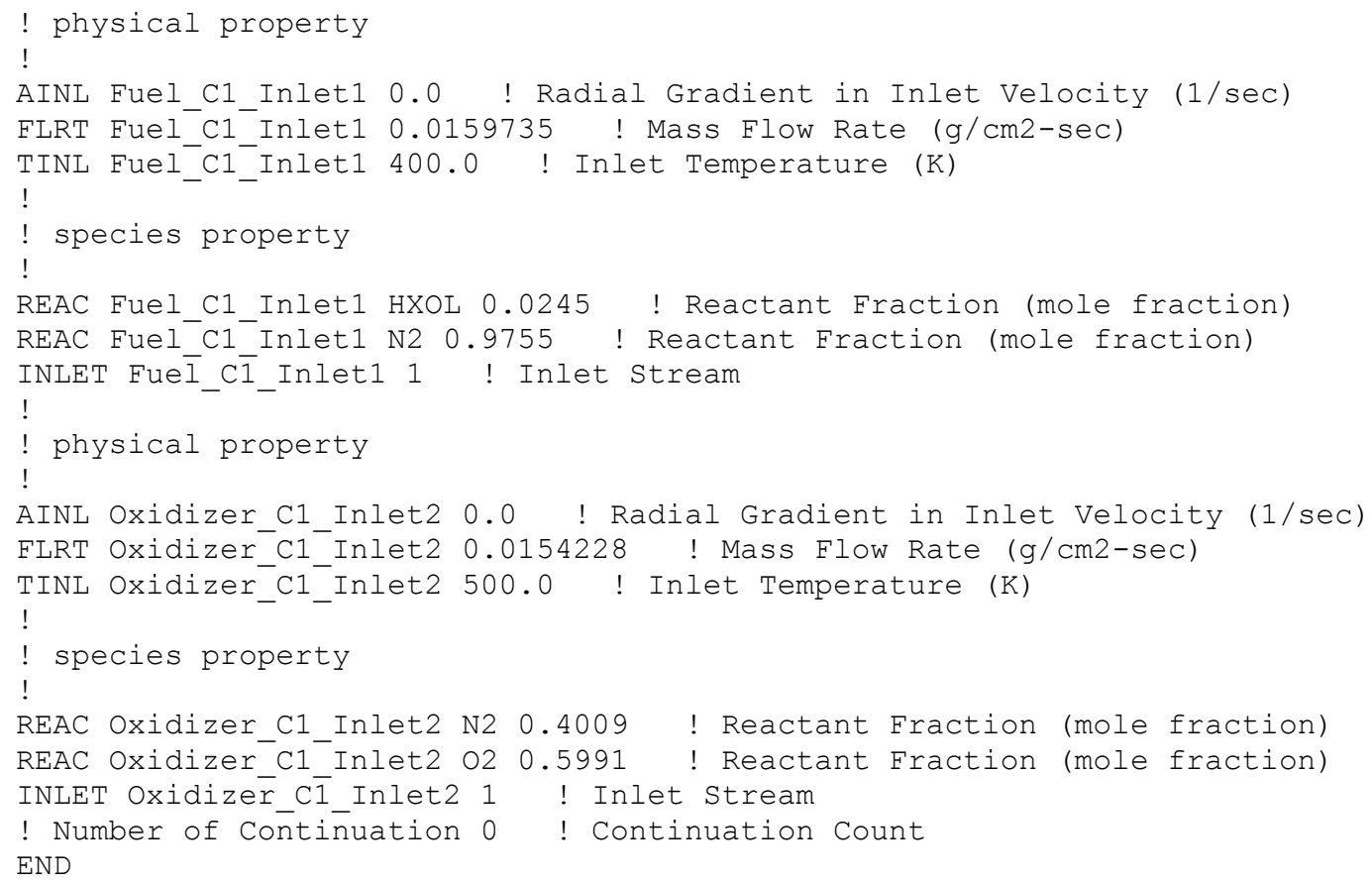




\section{Appendix F - Experimental Data of 1-Hexanol in an Opposed-Flow Diffusion Flame}

Uncoated Thermocouple

\begin{tabular}{c|c|c}
\hline $\begin{array}{c}\text { Distance From Fuel } \\
\text { Port (mm) }\end{array}$ & $\begin{array}{c}\text { Measured } \\
\text { Temperature (K) }\end{array}$ & $\begin{array}{c}\text { Corrected } \\
\text { Temperature (K) }\end{array}$ \\
\hline 2 & 413 & 413 \\
\hline 4 & 414 & 414 \\
\hline 5 & 422 & 422 \\
\hline 6 & 537 & 537 \\
\hline 7 & 990 & 994 \\
\hline 7.5 & 1319 & 1332 \\
\hline 8 & 1627 & 1659 \\
\hline 8.5 & 1657 & 1695 \\
\hline 9 & 1612 & 1649 \\
\hline 10 & 1467 & 1500 \\
\hline 11 & 1276 & 1291 \\
\hline 12 & 1055 & 1061 \\
\hline 14 & 594 & 594 \\
\hline 16 & 502 & 502 \\
\hline
\end{tabular}

Coated Thermocouple

\begin{tabular}{c|c|c}
\hline $\begin{array}{c}\text { Distance From Fuel } \\
\text { Port (mm) }\end{array}$ & $\begin{array}{c}\text { Measured } \\
\text { Temperature (K) }\end{array}$ & $\begin{array}{c}\text { Corrected } \\
\text { Temperature (K) }\end{array}$ \\
\hline 2 & 419 & 419 \\
\hline 4 & 419 & 419 \\
\hline 5 & 434 & 434 \\
\hline 6 & 586 & 587 \\
\hline 7 & 1088 & 1097 \\
\hline 7.5 & 1377 & 1397 \\
\hline 8 & 1547 & 1578 \\
\hline 8.5 & 1557 & 1592 \\
\hline 9 & 1515 & 1549 \\
\hline 10 & 1377 & 1410 \\
\hline 11 & 1181 & 1197 \\
\hline 12 & 942 & 948 \\
\hline 14 & 563 & 564 \\
\hline 16 & 513 & 513 \\
\hline
\end{tabular}




\begin{tabular}{c|c|c}
\hline $\begin{array}{c}\text { Distance } \\
(\mathbf{m m})\end{array}$ & $\mathbf{C O 2}$ & $\mathbf{C O}$ \\
\hline 2 & $0.00 \%$ & $0.00 \%$ \\
\hline 4 & $0.00 \%$ & $0.00 \%$ \\
\hline 5 & $0.04 \%$ & $0.00 \%$ \\
\hline 6 & $0.56 \%$ & $0.29 \%$ \\
\hline 6.5 & $1.44 \%$ & $0.64 \%$ \\
\hline 7 & $2.75 \%$ & $1.13 \%$ \\
\hline 7.25 & $4.45 \%$ & $1.74 \%$ \\
\hline 7.5 & $4.83 \%$ & $2.21 \%$ \\
\hline 7.75 & $5.78 \%$ & $2.31 \%$ \\
\hline 8 & $7.52 \%$ & $1.61 \%$ \\
\hline 8.5 & $8.24 \%$ & $0.28 \%$ \\
\hline 9 & $8.23 \%$ & $0.21 \%$ \\
\hline 10 & $6.17 \%$ & $0.05 \%$ \\
\hline 12 & $1.89 \%$ & $0.03 \%$ \\
\hline 14 & $0.19 \%$ & $0.03 \%$ \\
\hline 16 & $0.00 \%$ & $0.00 \%$ \\
\hline
\end{tabular}

\begin{tabular}{c|c|c|c|c|c|c|c|c}
\hline $\begin{array}{c}\text { Distance } \\
(\mathbf{m m})\end{array}$ & HXOL & C2H4 & C2H2 & CH4 & & CH3HCO & CH2O \\
\hline 2 & $2.45 \%$ & & & & & & \\
\hline 4 & $2.49 \%$ & & & & & & \\
\hline 5 & $2.53 \%$ & & 74 & 21 & 22 & & 6 & 3 \\
\hline 6 & $2.43 \%$ & 941 & 273 & 170 & & 86 & 108 \\
\hline 6.5 & $2.19 \%$ & 2120 & 590 & 336 & & 220 & 292 \\
\hline 7 & $1.65 \%$ & 3944 & 945 & 555 & & 479 & 659 \\
\hline 7.25 & $0.62 \%$ & 6206 & 1530 & 843 & & 779 & 1126 \\
\hline 7.5 & $0.09 \%$ & 11457 & 1923 & 1833 & & 629 & 820 \\
\hline 7.75 & $0.04 \%$ & 5289 & 2723 & 1212 & & 131 & 207 \\
\hline 8 & $0.03 \%$ & 29 & 128 & 36 & & 0 & 0 \\
\hline 8.5 & $0.01 \%$ & 1 & 3 & 1 & & & \\
\hline 9 & $0.00 \%$ & 1 & 2 & 1 & & & \\
\hline 14 & $0.00 \%$ & & & & & & & \\
\hline
\end{tabular}




\begin{tabular}{c|c|c|c|c|c|c|c}
\hline $\begin{array}{c}\text { Distance } \\
(\mathbf{m m})\end{array}$ & AC3H4+C4H8 & C2H6 & $\mathbf{1 - C 5 H 1 0}$ & & $\mathbf{C 3 H 6}$ & PC3H4+C4H6 & 1-C6H12 \\
\hline 2 & & & & & & & \\
\hline 4 & & & & & & & \\
\hline 5 & 2 & 3 & 7 & & 5 & 2 & \\
\hline 6 & 19 & 46 & 12 & & 106 & 17 & \\
\hline 6.5 & 57 & 109 & 29 & & 267 & 44 & 95 \\
\hline 7 & 144 & 204 & 85 & & 544 & 83 & 177 \\
\hline 7.25 & 425 & 310 & 179 & & 929 & 205 & 302 \\
\hline 7.5 & 593 & 631 & 58 & & 1274 & 594 & 102 \\
\hline 7.75 & 60 & 290 & 1 & & 308 & 376 & 18 \\
\hline 8 & 8 & 3 & 1 & & 2 & 171 & 14 \\
\hline 8.5 & 1 & 0 & & & 4 & 1 & 16 \\
\hline 9 & & & & & 3 & & \\
\hline 14 & & & & & & & \\
\hline
\end{tabular}

\begin{tabular}{c|c}
\hline $\begin{array}{c}\text { Distance } \\
(\mathbf{m m})\end{array}$ & O2 \\
\hline 7.5 & $0.20 \%$ \\
\hline 8 & $0.30 \%$ \\
\hline 8.5 & $0.45 \%$ \\
\hline 9 & $1.94 \%$ \\
\hline 10 & $9.30 \%$ \\
\hline 11 & $17.21 \%$ \\
\hline 12 & $26.91 \%$ \\
\hline 13 & $37.39 \%$ \\
\hline 14 & $40.16 \%$ \\
\hline 16 & $40.54 \%$ \\
\hline
\end{tabular}




\section{Appendix G - Procedures for Lighting an Opposed-Flow Diffusion Flame}

\section{Warming up the Burner:}

1. Turn on the temperature controller box from Unique Heated Products (as pictured below) to heat up the heated transfer line for the fuel mixture that connects the vaporizer unit to the bottom port of the burner. Ensure that the cable is connected between the controller box and the heated transfer line. Set the temperature set point to $450{ }^{\circ} \mathrm{F}$.

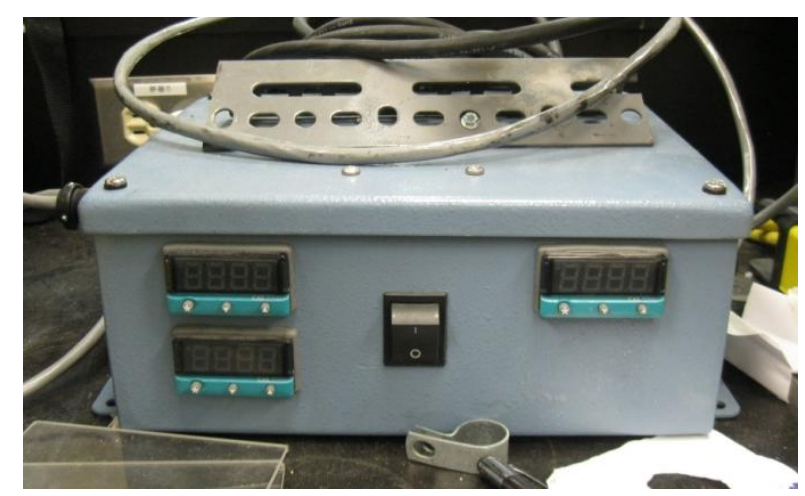

2. Turn on the Variac transformer (between the GC/FID and burner) and power bars for the heating tapes on the burner. The Variac should be set at " 100 "

3. Turn the handle of the compressed air line, which is located between the GC/FID and GC/TCD, to start circulating air through the burner. As pictured below, the handle on the right should always be open, as it feeds compressed air to the GC/FID. Turn the handle on the left about half way to start circulating air through the burner. 


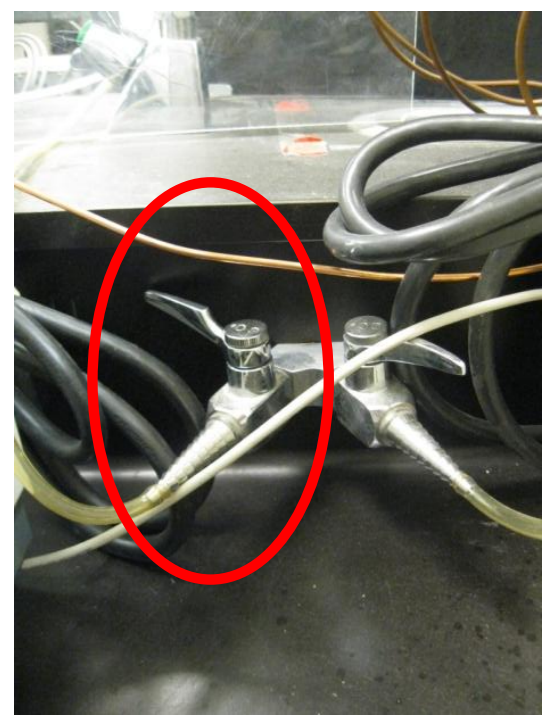

4. The air being delivered to the burner from Step 3 is heated in an air heater (pictured below), which is plugged into a power bar that is connected to a Variac transformer. The heated air circulates the burner ports and exit near the bottom port.

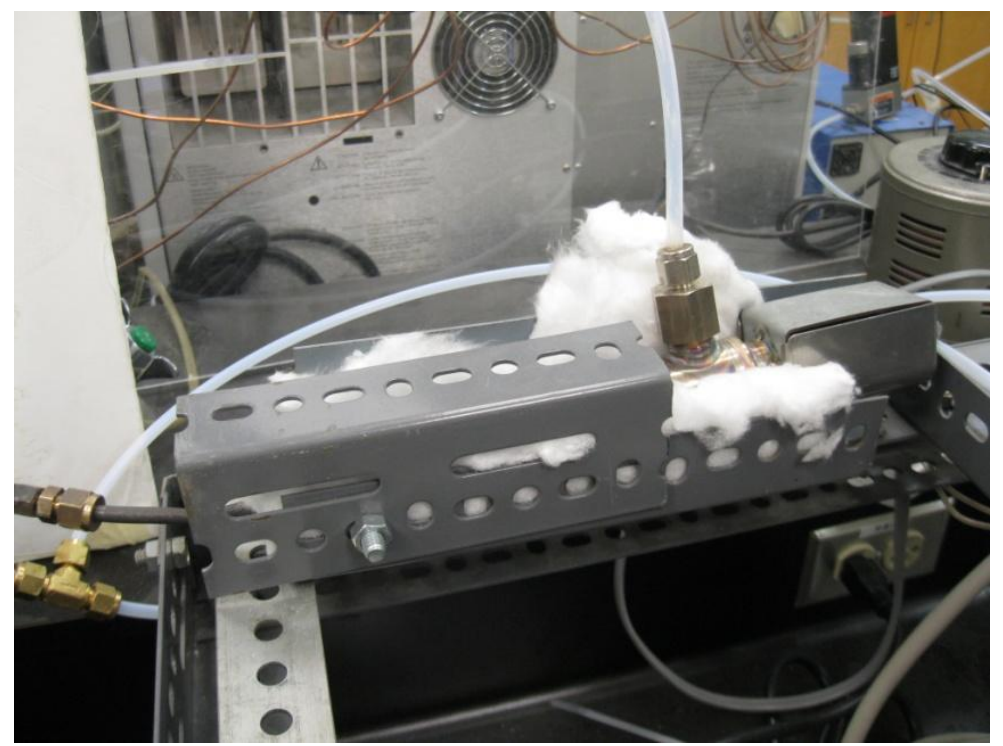

5. This Variac transformer, as pictured below, needs to be turned on to heat up the air heater. The setting should be at " 50 ". 


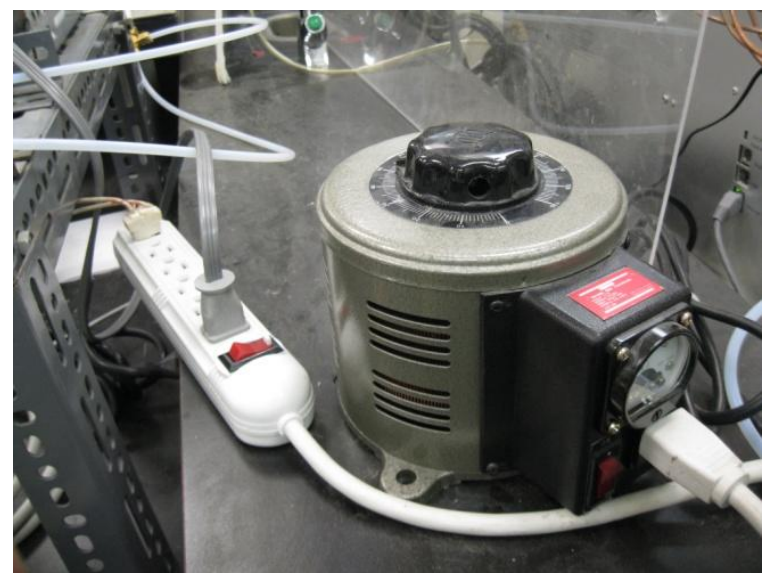

6. Allow the burner to warm up for about 20 minutes (or until the burner reaches about $80^{\circ} \mathrm{C}$ ). The temperature of the air circulating the burner can be checked with a temperature reader as a $\mathrm{K}$ type thermocouple is inserted into the bottom port. 


\section{Starting the Gas and Fuel Streams:}

1. Power on the Brooks controller box, as pictured on the right (used to control Hastings mass flow controllers for Air and Oxygen). The air supply is from the building compressed air line, which is always open. Check that the Hastings mass flow controllers are connected to the Brooks controller box.

2. Power on the Bronkhorst Control box, pictured below on the left. Set temperature to heat up CEM unit. Check that the Bronkhorst mass flow controllers are connected to the control box.

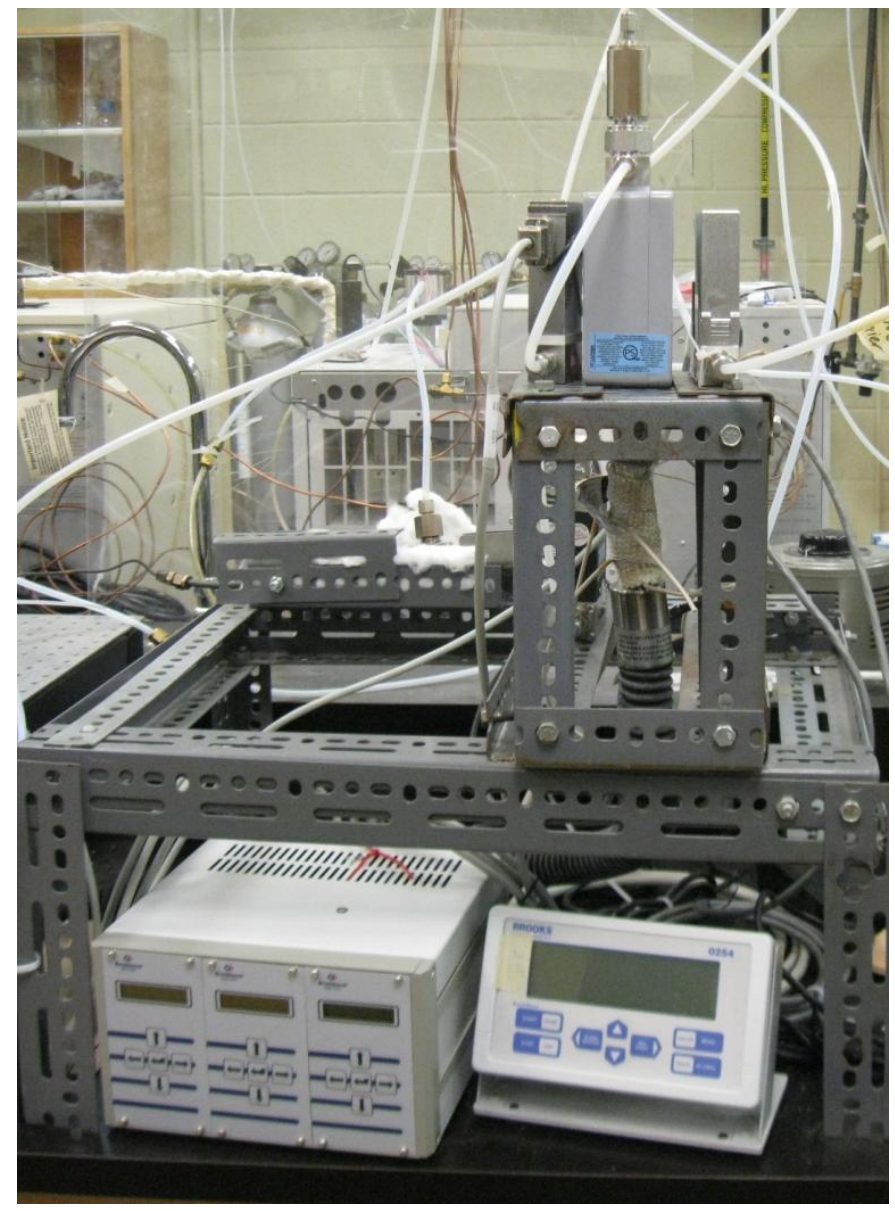

3. Open valve for one Oxygen and two Nitrogen (One to pressurize liquid pressure vessel, the other used to vaporize fuel) gas cylinders.

4. Enter in Set Points for Oxygen and Nitrogen on the Brooks unit

5. Enter in Set Point for Nitrogen on the Bronkhorst unit

6. Follow the Bronkhorst guide to set up and fill the liquid line that is connected to the mass flow controller. 
7. When ready, enter in set point for fuel flow rate. Note that the liquid mass flow controller is programmed for 1-hexanol. Using the liquid mass flow controller for a different fuel will require the read-out flow rates to be converted by a conversion factor. The conversion can be found at http://www.fluidat.com/default.asp

8. As soon as the fuel is flowing through the liquid mass flow controller and through the CEM unit, try to light the flame in the burner.

9. A scale can be used to measure the mass of the pressure vessel over time to determine the actual flow rate of fuel.

\section{Warming up the Sampling line:}

1. The sampling line has a heated transfer line component which needs to be heated up. Ensure that the heated transfer line is connected to the temperature controller box from Unique Heated Products (as pictured earlier). Set the temperature set point to $450{ }^{\circ} \mathrm{F}$.

2. Turn on the yellow power bar resting on the GC/FID which is connected to heating tapes used to heat the sampling probe and the delivery lines between the heat vacuum pump, the GC/FID and the GC/TCD. The power bar is connected to a Powerstat transformer, which is set at " 50 ".

3. Turn on the heated vacuum pump with the switch to warm up the unit.

4. Prepare the sampling probe tip using the Agilent microtubing and ferrules from SPE. Make sure the nut is secured to avoid leaks.

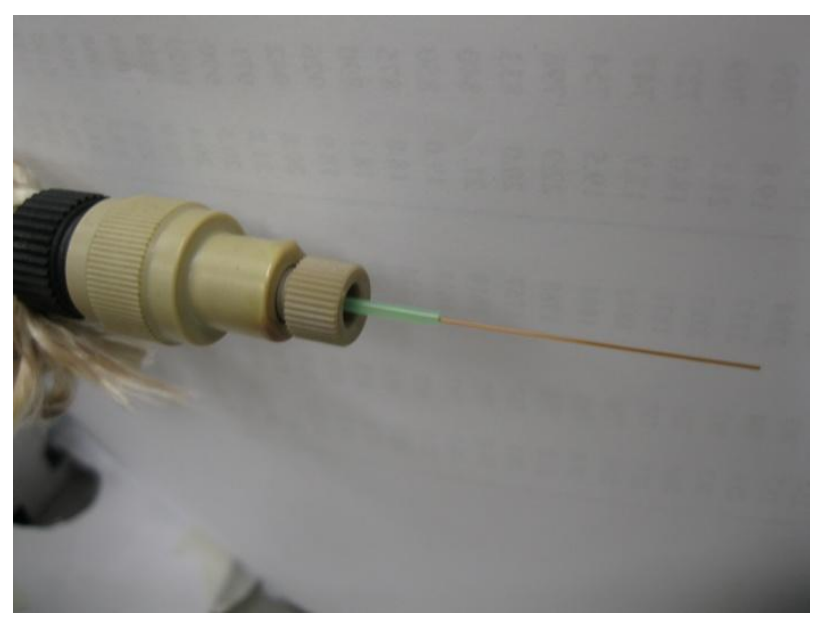


